\title{
Big and beautiful: the Megaxyela species (Hymenoptera, Xyelidae) of East Asia and North America
}

\author{
Stephan M. BLANK ${ }^{1, *}$, Katja KRAMP ${ }^{2}$, David R. SMITH ${ }^{3}$, Yuri N. SUNDUKOV ${ }^{4}$, \\ Meicai WEI ${ }^{5}$ \& Akihiko SHINOHARA $^{6}$ \\ ${ }^{1,2}$ Senckenberg Deutsches Entomologisches Institut, Eberswalder Str. 90, \\ 15374 Müncheberg, Germany. \\ ${ }^{3}$ Systematic Entomology Laboratory, Agricultural Research Service, \\ U.S. Department of Agriculture, c/o National Museum of Natural History, P.O. Box 37012, \\ MRC 168, Washington, DC 20013-7012, USA. \\ ${ }^{4}$ State Nature Reserve "Kurilskiy", Zarechnaya str. 5, Yuzhno-Kurilsk, \\ Sakhalinskaya oblast, 694500 Russia.
}

${ }^{5}$ Key Laboratory of Cultivation and Protection for Non-Wood Forest Trees (Central South University of Forestry and Technology), Ministry of Education, Changsha 410004, China.

${ }^{6}$ Department of Zoology, National Museum of Nature and Science, 4-1-1 Amakubo,

Tsukuba, Ibaraki, 305-0005 Japan.

*Corresponding author: sblank@senckenberg.de

${ }^{2}$ Email: kkramp@senckenberg.de

${ }^{3}$ Email: sawfly2@aol.com

${ }^{4}$ Email: yun-sundukov@mail.ru

${ }^{5}$ Email:weimc@126.com

${ }^{6}$ Email: shinohar@kahaku.go.jp

\footnotetext{
${ }^{1}$ urn:1sid:zoobank.org:author:0E65D322-6E6B-489E-9243-921D28E0472D

${ }^{2}$ urn:1sid:zoobank.org:author:72579D81-D3A8-4803-91AC-4C928C83EBEB

${ }^{3}$ urn:Isid:zoobank.org:author:B25C3A30-9EF6-4561-8DCE-C95869DFD7E8

${ }^{4}$ urn:lsid:zoobank.org:author:0D46A0A2-6555-4045-A276-B9539EC54088

${ }^{5}$ urn:Isid:zoobank.org:author:E687AE23-588C-4866-8C14-19B3112BB4BA

${ }^{6}$ urn:1sid:zoobank.org:author:C7382A9B-948F-479B-BEE7-848DAFECD3BA
}

Blank S.M., Kramp K., Smith D.R., Sundukov Y.N., Wei M. \& Shinohara A. 2017. Big and beautiful: the Megaxyela species (Hymenoptera, Xyelidae) of East Asia and North America. European Journal of Taxonomy 348: 1-46. https://doi.org/10.5852/ejt.2017.348

\begin{abstract}
Megaxyela Ashmead, 1898 comprises 13 species, four of which are described as new and one is removed from synonymy: Megaxyela euchroma Blank, Shinohara \& Wei sp. nov. from China (Zheijang), M. fulvago Blank, Shinohara \& Wei sp. nov. from China (Hunan, Jiangsu, Zhejiang), M. inversa Blank \& D.R. Smith sp. nov. from the USA (West Virginia), M. langstoni Ross, 1936 sp. rev. from the eastern USA, and M. pulchra Blank, Shinohara \& Sundukov sp. nov. from China (Hubei, Jilin, Liaoning, Shaanxi, Tibet), South Korea (Kangwon-do) and Russia (Primorskiy Kray). The male
\end{abstract}


of M. parki Shinohara, 1992 is described for the first time. A lectotype is designated for M. gigantea Mocsáry, 1909. A cladogram, based on COI sequences of seven species, is presented and interpreted in view of selected morphological characters. Records of M. fulvago sp. nov. from Hunan and of M. pulchra sp. nov. from Tibet extend the known distribution of Megaxyela in the Old World 600 kilometers farther south and 2500 kilometers farther west than previous records.

Keywords. Key, new species, distribution, larval hostplants, COI barcoding.

\section{Introduction}

Adults of Megaxyela Ashmead, 1898 represent the most colorful and the largest extant xyelids with a body length of up to $14 \mathrm{~mm}$. Despite their conspicuousness, collection records are comparatively seldom. The distribution of the extant species of Megaxyela covers the eastern part of the Nearctic and the southeastern part of East Asia (Shinohara 1992; Smith \& Schiff 1998; this paper). Outside this area, the Oligocene ${ }^{\dagger}$ Megaxyela petrefacta Brues, 1908 was recorded from western North America from deposits of Florissant (Colorado, USA; Brues 1908; Zhelochovtsev \& Rasnitsyn 1972). A second fossil species, ${ }^{\dagger} M$. yaoshanica Zhang, 1989 from deposits at Shanwang (Shandong, China) dates back to the mid-Miocene (Zhang 1989). Fossils of Megaxyela are young in comparison with the earliest Megaxyelinae from the Upper Jurassic (e.g., Rasnitsyn 1966, 2008; Zhang \& Zhang 2000) and the oldest Xyelidae from the Late Triassic (e.g., Kopylov 2014; Lara et al. 2014).

Larvae of Megaxyela are external feeders of Juglandaceae. The East Palaearctic M. gigantea Mocsáry, 1909 feeds on the leaves of Juglans Linné and Pterocarya Nuttal ex Moquin. Saito (1941) reported on the oviposition behavior of this species. Taeger et al. (2010: pl. 21, fig. 3) depicted an unidentified larva found in Yunnan, China, feeding on J. sigillata Dode. The Japanese M. togashii Shinohara, 1992, which is associated with $J$. ailanthifolia Carrière, represents the first Eurasian species for which the larva and ecological traits have been described in detail (Shinohara et al. 2017). The North American M. aviingrata (Dyar, 1898), M. langstoni Ross, 1936 and M. major (Cresson, 1880) have also been found on Juglandaceae like pecan (Carya illinoinensis (Wangenh.) K.Koch) and butternut (Juglans cinerea L.) (e.g., Dyar 1898a; Smith 1967; Smith \& Schiff 1998). Megaxyela major has been reported as a minor pest of cultivated pecan trees in Texas (Ree 2012, 2014). Collection circumstances of Proctorenyxa incredibilis Kozlov, 1994 on Juglans mandshurica Maxim. in the Russian Far East indicate that Megaxyela might be the hosts of Proctorenyxidae, an enigmatic family of the parasitic Proctotrupoidea represented by only two species (Lelej 2012; Kim et al. 2016).

Five Nearctic and three East Palaearctic species were previously known for the extant fauna (Shinohara 1992; Smith \& Schiff 1998). Here, we add four new species, M. euchroma Blank, Shinohara \& Wei sp. nov., M. fulvago Blank, Shinohara \& Wei sp. nov., M. inversa Blank \& D.R. Smith sp. nov. and M. pulchra Blank, Shinohara \& Sundukov sp. nov., and we remove M. langstoni from synonymy. We review Megaxyela with focus on the Old World taxa and summarize data on larval hosts and distribution. The analysis of COI barcodes is used to complement morphological studies.

\section{Material and methods}

\section{Morphological terminology}

Morphological terminology generally follows Huber \& Sharkey (1993) and Viitasaari (2002); for surface microsculpture it follows Harris (1979). The elongate and widened third antennal article, which is the ontogenetical product of the fusion of a variable number of articles, is called synantennomere 3 (Fig. 1D; Blank 2002; Blank et al. 2005, 2013). The combination of the thinner articles following distally is the antennal filament (Fig. 1D). In Xyela and Pleroneura the male genitalia are revolved at $180^{\circ}$ along their longitudinal axis after ecdysis (strophandrous state), whilst in Xyelecia, Macroxyela 

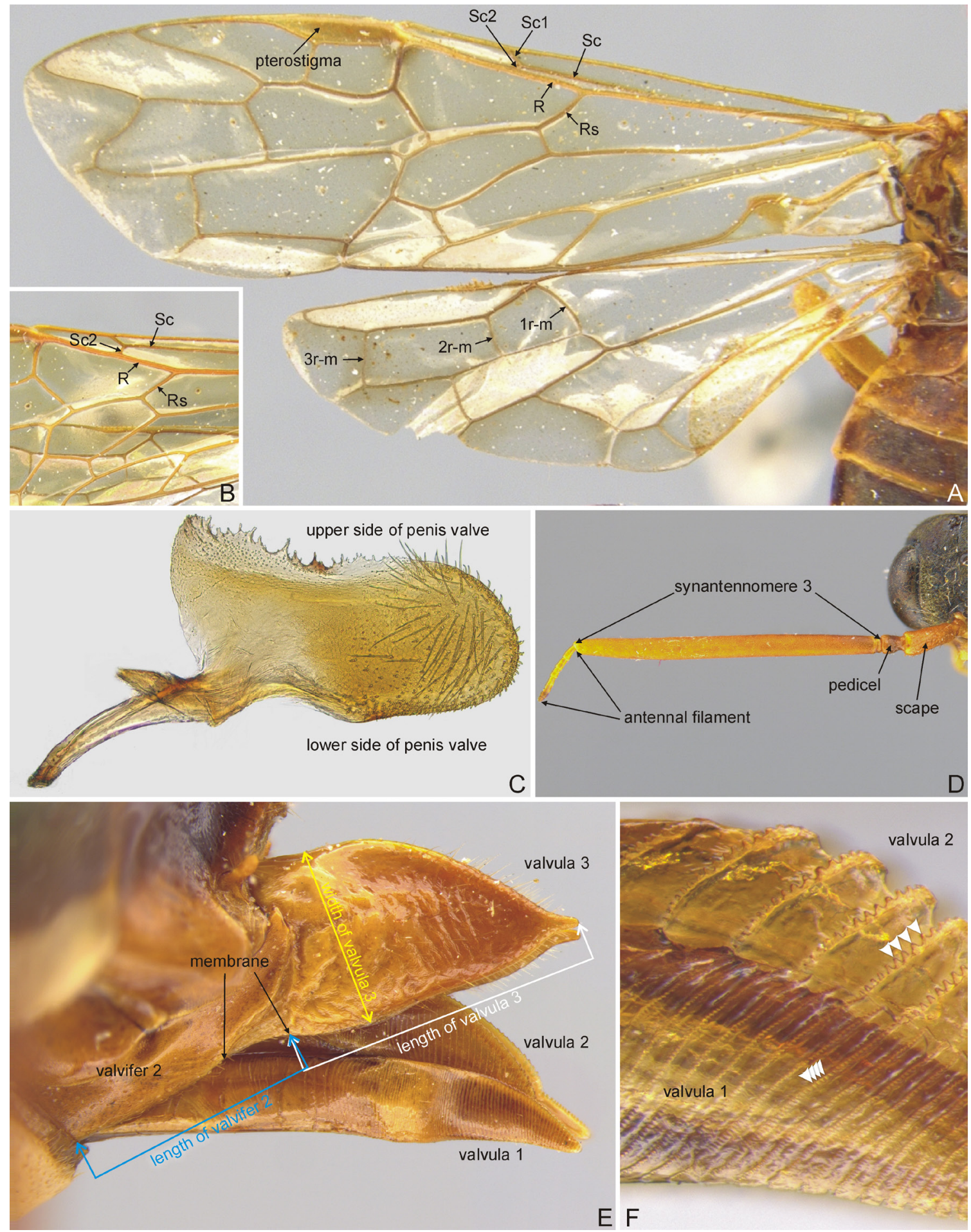

Fig. 1. Megaxyela Ashmead, 1898, morphological terminology. A. M. major (Cresson, 1880) ( $q$, paralectotype, DEI-GISHym 30823, ANSP), wings. B. M. parki Shinohara, 1992 (†, 18509, NSMT), section of fore wing. C. M. euchroma Blank, Shinohara \& Wei sp. nov. (ð, paratype, 22513, NSMT), penis valve. D. M. parki (ô, 710, NSMT), antenna. E. M. gigantea Mocsáry, 1909 (q, holotype of M. mikado Sato, 1930, 22350, NSMT), ovipositor and ovipositor sheath, with indication of measurement of length of valvifer 2 (blue), valvula 3 (white), and width of valvula 3 (yellow). F. M. euchroma sp. nov. ( 9 , paratype, 22558, CSCS), section of ovipositor, white arrow heads indicating teeth of ctenidia on valvulae 1 and 2 . 
and Megaxyela they remain untwisted in the adult (orthandrous state). To avoid confusion in comparing characters among strophandrous and orthandrous taxa, the penis valves of Megaxyela are illustrated with the ventral margin directed upwards as it is usual for most sawflies. Accordingly, the physiological ventral vs. dorsal parts are called upper vs. lower parts of the penis valve (Fig. 1C). Terminology for wing veins as applied here is illustrated in Fig. 1A-B. The ovipositor sheath is composed of the proximal valvifer 2 and the distal valvula 3, which are connected by a membrane (Fig. 1E). Valvula 1 (lancet) is the movable part of the ovipositor situated at rest ventral to valvula 2 (lance) forming the guide for valvula 1 (Fig. 1E-F). Along the annuli of these valvulae, rows of teeth may occur called ctenidia (Fig. 1F; Smith 1968). Ctenidia represent protrusions of the integument, not sensilla trichodea as observed along the annuli in many sawfly species (Blank \& Schönitzer 1994).

\section{Measurements}

The following measurements have been taken: Length of body: distance between interantennal area and tip of tergum 9+10 in females (ovipositor not included in measurement), between interantennal area and tip of hypopygium in males. Length of fore wing: distance between anterior edge of tegula and distal edge of wing. POL, postocellar line: shortest distance between medial edges of posterior ocelli. OOL, ocellus-ocular line: shortest distance between lateral edge of posterior ocellus and nearest edge of neighboring eye. OCL, ocellus-occipital line: shortest distance between posterior edge of posterior ocellus and posterior edge of head. POL, OOL and OCL are each taken in vertical view on the measured line. Distance of antennal toruli: shortest distance between medial (sclerotized) edges of toruli. Distance between eye and antennal torulus: shortest distance between lateral (sclerotized) edge of torulus and medial edge of eye. Width of frons: distance between medial edges of eyes at level of dorsal edges of antennal toruli. Length and width of eye: longest distance between dorsal/ventral and medial/posterior edge of eye in obliquely lateral view (respective edges in same focus plain). Length of malar space: shortest distance between ventral edge of eye and edge of mandibular concavity. Number of articles of antennal filament: completely and incompletely separated articles counted as single articles. This applies in particular to the distal two articles that are sometimes separated by a suture on the posterior/anterior side but continuous anteriorly/posteriorly. More rarely, malformed articles with partial separation occur in the medial section of the filament. Length of synantennomere 3, antennal filament, article 3 of maxillary palp, metafemur, metatibia, longer metatibial spur: distance between proximal and distal end of these articles, in the parallel-sided synantennomere 3 and antennal filament taken parallel to outer edge, in the maxillary article 3 along lateral surface, in the metafemur parallel to ventral edge from basal to dorsal tip. Length of metatarsomeres: measured along dorsal edge of tarsomeres, for metatarsomere 1 distance between tip of metatibia and dorsal distal edge of metatarsomere 1, for metatarsomeres 2-5 from tip of tarsomere 1 to tip of tarsomere 5. Width of metatarsomere 1: largest width in lateral view between dorsal and ventral surfaces of article, setae not taken into account. Length of ovipositor sheath: combined length of valvifer 2 and valvula 3, both measured as straight lines along ventral edge of the sclerite (Fig. 1E). Width of valvula 3 of ovipositor sheath: greatest distance between dorsal and ventral edge of valvula 3 (Fig. 1E).

\section{Host nomenclature}

The nomenclature of the taxa of Juglandaceae, which are considered as larval hosts of Megaxyela, follows The Plant List (2013).

\section{Barcoding}

Treatment of the specimens with DEI-GISHym numbers 5751-5752 of Megaxyela fulvago sp. nov., 18503-18504 of M. pulchra sp. nov.: for DNA extraction, the single leg of these adults was removed and submitted to the Canadian Centre for DNA Barcoding (CCDB) in Guelph, Canada, where the DNA sequencing was performed (see Blank et al. 2013 and Schmidt et al. 2017 for details). Sequencing of M. gigantea (2 $q$ q, 1 from 1996, 2002), M. parki Shinohara, 1992 (3 $q$ ㅇ from 1990, 1993) and of 
additional specimens of M. pulchra sp. nov. (2 $q$ from 1994, 1998) was unsuccessful, supposedly due to the age of the pinned material, relaxing in a moist chamber before mounting, and supposedly due to storage in a collection environment where 1,4-dichlorobenzene is continuously applied for pest control. Data of the analyzed specimens are accessible through the website of Barcode of Life Data Systems (BoldSystems, http://www.boldsystems.org).

Treatment of the specimens with DEI-GISHym numbers 22355, 22513 and 22515 of Megaxyela euchroma sp. nov., 5237, 5239 and 30883 of M. fulvago sp. nov., 18507 of M. gigantea, 30796 of M. langstoni, 30767 and 30797 of M. major, 22347, 22349 and 86249 of M. pulchra sp. nov., 22354 and 22521 of $M$. togashii: total genomic DNA was extracted from one leg or from the genital capsule (without mechanical disruptions) of these specimens using the E.Z.N.A. Tissue DNA Kit (Omega Bio-tek Inc., Norcross, USA) according to the manufacturer protocol for tissue DNA, except some smaller modifications. Lysis time was at least 3 hours for the legs and 4 hours for the genital capsules. Elution was performed twice with $100 \mu 1$ Elution Buffer each. A partial fragment $(658 \mathrm{bp})$ of the mitochondrial cytochrome c oxidase subunit I (COI) gene was amplified by PCR using the primers SymF2 (5'-TTTCAACAAATCATAAARAYATTGG-3') and SymR2 (5'-TAAACTTCTGGRTGTCCAAARAATCA) (Prous et al. 2016). Amplifications were performed in $15 \mu 1$ reactions containing $7.5 \mu 12 \times$ Qiagen Multiplex PCR Master Mix (Qiagen, Hilden, Germany), $0.2 \mu \mathrm{M}$ of each primer, RNase-free water and template DNA (1-3 $\mu \mathrm{l})$. Amplification conditions were as follows: initial PCR activation step at $95^{\circ} \mathrm{C} 5 \mathrm{~min}, 38$ cycles of $30 \mathrm{~s}$ denaturing at $95^{\circ} \mathrm{C}, 90 \mathrm{~s}$ annealing at $46^{\circ} \mathrm{C}, 1 \mathrm{~min}$ extension at $72^{\circ} \mathrm{C}$, followed by a final extension of $30 \mathrm{~min}$ at $68^{\circ} \mathrm{C}$. PCR products were visualized on a $1.4 \%$ agarose gel stained with Gel Red (0.1, Biotium, Hayward, USA). PCR products were purified with Exonuclease I and FastAP Thermosensitive Alkaline Phosphatase (Life Technologies, Darmstadt, Germany) and sequenced on an ABI3730XL sequencer using Big Dye v. 3.1 Terminator Kit (Thermo Fisher Scientific, Darmstadt, Germany) by Macrogen Europe (Amsterdam, the Netherlands. Sequencing was performed with the same primers used for amplification. Sequences were checked, manually edited using Geneious 9.1.2 (Kearse et al. 2012) and aligned using BioEdit 7.2.5 (Hall 1999).

All sequences of the Megaxyela species have been deposited in GenBank. The individual accession numbers are listed in Table 1. For the calculation of the cladogram we considered two specimens of Macroxyela ferruginea (Say, 1824) (GenBank accession numbers EF032211.1, KF936523.1) in addition.

The evolutionary history was inferred by using the Maximum Likelihood method conducted in MEGA7 (Kumar et al. 2016). The best-fitting model for the analysis, the Jukes-Cantor model (Jukes \& Cantor 1969), was retrieved by jModelTest 2.1.7 (Darriba et al. 2012). It was run with 1000 bootstrap replications. Bootstrap values $>50 \%$ are shown on the ML tree next to the concerned nodes. The tree is drawn to scale, with branch lengths measured as the number of substitutions per site. The analysis involved 22 nucleotide sequences. There were a total of 658 positions in the final dataset, and all sites were used. The number of base differences per site (p-distance) between sequences was calculated. Codon positions included were $1 \mathrm{st}+2 \mathrm{nd}+3 \mathrm{rd}+$ Noncoding. All ambiguous positions were removed for each sequence pair.

\section{Imaging}

Digital images of the specimens were taken with a Leica DFC450C camera attached to a Leica M205 C stereo microscope. Lighting was either from the high diffuse dome illumination Leica LED5000 HDI or from a cold light source attached to double light guides which produced indirect illumination by diffused light reflected from the inner surface of a styrofoam cup set up around the specimen. A grey card was used as the background and for white balance. Images from preparations of the penis valves and an ovipositor were taken from an Olympus BX50 compound microscope with a Leica DFC450 C camera. For this purpose, the specimens were mounted in glycerin temporarily. Composite images with an extended depth of field were created using the software CombineZP (Hadley 2010). Large specimens exceeding the field of view of the camera were stitched with Image Composite Editor (Microsoft Research 2015). 
Table 1. COI sequences of Megaxyela species analyzed in this work, with specimen identifier (DEIGISHym number), sex, collection data (including deposition of the voucher), length of COI-5P sequence (bp), and GenBank accession number.

\begin{tabular}{|c|c|c|c|c|}
\hline DEI-GISHym & Sex & Collection data & bp & GenBank \\
\hline \multicolumn{5}{|c|}{ Megaxyela euchroma Blank, Shinohara \& Wei sp. nov. } \\
\hline 22355 & P & $\begin{array}{l}\text { China, Zhejiang Province, Kaishan, Laodian, Mt. Tianmushan, Lin'an, } \\
30.333^{\circ} \mathrm{N}, 119.433^{\circ} \mathrm{E}, 1150 \mathrm{~m} \text { alt., } 16 \text { Apr. 2014, leg. A. Shinohara, NSMT }\end{array}$ & 658 & KU323846 \\
\hline 22513 & $\hat{0}$ & $\begin{array}{l}\text { China, Zhejiang Province, Kaishan, Laodian, Mt. Tianmushan, Lin’an, } \\
30.333^{\circ} \mathrm{N}, 119.433^{\circ} \mathrm{E}, 1150 \mathrm{~m} \text { alt., } 9 \text { Apr. } 2014 \text {, leg. A. Shinohara, NSMT }\end{array}$ & 658 & KU323847 \\
\hline 22515 & o & $\begin{array}{l}\text { China, Zhejiang Province, Kaishan, Laodian, Mt. Tianmushan, Lin'an, } \\
30.333^{\circ} \mathrm{N}, 119.433^{\circ} \mathrm{E}, 1150 \mathrm{~m} \text { alt., } 4 \text { Apr. } 2014 \text {, leg. A. Shinohara, SDEI }\end{array}$ & 658 & KU323848 \\
\hline \multicolumn{5}{|c|}{ Megaxyela fulvago Blank, Shinohara \& Wei sp. nov. } \\
\hline 5237 & $0^{\pi}$ & $\begin{array}{l}\text { China, Hunan Province, Mt. Yunshan, nr. Wugang, } 26.650^{\circ} \mathrm{N}, 110.617^{\circ} \mathrm{E} \text {, } \\
1250 \mathrm{~m} \text { alt., } 12 \text { Apr. } 2012 \text {, leg. A. Shinohara, NSMT }\end{array}$ & 245 & KX154260 \\
\hline 5239 & $\hat{\sigma}$ & $\begin{array}{l}\text { China, Hunan Province, Mt. Yunshan, nr. Wugang, } 26.650^{\circ} \mathrm{N}, 110.617^{\circ} \mathrm{E} \text {, } \\
1250 \mathrm{~m} \text { alt., } 12 \text { Apr. } 2012 \text {, leg. A. Shinohara, SDEI }\end{array}$ & 658 & KX154259 \\
\hline 5751 & $a^{2}$ & $\begin{array}{l}\text { China, Hunan Province, Mt. Yunshan, nr. Wugang, } 26.650^{\circ} \mathrm{N}, 110.617^{\circ} \mathrm{E} \text {, } \\
1250 \mathrm{~m} \text { alt., } 12 \text { Apr. 2012, leg. A. Shinohara, NSMT }\end{array}$ & 658 & KF642802 \\
\hline 5752 & o & $\begin{array}{l}\text { China, Hunan Province, Mt. Yunshan, nr. Wugang, } 26.650^{\circ} \mathrm{N}, 110.617^{\circ} \mathrm{E} \text {, } \\
1250 \mathrm{~m} \text { alt., } 12 \text { Apr. } 2012 \text {, leg. A. Shinohara, NSMT }\end{array}$ & 658 & KF642873 \\
\hline 30882 & $q$ & $\begin{array}{l}\text { China, Zhejiang Province, Kaishan Laodian, Tianmushan, Lin'an, } 30.343^{\circ} \\
\text { N, } 119.435^{\circ} \text { E, } 1140 \mathrm{~m} \text { alt., } 10 \text { Apr. 2014, leg. Liu Ting \& Yu Xinjie, CSCS }\end{array}$ & 658 & KX922681 \\
\hline 30883 & o & $\begin{array}{l}\text { China, Zhejiang Province, Kaishan Laodian, Tianmushan, Lin’an, } 30.343^{\circ} \\
\text { N, } 119.435^{\circ} \text { E, } 1110 \text { m alt., } 14 \text { Apr. 2016, leg. Li Zejian, Liu Mengmeng \& } \\
\text { Chen Zhiwei, CSCS }\end{array}$ & 658 & KX922682 \\
\hline \multicolumn{5}{|c|}{ Megaxyela gigantea Mocsáry, 1909} \\
\hline 18507 & $\hat{0}$ & $\begin{array}{l}\text { South Korea, Gangwon-do, Mirugam (Pugdaesa), Mt. Odaesan, } 37.800^{\circ} \text { N, } \\
128.567^{\circ} \text { E, } 1300 \text { m alt., } 1 \text { Jun. 2002, leg. A. Shinohara, NSMT }\end{array}$ & 261 & KU323849 \\
\hline \multicolumn{5}{|c|}{ Megaxyela langstoni Ross, 1936} \\
\hline 30796 & q & $\begin{array}{l}\text { USA, Oklahoma, Pawnee County, Pawnee, } 352736 \text { East Hwy } 64,36.292^{\circ} \mathrm{N} \text {, } \\
96.716^{\circ} \mathrm{W}, 9-23 \mathrm{Apr} .2016 \text {, leg. C. Apgar, USNM }\end{array}$ & 658 & KX922683 \\
\hline \multicolumn{5}{|c|}{ Megaxyela major (Cresson, 1880) } \\
\hline 30767 & P & $\begin{array}{l}\text { USA: Oklahoma, Pawnee County, Pawnee, } 352736 \text { East Hwy } 64,36.292^{\circ} \mathrm{N} \text {, } \\
96.716^{\circ} \text { W, } 23 \text { Apr.-3 May 2011, leg. C. Apgar, USNM }\end{array}$ & 658 & KX154258 \\
\hline 30797 & q & $\begin{array}{l}\text { USA: Oklahoma, Pawnee County, Pawnee, } 352736 \text { East Hwy } 64,36.292^{\circ} \mathrm{N} \text {, } \\
96.716^{\circ} \mathrm{W}, 9-23 \text { Apr. 2016, leg. C. Apgar, USNM }\end{array}$ & 658 & KX922684 \\
\hline \multicolumn{5}{|c|}{ Megaxyela pulchra Blank, Shinohara \& Sundukov sp. nov. } \\
\hline 18503 & $\overline{0}$ & $\begin{array}{l}\text { South Korea, Gangwon-do, Mirugam (Pugdaesa), Mt. Odaesan, } 37.800^{\circ} \mathrm{N} \text {, } \\
128.567^{\circ} \text { E, } 1300 \mathrm{~m} \text { alt., } 1 \text { Jun. } 2002 \text {, leg. A. Shinohara, NSMT }\end{array}$ & 319 & KC974015 \\
\hline 18504 & $\hat{0}$ & $\begin{array}{l}\text { China, Hubei Province, Shennongjia, Guanmenshan, } 31.433^{\circ} \mathrm{N}, 110.367^{\circ} \mathrm{E} \text {, } \\
1580 \mathrm{~m} \text { alt, } 21 \text { May } 2010 \text {, leg. A. Shinohara, NSMT }\end{array}$ & 658 & КC974499 \\
\hline 22347 & q & $\begin{array}{l}\text { South Korea, Gangwon-do, Mirugam (Pugdaesa), Mt. Odaesan, } 37.800^{\circ} \mathrm{N} \text {, } \\
128.567^{\circ} \mathrm{E}, 1300 \mathrm{~m} \text { alt., } 1 \text { Jun. } 2002 \text {, leg. A. Shinohara, NSMT }\end{array}$ & 658 & KU323842 \\
\hline 22349 & q & $\begin{array}{l}\text { South Korea, Gangwon-do, Mirugam (Pugdaesa), Mt. Odaesan, } 37.800^{\circ} \mathrm{N} \text {, } \\
128.567^{\circ} \mathrm{E}, 1300 \mathrm{~m} \text { alt., } 27 \text { May } 2002 \text {, leg. A. Shinohara, NSMT }\end{array}$ & 658 & KU323843 \\
\hline 86249 & o & $\begin{array}{l}\text { Russia, Primorskiy Kray, Ussuri Nature Reserve, } 43.644^{\circ} \text { N, } 132.346^{\circ} \text { E, } \\
150 \text { m alt., } 23 \text { May } 2016 \text {, leg. K. Kramp, M. Prous \& A. Taeger, ZIN }\end{array}$ & 658 & KX922685 \\
\hline \multicolumn{5}{|c|}{ Megaxyela togashii Shinohara, 1992} \\
\hline 22354 & $\hat{\sigma}$ & $\begin{array}{l}\text { Japan, Honshu, Okayama-shi, Tamagashi, } 43.717^{\circ} \mathrm{N}, 133.967^{\circ} \mathrm{E}, 10 \mathrm{~m} \text { alt., } \\
3 \text { May 2005, leg. A. Shinohara, NSMT }\end{array}$ & 658 & KU323844 \\
\hline 22521 & $\sigma^{\pi}$ & $\begin{array}{l}\text { Japan, Honshu, Okayama-shi, Tamagashi, } 43.717^{\circ} \text { N, } 133.967^{\circ} \text { E, } 10 \mathrm{~m} \text { alt., } \\
2 \text { May 2006, leg. A. Shinohara, NSMT }\end{array}$ & 658 & KU323845 \\
\hline
\end{tabular}


The images were processed with PhotoImpact (Ulead Systems Inc.) and Adobe Photoshop CS4 (Adobe Systems Inc.) and mounted with CorelDraw (Corel Co.).

The distribution map was prepared from draft maps produced by Carto Fauna-Flora 1.2 (Barbier \& Rasmont 1996) and was enhanced with help of Adobe Photoshop CS4.

\section{Specimen citation}

Original labels of type specimens are quoted literally between “...”. Data for paratypes and additional material is listed in a standardized way. Additional explanations and interpretations, like geographic coordinates not written on the collection label, are given in square brackets [...].

\section{Collection abbreviations}

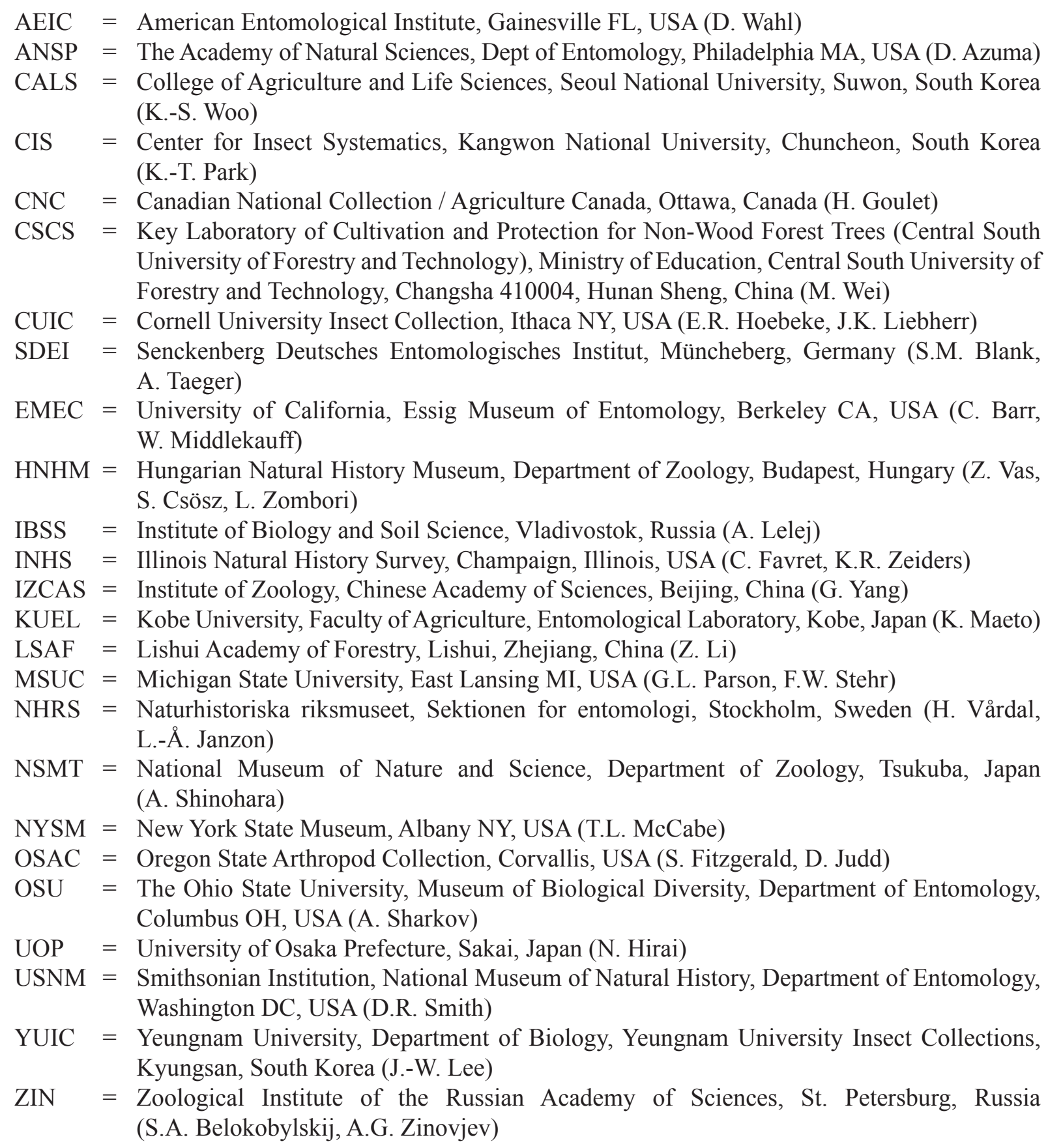




\section{Comparative material examined}

Below we discuss the individual species as far as additional information has been gained since the revisions of Shinohara (1992) and Smith \& Schiff (1998). We studied the following material of Nearctic species, which is not listed in detail below: Megaxyela alisonae D.R. Smith \& Schiff, 1998: 3 q from USA: New York (including holotype), Ohio (EMEC, NYSM, OSU); M. aviingrata: 9 q 9 from Canada: Ontario and from USA: Indiana, Mississippi, New York (including holotype) (CNC, CUIC, EMEC, INHS, MSUC, USNM); M. bicoloripes (Rohwer, 1924): 4 우 from USA: Mississippi (holotype), Pennsylvania, Virginia, West Virginia (AEIC, USNM); M. tricolor (Norton, 1862): 1 +, 3 $\widehat{\jmath}$ from Canada: Ontario and from USA: Connecticut, Kansas (holotype), Illinois (INHS, USNM).

\section{Results}

\section{Genetic analysis}

The internal branching of Megaxyela resulting from the analysis of COI sequences of two Nearctic and five East Asian species is (M. langstoni + M. major) + (M. euchroma sp. nov. + (M. fulvago sp. nov., M. gigantea $)+($ M. togashii + M. pulchra sp. nov.)) (Fig. 2). Megaxyela is supported by a bootstrap value

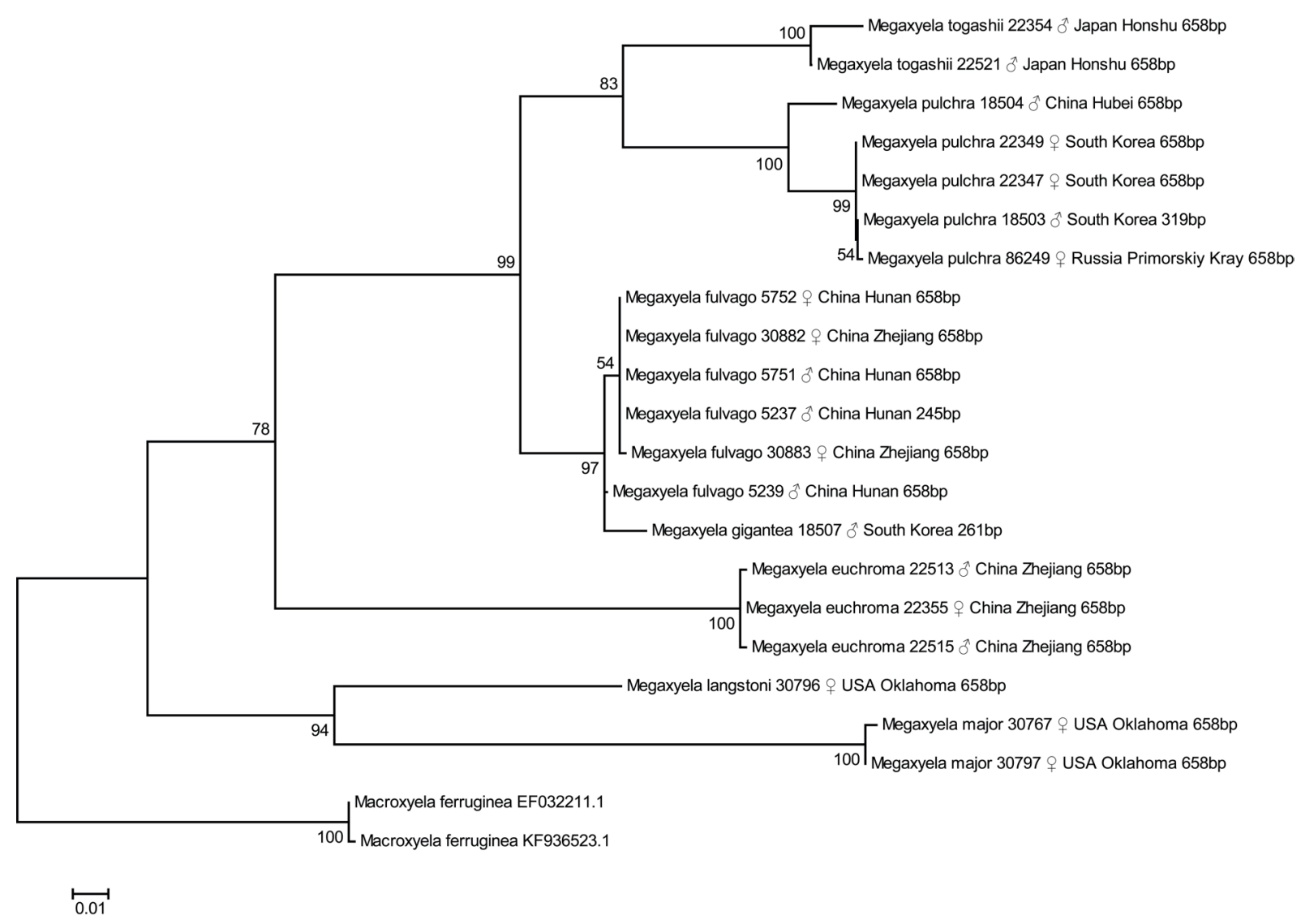

Fig. 2. Phylogenetic hypothesis of Megaxyela Ashmead, 1898, based on a Maximum Likelihood analysis of the barcoding region (COI-5P) applying the the Jukes-Cantor model. Two specimens of Macroxyela ferruginea (Say, 1824) have been included as outgroup. See Material and Methods for details. Bootstrap values above $50 \%$ are shown next to the concerning nodes. The labels of the individual specimens consist of species name, voucher number (for Megaxyela identical with the DEI-GISHym numbers used in the text, for Macroxyela GenBank accession number), sex ( $q$ for females, $\widehat{\partial}$ for males) or larva, country and province of origin, and sequence length. 
of $100 \%$, the single nodes between species by $78-99 \%$. The nearest neighbors Macroxyela ferruginea and Megaxyela langstoni are separated by a minimum pairwise distance of $13.7 \%$. The species, for which more than one specimen could be analyzed genetically, result as monophyletic, each with a bootstrap support of $100 \%$, except for the group of M. fulvago sp. nov., which also includes a specimen of M. gigantea (bootstrap 97\%). The maximum intraspecific variation ranging from $0.3 \%$ (M. euchroma sp. nov., M. major) to $3.1 \%$ (M. pulchra sp. nov.) is always smaller than the minimum interspecific distance ranging from $7.6 \%$ (M. fulvago sp. nov. - M. togashii) to $13.5 \%$ (M. langstoni - M. major).

\title{
Taxonomical treatment
}

\author{
Class Hexapoda Blainville, 1816 \\ Order Hymenoptera Linnaeus, 1758 \\ Family Xyelidae Newman, 1834 \\ Subfamily Macroxyelinae Ashmead, 1898
}

Megaxyela Ashmead, 1898

Megaxyela Ashmead in Dyar, 1898a [May]: 214 (nec Ashmead in Dyar 1898b [July]: 174), type species: Xyela major Cresson, 1880 (now Megaxyela major), by original designation.

Odontophyes Konow, 1899: 42, type species: Pleroneura avingrata Konow, 1899 (unjustified emendation and homonym of Pleuroneura [sic!] aviingrata Dyar, 1898; now Megaxyela aviingrata), by monotypy.

Megaloxyela Schulz, 1906: 88, unjustified emendation of Megaxyela Ashmead, 1898.

Paraxyela MacGillivray, 1912: 294, type species: Xyela tricolor Norton, 1862 (now Megaxyela tricolor), by original designation.

Odontophyes - Ross 1932: 161 (synonymy with Megaxyela).

Paraxyela - Ross 1932: 161 (synonymy with Megaxyela).

Megaloxyela - Smith 1978: 24 (listed in synonymy with Megaxyela).

\section{Remarks}

Megaxyela species differ from other extant xyelids by the following characters: carina along inner orbit present (e.g., Figs 3F-G, 4G), sometimes obscured by other surface sculpture (e.g., Figs 6C, 8F); vein $\mathrm{Sc} 2$ of fore wing joining $\mathrm{R}$ at $0.25-0.50$ of distance between separation of Rs from $\mathrm{R}$ and pterostigma (Fig. 1A-B); hind legs extended, about 1.5-2.0 $\times$ as long as body (e.g., Fig. 3A-B, 3D-E). The taxonomic recognition of Megaxyela from other extant Xyelidae is possible with the keys of Ross (1937), Benson (1945) and Blank (2002).

Megaxyela bicoloripes (Rohwer, 1924)

Odontophyes bicoloripes Rohwer, 1924: 215 (, type locality: USA, Mississippi, Agricultural College).

Megaxyela bicoloripes - Ross 1932: 162-164 (combination). — Smith \& Schiff 1998: 639-640 (key), 642 (description, distribution, references), figs 10, 14, 26-29, 34.

\section{Material examined}

USA: 1 \% , West Virginia, Pocahontas County, Monongahela National Forest, ca $38.63^{\circ} \mathrm{N}, 79.83^{\circ} \mathrm{W}$, Plot 17, lower Site, 7 May 2001, Malaise trap, L. Butler \& J. Strazanac leg., DEI-GISHym 30766 (USNM). 


\section{Remarks}

The above data from West Virginia represent a new state record. Among others, the species has been found in the neighboring states of Pennsylvania and Virginia (Smith \& Schiff 1998).

\section{Megaxyela euchroma Blank, Shinohara \& Wei sp. nov. urn:1sid:zoobank.org:act:63EF6069-E728-4107-8DC2-F02C9081880A}

Figs $1 \mathrm{~F}, 3 \mathrm{~A}-3 \mathrm{~K}, 11 \mathrm{~A}, 12 \mathrm{~A}, 13 \mathrm{~A}$

Megaxyela sp. 3 - Shinohara et al. 2017: fig. 15 (phylogenetic analysis).

\section{Diagnosis}

This species is unique upon the black head bearing narrow yellow lines along inner and outer orbits and a linear yellow spot on vertex (Fig. 3A-B, D, F-G), and the presence of ctenidia along the annuli of the ovipositor (Figs 1F, 12A). It is separated from other Eurasian species by the metallic blue shine of dark colored body parts (Fig. 3A-G), the laterally black terga 2-4 (Fig. 3A-E; only the ventral margins of the terga bear a narrow longitudinal white line ventrally, Fig. 3C, E), the almost completely black valvula 3 of the ovipositor sheath (Fig. 11A), the black hypopygium of the male (Fig. 3E), and the large and irregular teeth of the upper edge of the valviceps (Fig. 13A).

\section{Etymology}

The species name is a noun derived from ancient Greek $\varepsilon v-$ (eu-, beautiful) and $\chi \rho \omega \mu \alpha$ (chroma, color).

\section{Type material}

\section{Holotype}

CHINA: O+: "CSCS14007 [..., Chinese characters for Kaishan Laodian, Mt. Tianmushan, Linan, Zhejiang Province], E119²6'05" N30²0'33" $1142 \mathrm{~m}$ 2014.IV.8 [..., Chinese characters for the collectors Nie Haiyan \& Hu Ping] $\mathrm{CH}_{3} \mathrm{COOC}_{2} \mathrm{H}_{5}$ ", [red:] "Holotype Megaxyela euchroma sp.n. det. SMBlank \& AShinohara 2015"; "DEI-DISHym 22554” (CSCS).

\section{Paratypes}

CHINA: 2 $q$, same site as holotype, 4-5 Apr. 2015, Li Zejian leg. (LSAF); $1 \uparrow$, same site as holotype, 8 Apr. 2014, Liu Ting and Yu Xingjie leg., CSCS14008 / DEI-DISHym 22555 (CSCS); 1 q, same site, 9 Apr. 2014, Liu Ting and Yu Xingjie leg., CSCS14010 / DEI-DISHym 22556 (CSCS); 1 §, same site, 10 Apr. 2014, Liu Ting and Yu Xingjie leg., CSCS14012 / DEI-DISHym 22557 (CSCS); 1 ค, 2 ๙ぇ, same site as holotype, 11 Apr. 2015, Li Zejian leg., CSCS); 3 우, same site, 16 Apr. 2014, Nie Haiyan and Hu Ping leg., CSCS14026 / DEI-DISHym 22558-22560 (CSCS, SDEI, YUIC); 1 + 1 o, same site, 16 Apr. 2014, Liu Ting and Yu Xingjie leg., CSCS14027 / DEI-DISHym 22561-22562, (CSCS); 1 ô, same site, 1150 m, 4 Apr. 2015, A. Shinohara leg., DEI-DISHym 22515 (SDEI) (specimen used for barcoding); 1 o, same site, 8 Apr. 2014, A. Shinohara leg., DEI-DISHym 22512 (NSMT); 1 , same site, 9 Apr. 2014, A. Shinohara leg., DEI-DISHym 22513 (NSMT) (specimen used for barcoding); 1 J, 1 q, same site, 11 Apr. 2015, A. Shinohara leg., DEI-DISHym 22514, DEI-DISHym 22516 (NSMT); 1 q, same site, 15 Apr. 2014, A. Shinohara leg., DEI-DISHym 22511 (NSMT); 3 ㅇ , same site, 16 Apr. 2014, A. Shinohara leg., DEI-DISHym 22509-22510 and 22355 (latter specimen used for barcoding) (NSMT, SDEI).

\section{Description}

\section{Female}

CoLOR. Body black with white, yellow white and red brown pattern, black parts with blue tinge (Fig. 3AB). Head black with three yellow white lines, one on vertex posterior of eye, one along dorsal half of inner 


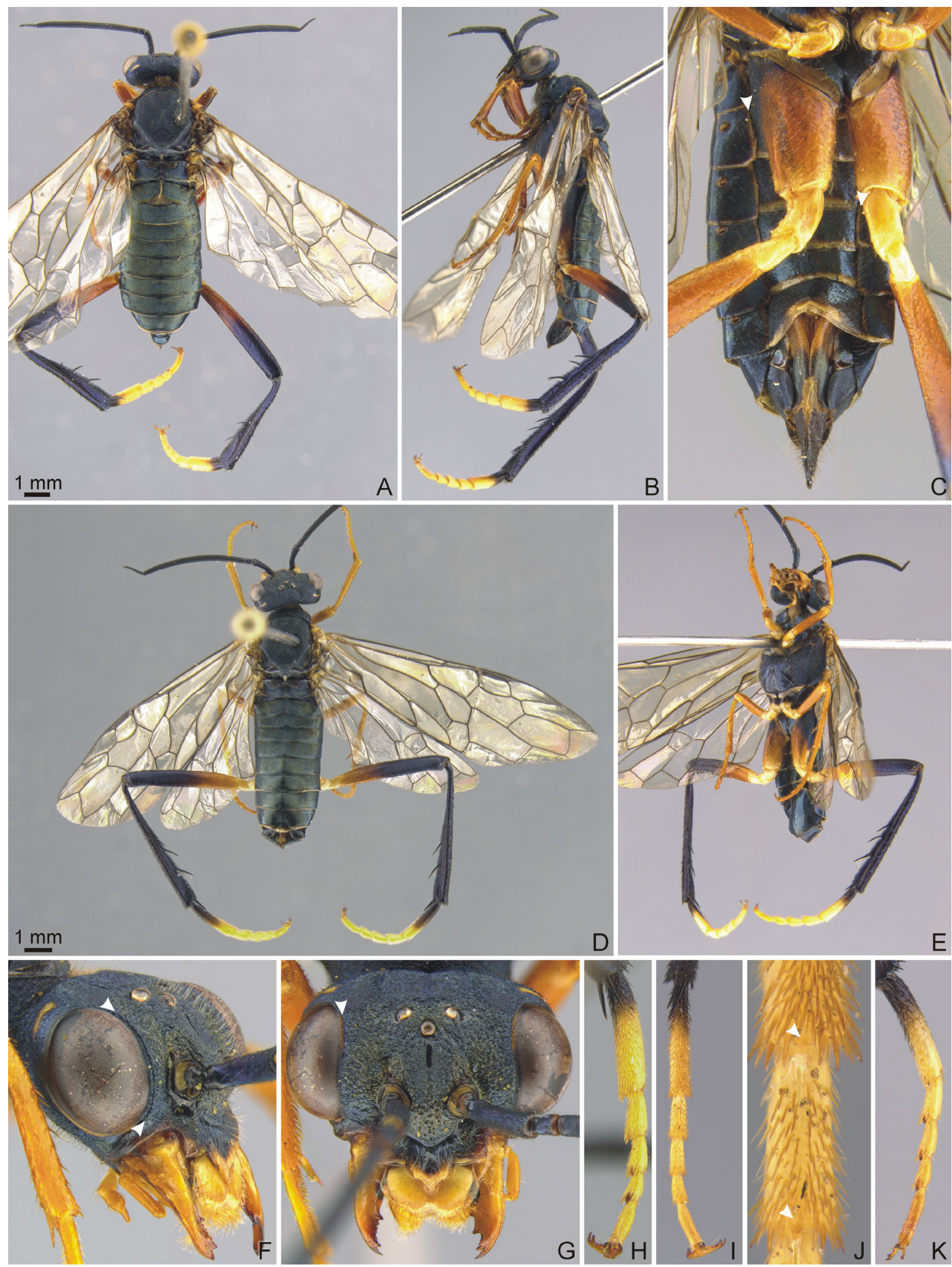

Fig. 3. Megaxyela euchroma Blank, Shinohara \& Wei sp. nov. A-B. Habitus dorsal/lateral (q, holotype, DEI-GISHym 22554, CSCS). C. Abdomen ventral, arrowheads indicating white stripe along ventral edge of terga (q, 22511, NSMT). D-E. Habitus dorsal/lateroventral (ð̂, 22514, NSMT). F-G. Head, obliquely lateral/frontal, arrowheads indicating carina along inner orbit (ð, 22510, NSMT). H-K. Metatarsus, lateroventral ( $q$, holotype, 22554, CSCS), ventral (q, 22510, NSMT), tarsomeres $1-2$, ventral, arrowheads indicating small pulvilli ( 9,22509, NSMT), lateroventral ( $\curvearrowright, 22513$, NSMT). 
orbits, one along ventral half of outer orbits and along ventral edge of eye; clypeus along anterior margin, labrum, mandibles and most of other mouthparts red brown to white (similar to Fig. 3F-G). Antenna black. Tegula, dorsolateral corner and narrow lateroventral margin of pronotum yellow white. Abdominal terga 1-8 with narrowly white distal margins, lateroventral portions of terga 2-7 with continuous $50-100 \mu \mathrm{m}$ wide white stripe along ventral margin (Fig. 3C). Abdominal sterna 2-7 broadly white along lateral and distal margins (Fig. 3C). Valvifer 2 of ovipositor red brown in basal half, black in distal half, valvula 3 black with brown tip, membrane in between valvifer 2 and valvula 3 white (Fig. 11A). Fore and mid legs red brown, coxae predominantly black from bases, trochanters partly white. On hind leg, basal third of coxa laterally black, distal portion red brown, trochanter and trochantellus white, femur predominantly red brown in basal half, predominantly black in distal half, tibia black, tarsus white, tarsomere 1 weakly infuscate in basal third (Fig. 3A-C, H-I). Wings weakly brown stained, venation brown, pterostigma black (Fig. 3D-E), sometimes brown (Fig. 3A-B, immature specimens?).

Morphology. Body $11.3-13.1 \mathrm{~mm}$, fore wing $14.1-14.6 \mathrm{~mm}$ long. POL : OOL : OCL $=1.0: 1.6-1.8$ : 1.8-2.0. Interantennal distance $0.9-1.0 \times$ as wide as distance between torulus and eye margin, malar space $0.4-0.5 \times$ as wide as interantennal distance. Eye $1.3-1.4 \times$ as long as wide, frons at dorsal edge of antennal toruli $1.6 \times$ as wide as maximum diameter of eye. Synantennomere $3(4.0-) 4.5-4.9 \mathrm{~mm}$, filament $0.9-1.1 \mathrm{~mm}$, with 7-8 articles ( 9 in one specimen). Article 3 of maxillary palp $0.5-0.6 \mathrm{~mm}$. Ovipositor sheath $2.5-2.7 \mathrm{~mm}$, valvula $31.4-1.6 \times$ as long as valvifer 2, valvula $32.0-2.1(-2.2) \times$ as long as wide. On hind leg, femur (4.5-)4.9-5.2 mm, tibia (5.4-)5.9-6.5 mm, tarsus (4.3-)4.6-5.2 mm, tarsomere $14.2-4.4 \times$ as long as wide, longer distal spur of tibia $0.4-0.5 \times$ as long as tarsomere 1 , subapical tooth of claw stout and little shorter than apical tooth. Head dull, medial part of frons and vertex minutely areolate, lateral parts of frons rugose, gena minutely areolate (Fig. $3 \mathrm{~F}$ and $3 \mathrm{G}$ ). Inner orbit and ventral half of gena with carina, on inner orbit partly obscured by generally rugose structure. Mesonotum minutely areolate, posterio-medial part of medial lobes of mesoscutum and lateral parts of mesoscutellum rugulose. Mesepisternum minutely areolate, dull, with scattered $20 \mu \mathrm{m}$ large pits. Metatarsomere 1 dorsally almost glabrous, laterally sparsely setose, lateroventrally with some stout setae up to $150 \mu \mathrm{m}$, ventrally densely setose, setae about $100 \mu \mathrm{m}$ long (Fig. 3H-I). Pulvilli present on metatarsomeres 1-4, on tarsomere 1 pulvillus 70-100 $\mu \mathrm{m}$ long, on tarsomere $4200-230 \mu \mathrm{m}$ (Fig. 3HJ). Valvula 3 of ovipositor sheath convex dorsally and ventrally in basal and medial sections, preapically weakly concave, setae up to $250 \mu \mathrm{m}$ long scattered mainly along dorsal and ventral margins (Fig. 11A). Ovipositor about $2.1 \mathrm{~mm}$ long, weakly curved ventrally, valvula 1 and valvula 2 without bulbous areas (Fig. 12A). Valvula 1 in distal 0.6 with annuli, basal annuli sigmoid, distal annuli weakly oblique, annuli with ctenidia composed of minute denticles, ventral edge in distal 0.3 bearing serrulae, cypsellae between distal 6 serrulae deep (Figs 1F, 11A). Valvula 2 in distal 0.4 with annuli, basal annuli weakly curved, distal annuli straight, annuli with ctenidia, denticles larger than those on valvula 1, dorsal edge of valvula 2 indented between annuli.

\section{Male}

CoLOR. Similar to female (Fig. 3D-G, K). Subgenital plate and genitalia black.

Morphology. Body 9.4-10.2 mm, fore wing 11.9-12.3 mm long. POL : OOL : OCL $=1.0: 1.5-1.8$ : 1.6-1.9. Interantennal distance $0.9-1.0 \times$ as wide as distance between torulus and eye margin, malar space $0.4-0.5 \times$ as wide as interantennal distance. Eye $1.3-1.4 \times$ as long as wide, frons at dorsal edge of antennal toruli $1.6-1.7 \times$ as wide as maximum diameter of eye. Synantennomere $34.0-4.4 \mathrm{~mm}$, filament (0.8-)0.9-1.1 mm, with 7-8 articles. Article 3 of maxillary palp $0.5 \mathrm{~mm}$ long. On hind leg, femur $4.1-4.4 \mathrm{~mm}$, tibia $5.1-5.3 \mathrm{~mm}$, tarsus $4.2-4.5 \mathrm{~mm}$, tarsomere $14.7-5.3 \times$ as long as wide, longer distal spur of tibia $0.40 \times$ as long as tarsomere 1 . Claws and microsculpture similar to female. Setation of metatarsus less dense than in female (Fig. 3K). Subgenital plate bluntly pointed at apex. Valviceps of penis valve distally evenly rounded, basal 0.4 of upper side expanded to a roundly angular lobe, upper 
edge of valviceps distal of lobe weakly concave, with large, irregular teeth. Distal half of valviceps in upper and medial portion with long setae, distal of middle in lower portion with dense assemblage of short, conical setae (Fig. 13A).

\section{Remarks}

Megaxyela euchroma sp. nov. is characterized by a number of unique characters (see Diagnosis). All other East Asian species are completely white on the ventral portion and partly on the dorsolateral portion of terga 2-3 or 2-4. In these cases, the white band on terga 2-3 or 2-4 is much wider than on the subsequent terga. The head is more extensively yellow or red brown, at least on the gena in M. gigantea, M. pulchra sp. nov. and M. togashii, or the eye is completely surrounded by black except for the malar space in M. parki. Megaxyela euchroma sp. nov. and M. parki share the white metatarsus, which is black in the other East Asian species.

With respect to the white pattern of the terga, M. euchroma sp. nov. is similar to the North American M. alisonae, M. bicoloripes, M. inversa sp. nov. and M. tricolor (Smith \& Schiff 1998). Megaxyela alisonae and M. bicoloripes have a white metatarsus similar to M. euchroma sp. nov., while M. tricolor has a black metatarsus. In the Nearctic species, a yellow white pattern on the orbits and the vertex, similar to that of M. euchroma sp. nov., is absent. Megaxyela alisonae and M. bicoloripes bear an extensive red brown pattern on thorax and abdomen, which is absent in M. euchroma sp. nov. Megaxyela inversa sp. nov. differs in the shape of the ovipositor sheath, which is straight dorsally in the basal and the medial sections, vs convex in M. euchroma sp. nov.

The analysis of the COI sequences supports the monophyly of the studied specimens by a bootstrap of $100 \%$. The maximum intraspecific variation is $0.3 \%$. The nearest neighbor, M. fulvago sp. nov., is placed at a distance of $12.7 \%$ (Fig. 2).

All the available adults were found on the undergrowth of open forests during cloudy weather. There were Juglans trees nearby and new shoots of leaflets were beginning to grow.

Megaxyela fulvago Blank, Shinohara \& Wei sp. nov. urn:lsid:zoobank.org:act:DF04584F-B33D-42A7-836D-E758A66F4081

Figs $4 A-G, 11 B, 12 B-C, 13 B$

Megaxyela gigantea - Takeuchi 1940: 484 (misidentification). - Maa 1949: 30 (misidentification).

Megaxyela sp. 2 - Shinohara et al. 2017: fig. 15 (phylogenetic analysis). — Blank et al. 2017: 115.

\section{Diagnosis}

The red brown head, prothorax and mesothorax are unique to this species.

\section{Etymology}

The Latin noun fulvago indicates the predominantly pale brown color of this species.

\section{Type material}

\section{Holotype}

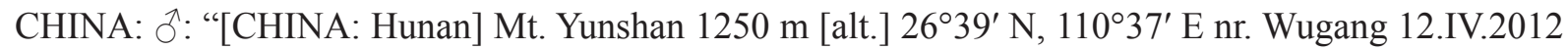
[leg.] A. Shinohara"; "DEI-GISHym 5236"; [red:] "Holotype Megaxyela fulvago det. SMBlank \& AShinohara 2015" (CSCS). 
Paratypes $(6 \circ \odot, 6 \hat{\jmath})$

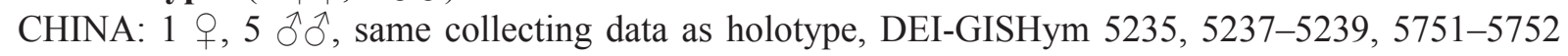
(5237, 5239, 5751-5752 used for barcoding) (SDEI, NSMT); 1 q, Jiangsu Sheng, Nanjing, $32.06^{\circ} \mathrm{N}$, $118.78^{\circ}$ E, 1 May 1985, Jinniang leg. (CSCS); 2 우, 1 ^, Jiangsu Sheng ["Prov. Kiangsu”], Zhenjiang

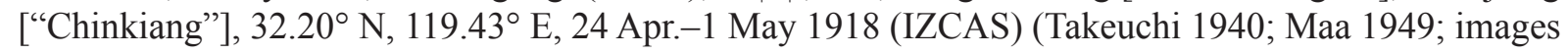
for re-identification provided by Yang Ganyan); 1 , Zhejiang Province, Kaishan Laodian, Tianmushan, Lin'an, $30.343^{\circ} \mathrm{N}, 119.435^{\circ} \mathrm{E}, 1140 \mathrm{~m}$ alt., 10 Apr. 2014, Liu Ting and Yu Xinjie leg., CSCS14012, DEIGISHym 30882 (specimen used for barcoding) (CSCS); 1 ㅇ, same locality, 1110 m alt., 14 Apr. 2016, Li Zejian, Liu Mengmeng and Chen Zhiwei leg., CSCS16143, DEI-GISHym 30883 (specimen used for barcoding) (CSCS).

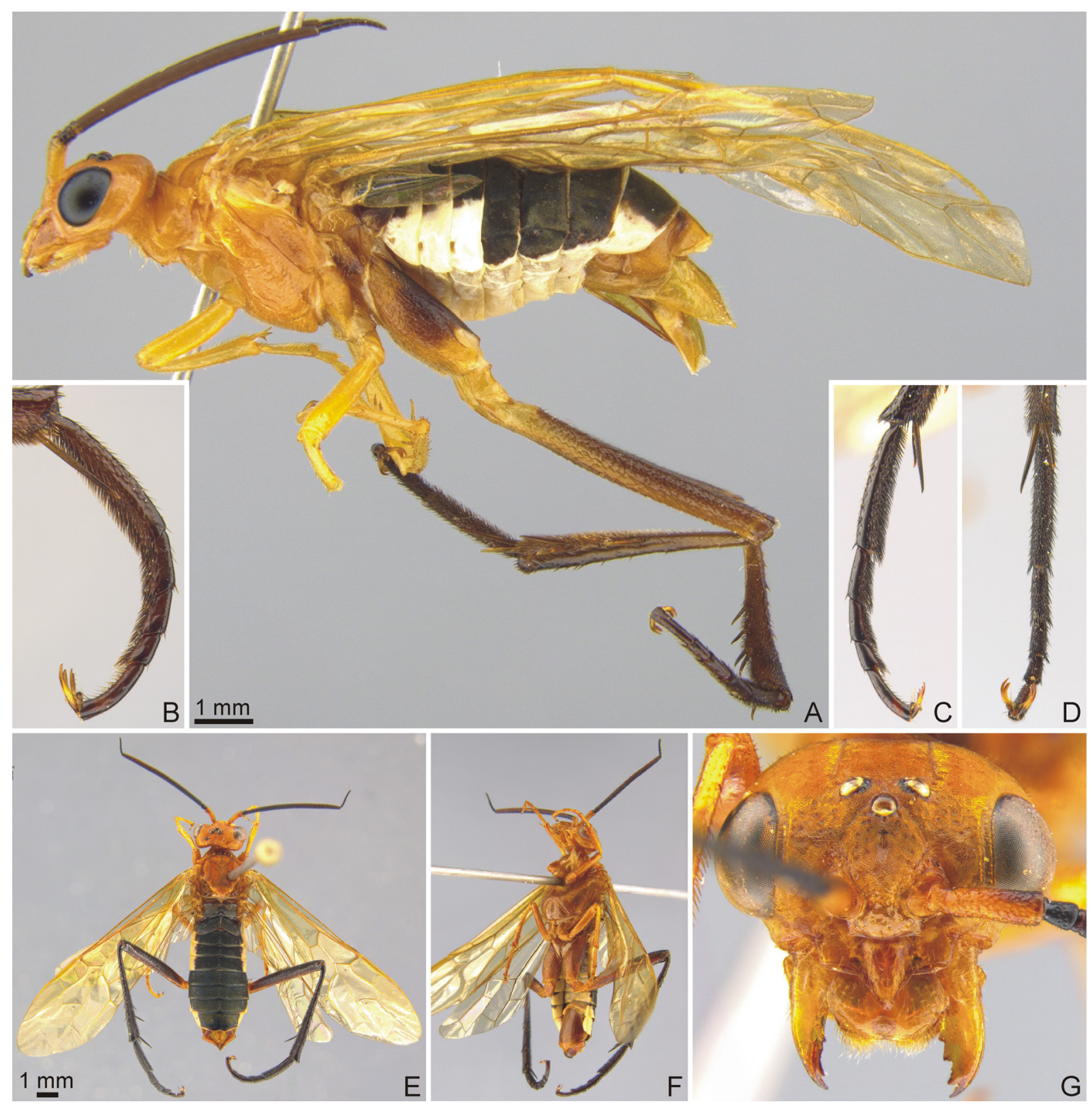

Fig. 4. Megaxyela fulvago Blank, Shinohara \& Wei sp. nov. A. Habitus lateral ( 9 , DEI-GISHym 5752, NSMT). B. Metatarsus lateral ( + , 5752, NSMT). C-D. Metatarsus lateral/ventral ( $\delta$, holotype, 5236, CSCS). E-F. Habitus dorsal/lateroventral (ð, holotype, 5236, CSCS). G. Head frontal (ð, 5239, NSMT). 


\section{Description}

\section{Female}

CoLor. Body red brown with black-and-white pattern, black parts partly with bronze tinge (Fig. 4A). Head and thorax red brown (specimen 30882 with diffuse transverse stripe on vertex - artifact?), posterior half of metanotum and ventral half of metepisternum infuscate. Scape red brown, pedicel black, flagellum dark brown. Abdomen in dorsal view black with continuous white bands laterally on terga $2-4$, each $0.15-0.20 \times$ as wide as tergal width, tergum 8 with narrower lateral white band, ventral portions of terga 2-4 and 8 completely white, terga 5-6 narrowly and tergum 7 broadly white along ventral margin, terga $9+10$ brown with small dark spot dorsolaterally. Sterna white. Valvifer 2 and valvula 3 red brown, membrane between valvifer 2 and valvula 3 pale (Fig. 11B). Fore and mid legs pale red brown. On hind leg, coxa red brown, infuscated laterally in middle and dorsally, trochanter and trochantellus pale red brown, femur brown dorsally and red brown ventrally, tibia and tarsus brown. Wings weakly yellow stained, venation and pterostigma yellow brown.

Morphology. Body 11.4-13.0 mm, fore wing $14.9-15.4 \mathrm{~mm}$ long. POL : OOL : OCL $=1.0: 2.2-2.4$ : 2.2-2.3. Interantennal distance $1.0-1.1 \times$ as wide as distance between torulus and eye margin, malar space $0.4-0.5 \times$ as wide as interantennal distance. Eye $1.3-1.4 \times$ as long as wide, frons at dorsal edge of antennal toruli 1.7-1.8 $\times$ as wide as maximum diameter of eye. Synantennomere 34.5-4.9 mm, filament $1.1 \mathrm{~mm}$, with 8-9 articles. Article 3 of maxillary palp $0.5-0.6 \mathrm{~mm}$ long. Ovipositor sheath $3.30-3.50 \mathrm{~mm}$ long, valvula $31.9-2.3 \times$ as long as wide. On hind leg, femur 4.9-5.0 mm, tibia 5.6-6.0 mm, tarsus 4.1-4.3 mm, tarsomere 1 4.5-5.1 $\times$ as long as wide, longer distal spur of tibia $0.70 \times$ as long as tarsomere 1, subapical tooth of claw stout and little shorter than apical tooth (Fig. 4B; similar to Shinohara 1992: fig. 4D). Face and vertex with areolate surface microsculpture, dull, interantennal area and frons above antennal toruli with scattered, shallow, $50 \mu \mathrm{m}$ large pits (similar to Fig. 4G), gena weakly coriarious, shining. Mesoscutum and mesoscutellum homogeneously areolate. Mesepisternum weakly coriarious and shining, with scattered pits. Metatarsomere 1 dorsally and dorsolaterally very sparsely setose, ventrally and ventrolaterally densely setose, setae 150-200 $\mu \mathrm{m}$ long ventrally (Fig. 4B). Pulvilli absent on article 1 of metatarsus, present on articles 3-4, presence ambiguous for article 2 , on article 4 pulvillus $50 \mu \mathrm{m}$ long. Basal and medial sections of valvula 3 of ovipositor sheath convex dorsally, almost straight ventrally, preapical section concave on dorsal and ventral edge, medial to preapical section of dorsal margin with setae up to $200 \mu \mathrm{m}$ long, ventral margin with setae up to $100 \mu \mathrm{m}$ long (Fig. 11B). Ovipositor about $2.4 \mathrm{~mm}$ long, weakly curved ventrally, valvula 1 and valvula 2 with bulbous areas in middle, without ctenidia (Fig. 12B-C). Valvula 1 in distal 0.7 with very narrowly spaced, subparallel, straight, vertical annuli, ventral margin in distal 0.3 bearing small serrulae. Valvula 2 in distal 0.6 with narrowly spaced annuli, distal 0.3 of dorsal edge of valvula 1 with small denticles.

\section{Male}

Color. Similar to female (Fig. 4E-G). Metepimeron red brown or predominantly infuscate. Ventral portions of terga 5-7 predominantly white. Subgenital plate and genitalia red brown. On hind leg, coxa sometimes completely black laterally, trochanter and trochantellus red brown, femur black dorsally and medially, dark red brown ventrally and laterally, tibia and tarsus black (Fig. 4C-D).

Morphology. Body $8.8-10.7 \mathrm{~mm}$, fore wing $11.3-12.8 \mathrm{~mm}$ long. POL : OOL : OCL $=1.0: 1.6-1.7(-$ 1.9) : 1.7-1.9(-2.0). Interantennal distance $0.9-1.1 \times$ as long as distance between torulus and eye margin, malar space $0.5 \times$ as wide as interantennal distance. Eye $1.3-1.4 \times$ as long as wide, frons at dorsal edge of antennal toruli 1.6-1.8 $\times$ as wide as maximum diameter of eye. Synantennomere 3 (3.6-)4.0-4.6 mm, filament 1.0-1.1 mm and with 8-9 articles (one male with left filament $0.8 \mathrm{~mm}$ long, 6 articles, right filament $1.0 \mathrm{~mm}$ long, 8 articles). Article 3 of maxillary palp $0.4-0.5 \mu \mathrm{m}$ long. On hind leg, femur 3.7-4.2 mm, tibia 4.5-5.2 mm, tarsus (3.8-)4.1-4.4 mm, tarsomere 14.9-5.5 $\times$ as long as wide, longer distal spur of tibia $0.60 \times$ as long as tarsomere 1 . Claws and microsculpture similar to female (Fig. 4D). 
Subgenital plate bluntly pointed at apex. Valviceps of penis valve distally parabolically rounded, basal 0.3 of upper side expanded to a round lobe coiled laterally, medial $0.3-0.8$ of upper edge shallowly convex, with numerous small teeth. Distal 0.7 of valviceps with long setae, most dense in medial lower portion of valviceps (Fig. 13B).

\section{Remarks}

Megaxyela fulvago sp. nov. is most similar to M. gigantea regarding color and structure. In both species, terga 2-4 are extensively white on the dorsolateral and ventral portion. This pattern is absent in M. euchroma sp. nov. and in most of the Nearctic species. White is present on the dorsal side of only terga 2-3 in M. parki, M. pulchra sp. nov. and M. togashii, as well as in the Nearctic M. major. Megaxyela fulvago sp. nov. and M. gigantea share the dull, minutely areolate and shallowly pitted face. A rugose surface structure is absent from the frons, which has been observed in the other East Asian species. Megaxyela fulvago sp. nov. and M. gigantea are primarily discriminated by color: head, prothorax and mesothorax are completely red brown in M. fulvago sp. nov., but these parts bear an extensive dark brown to black pattern in $M$. gigantea. The antennal filament of females is longer in M. fulvago sp. nov. $(1.1 \mathrm{~mm})$ than in $M$. gigantea $(0.8 \mathrm{~mm})$, and sometimes it is subdivided into fewer

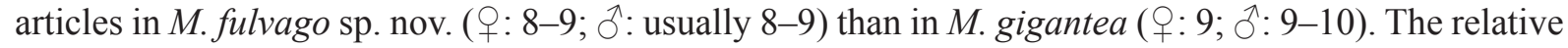
distance of POL : OOL : OCL differs weakly in males $(1.0: 1.6-1.7[-1.9]: 1.7-1.9[-2.0]$ and 1.0 : $1.8-2.0: 2.0-2.2$, respectively). The metatarsomere 1 of males is $4.9-5.5 \times$ as long as wide in M. fulvago sp. nov. but 4.6-5.0 $\times$ in M. gigantea. The female of $M$. fulvago sp. nov. falls into the range of variability of $M$. gigantea regarding these two characters.

The COI sequences group the specimens identified as M. fulvago sp. nov. by morphology into a clade which is supported by a bootstrap of $97 \%$. This clade additionally includes a specimen of M. gigantea. Supposedly this placement is an artefact caused by the short sequence length (261 bp) of this specimen. The maximum intraspecific variation within M. fulvago sp. nov. is $0.8 \%$. Megaxyela togashii is placed at a minimum pairwise distance of $7.6 \%$ (Fig. 2).

The specimens from Mount Yunshan were collected on a sunny day flying around birch trees with lots of catkins shedding pollen. Pollen feeding of adults is well known for Xyela species, which bear distally modified and usually extended maxillary palps (Burdick 1961). A similar behavior is unknown for adult Macroxyelinae. Although M. major has been caught from catkins of willow (Bridwell 1906) and pollen has been identified from the intestine of two fossil Macroxyelinae species (Krasilov \& Rasnitsyn 1982), Megaxyela is not specialized in pollen feeding but is facultatively palynivorous, because the labiomaxillar complex exhibits no particular modifications for the uptake of pollen as in Xyelinae.

Takeuchi (1940) and Maa (1949) referred to the specimens of M. gigantea collected in "Chinkiang [= Zhenjiang], Prov. Kiangsu [= Jangsu Sheng]" deposited in the collection of the Musée Heude, Shanghai at that time. Major parts of this collection have been incorporated into IZCAS, Beijing (Yang Ganyan, personal communication). The two females and one male collected in "Chinkiang" in 1918 could be identified as M. fulvago sp. nov. with help of photos kindly provided by Yang Ganyan. An additional female from "Chinkian" (3 May 1936, E. Suenson leg.), which we identified as M. gigantea prior to the recognition of M. fulvago sp. nov., is kept at INHS.

\section{Megaxyela gigantea Mocsáry, 1909}

Figs $5 \mathrm{~A}-\mathrm{H}, 11 \mathrm{C}, 12 \mathrm{E}, 13 \mathrm{C}, \mathrm{G}-\mathrm{H}$

Megaxyela gigantea Mocsáry, 1909: 39 (†, type locality: Russia, Khabarovskiy Kray, Kazakevichevo). Megaxyela mikado Sato, 1930: 4-5, figs a-b (+, type locality: South Korea, Suwon, Kazan). 
Megaxyela mikado - Takeuchi 1937: 25 (synonymy with M. gigantea).

Megaxyela gigantea - Shinohara 1992: 785-789 (description, distribution, hosts, references), 794-795 (key), figs 1A-B, 2A-B, 2E, 3A-C, 4A, 4F-G.

\section{Type material}

Lectotype (here designated)

RUSSIA: +, lectotype of Megaxyela gigantea, "Ussuri Kasakewitsh [= Khabarovskiy Kray, Kazakevichevo, $48.27^{\circ}$ N, $134.77^{\circ}$ E] 1907 Korb"; "Megaxyela gigantea det. Mocsáry"; [rectangular red label without inscription]; "Megaxyela gigantea Mocs."; [red:] "Lectotype Megaxyela gigantea Mocsáry, 1909 Det. A. Shinohara 1997", in perfect condition (HNHM). The lectotype corresponds well with Shinohara's (1992) characterization of the species.

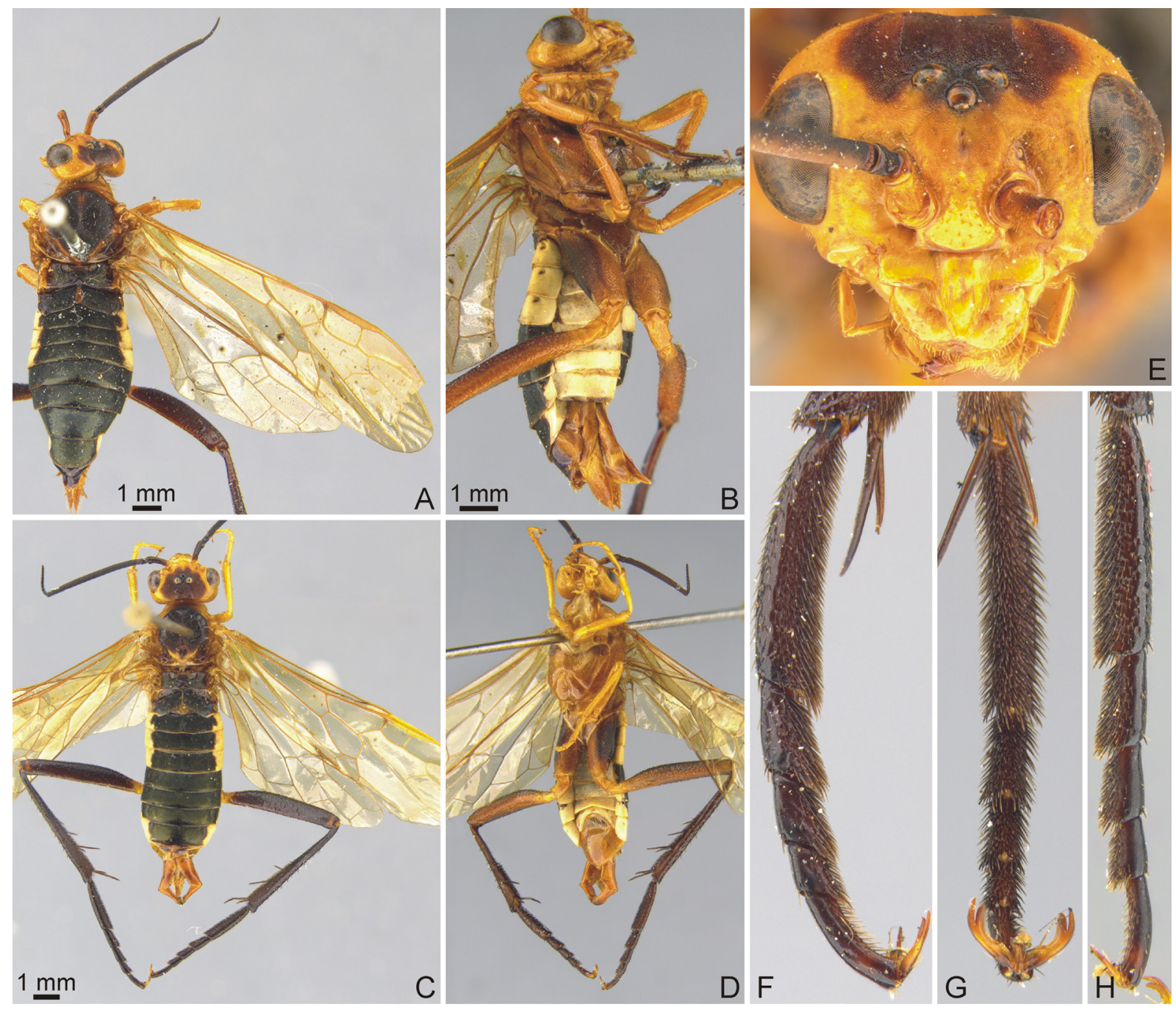

Fig. 5. Megaxyela gigantea Mocsáry, 1909. A-B. Habitus dorsal/lateroventral ( + , holotype of M. mikado, DEI-GISHym 22350, NSMT). C-D. Habitus dorsal/lateroventral (ô, 18507, NSMT). E. Head frontal ( $q$, holotype of M. mikado, 22350, NSMT). F-G. Metatarsus lateral/ventral ( $q$, holotype of M. mikado, 22350, NSMT). H. Metatarsus ventral ( $\curvearrowright$, 18507, NSMT). 


\section{Paralectotypes}

RUSSIA: 1 , , same collecting data as lectotype (HNHM), Mocsáry (1909) described M. gigantea from an unknown number of females.

SOUTH KOREA: 1 o, holotype of Megaxyela mikado, "Suigen [= Suwon, 37.28 N, 127.02 E], Chosen [= Korea], Apr. 24., 1927, coll. K. Sato"; "270", "Type of Megaxyela mikado Sato", "Megaxyela gigantea Mocs. det. K. Sato, XI-1957", "DEI-GISHym 22350", left wings missing (NSMT). The holotype of M. mikado is a comparatively dark female of M. gigantea with a large dark brown spot on ocellar area and vertex. Terga 2-4 bear white stripes laterally, which are of equal width (see figure in Sato 1930; Shinohara \& Smith 1979: fig. 13, in synonymy with M. gigantea). The synonymy first proposed by Takeuchi (1937) is here confirmed.

\section{Additional material examined or reported in literature}

NORTH KOREA: 1 q, P'yŏngan-pukto ["Pyongah Prov. N"], Mt. Myohyang, 40.02 N, 126.33 E, 23 May 1985, Vojnits \& Zombori leg. (HNHM).

RUSSIA: 1 , Primorskiy Kray, Voroshilovskiy rayon, southern slopes of Sikhote Alin, on river

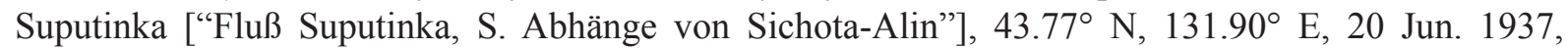
T. Samoylov leg. (NHRS).

SOUTH KOREA: 4 우, 51 $\widehat{\jmath}$ (including DEI-GISHym 708), Chollanam-do, Mt. Nogodan, Mts. Chirisan, $35.30^{\circ} \mathrm{N}, 127.53^{\circ} \mathrm{E}, 1220 \mathrm{~m}$ alt., $4-5$ Jun. 1996, A. Shinohara leg. (NSMT); 1 o, Kangwon-

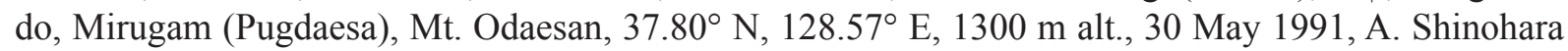
leg. (NSMT) (Shinohara 1992); 1 q, same locality, 27 May 1998, A. Shinohara leg. (NSMT); 1 (specimen DEI-GISHym 18507 used for barcoding), same locality, collected from Juglans ?mandshurica,

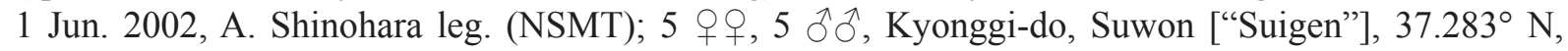

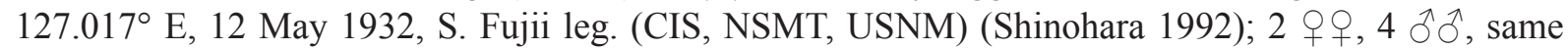
locality, 14 May 1932, S. Fujii leg. (NSMT, USNM) (Shinohara 1992); 5 q $q$, Seoul ["Keijo"], $37.57^{\circ}$ N, $127.00^{\circ}$ E, 11 May 1935, K. Sato leg. (NSMT) (Shinohara 1992); 2 우, Seoul, Ch'ongnyangni [“Seiryori”], $37.58^{\circ}$ N, $127.05^{\circ}$ E, 6 May 1934, H. Doi leg. (UOP) (Shinohara 1992).

\section{Description}

See Shinohara (1992) and Figs 5A-B, E, 11C (ovipositor sheath).

\section{Female}

Ovipositor about $2.7 \mathrm{~mm}$ long, weakly curved ventrally, valvula 1 and valvula 2 bulbous distal of middle, without ctenidia (Fig. 12E). Pulvilli absent on article 1 of metatarsus, present on article 4 and $50 \mu \mathrm{m}$ long, presence ambiguous for articles 2-3 (Fig. 5F-G).

\section{Male}

See Figs 5C-D, H, 13G-H. Valviceps of penis valve distally parabolically rounded, basal quarter of upper side expanded to a round lobe coiled laterally, medial $0.3-0.8$ of upper edge with one or two shallow elevations and numerous small teeth. Distal 0.7 of valviceps with long setae, most dense in medial lower portion (Fig. 13C).

\section{Host plant}

Saito (1941), Ko (1969) and Xiao (2006) reported Juglans ailanthifolia Carrière (cited as J. sieboldiana Maxim.), J. mandshurica Maxim., J. regia L. (including the synonym J. sinensis [C. DC.] Dode), Pterocarya rhoifolia Sieb. \& Zucc., and P. stenoptera C. DC. All recorded hostplant associations of M. gigantea need confirmation, because they can also refer to the new species $M$. pulchra sp. nov. 
In South Korea, A. Shinohara captured a male of M. gigantea together with 3 우, 2 ○े M. pulchra sp. nov. from the same $J$. ?mandshurica tree at end of May and beginning of June 2002.

\section{Remarks}

Megaxyela gigantea is similar to species with the terga 2-3 or 2-4 laterally extensively white (dorsally black in M. euchroma sp. nov. and in the Nearctic species except for M. major). It is unique among the East Asian species in the predominantly red brown head (predominantly black in $M$. parki, pale yellow color and less extensive in $M$. togashii) bearing a large infuscate spot on face and vertex (completely red brown in $M$. fulvago sp. nov.), which does not extend to the antennal toruli ventrally (spot extending to toruli in M. pulchra sp. nov.). As in M. fulvago sp. nov., the surface of the face is minutely areolate and bears scattered, shallow, $50 \mu \mathrm{m}$ large pits (face rugose in other East Asian species at least laterally). The dorsal side of terga 2-4 is white laterally for $0.15-0.20 \times$ the tergal width in M. gigantea and M. fulvago sp. nov., whereas the white marks are generally narrower in $M$. parki or narrower at least on tergum 4 in M. pulchra sp. nov. and M. togashii.

The single specimen studied genetically is placed within the group, which otherwise comprises $M$. fulvago sp. nov., but we interpret this placement as an artefact caused by the very short sequence length of $M$. gigantea. Morphological results indicate two separate species.

Megaxyela inversa Blank \& D.R. Smith sp. nov. urn:1sid:zoobank.org:act:5BA86B4F-CFAC-42E0-A2B8-BC81E1C0B517

Figs $6 \mathrm{~A}-\mathrm{G}, 11 \mathrm{D}, 12 \mathrm{D}$

\section{Diagnosis}

This species is unique by the very long ovipositor sheath with the dorsal outline of valvula 3 straight and the ventral outline convex, and the ovipositor curved dorsally along its longitudinal axis.

\section{Etymology}

The Latin adjective inversus (fem. inversa) indicates the shape of the ovipositor, that, in contrast to other Megaxyela species, is dorsally curved.

\section{Type material}

Holotype

USA: O+: "USA West Virginia, Randolph Co., Job, 38.8528 N, 79.5293 W, 1-20 April 2012, J. Whitaker 10067, USGS-DRO 292937”, [red:] “Holotype Megaxyela inversa det. S.M. Blank \& D.R. Smith 2017”, "DEI-GISHym 32152" (USNM).

\section{Paratype}

UNKNOWN: 1 + , “4/22/91" [supposed collection date: 22 . Apr. 1891, no collecting locality given, see insertion in Fig. 6A for original labels], DEI-GISHym 22356 (USNM).

\section{Description}

\section{Female}

CoLOr. Black with white pattern, black parts with bronze to blue tinge (Fig. 6A, C). Head below toruli brown, clypeus and labrum white, preapical region of labrum and mandibles brown white, labial palpomeres 1-2 white (Fig. 6C). Antenna black with basal 3/4 of scape in inner surface light orange. Pronotum and metanotum with bronze tinge, mesonotum and mesepisternum with blue tinge. Tegula basally brown, distally white. Abdominal terga and sterna black, terga 1-8 and sterna with white distal margins, ventral part of terga laterally with $100 \mu \mathrm{m}$ wide white stripe, sterna 5-7 with $40-50 \mu \mathrm{m}$ 


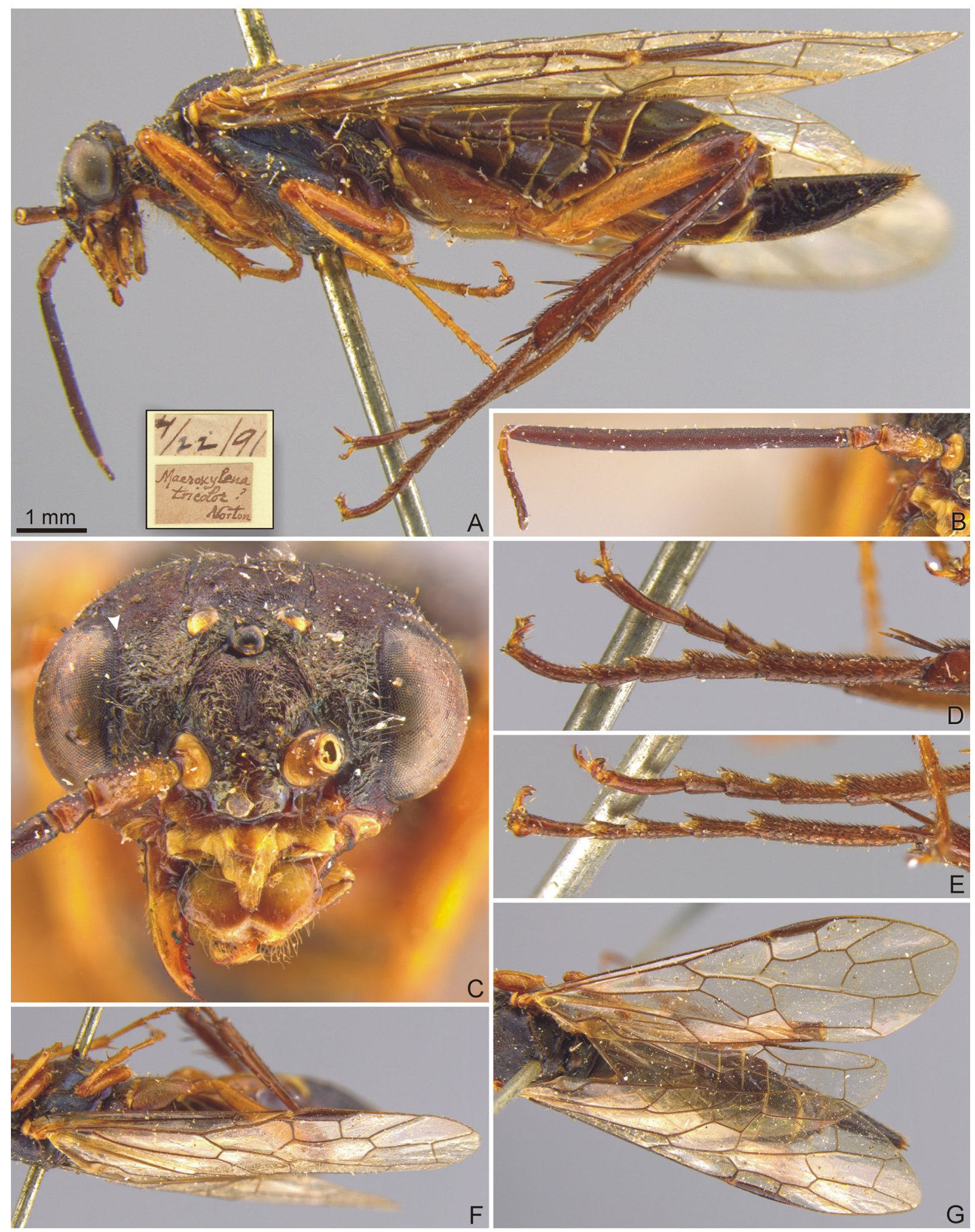

Fig. 6. Megaxyela inversa Blank \& D.R. Smith sp. nov. (q, paratype, DEI-GISHym 22356, USNM). A. Habitus, lateral; small insertion: original collection labels. B. Antenna. C. Head, frontal, arrowhead indicating carina along inner orbit. D-E. Metatarsus, lateral/lateroventral view. F-G. Wings. 
wide lateral white stripe (Fig. 6A). Valvifer 2 red brown, valvula 3 black except for narrow brown tip, membrane between valvifer 2 and valvula 3 white (Fig. 11D). Legs orange, procoxa and mesocoxa basally infuscate, distal 0.20 of metafemur, complete metatibia and metatarsus black. Wing subhyaline, venation and pterostigma black (Fig. $6 \mathrm{~F}-\mathrm{G})$.

Morphology. Body $10.2 \mathrm{~mm}$, fore wing $11.2 \mathrm{~mm}$ long. POL : $\mathrm{OOL}: \mathrm{OCL}=1.0: 1.3: 1.5$. Interantennal distance $1.3 \times$ as wide as distance between torulus and eye margin, malar space $0.4 \times$ as wide as interantennal distance. Eye $1.5 \times$ as long as wide, frons at dorsal edge of antennal toruli $1.4 \times$ as wide as maximum diameter of eye. Synantennomere $33.1 \mathrm{~mm}$, filament $0.9 \mathrm{~mm}$, with 9 articles. Article 3 of maxillary palp $0.4 \mu \mathrm{m}$. Ovipositor sheath $5.1 \mathrm{~mm}, 3.8 \times$ as long as metatarsomere 1 , valvula $31.3 \times$ as long as valvifer 2, valvula $33.3 \times$ as long as wide. On hind leg, femur $3.1 \mathrm{~mm}$, tibia $4.5 \mathrm{~mm}$, tarsus $3.6 \mathrm{~mm}$, tarsomere $15.8 \times$ as long as wide, longer distal spur of tibia $0.3 \times$ as long as tarsomere 1 , claws cleft, subapical tooth of claw little smaller at base than apical tooth. Head dull, lateral part of frons rugose, medial part minutely areolate with some $50 \mu \mathrm{m}$ large pits, vertex and postocellar area mostly minutely areolate to rugulose, gena rugulose (Fig. 6C). Mesoscutum and mesoscutellum homogeneously minutely areolate. Mesepisternum medially coriarious and shining, with $20 \mu \mathrm{m}$ large pits. Metatarsomere 1 dorsally and laterally almost glabrous, ventrally densely setose, setae 70-100 $\mu \mathrm{m}$ long (Fig. 6D). Pulvilli present on metatarsomeres 1-4, on article 1 pulvillus $150 \mu \mathrm{m}$ long, on article 4 $230 \mu \mathrm{m}$ (Fig. 6E). Basal and medial sections of valvula 3 of ovipositor sheath straight dorsally, convex ventrally, preapical section almost straight on dorsal and ventral edge, with dense pattern of up to 200 $\mu \mathrm{m}$ long setae (Figs 6A, 11D). Ovipositor $4.6 \mathrm{~mm}$ long, weakly curved dorsally, without bulbous areas in middle, without ctenidia (Fig. 12D). Valvula 1 in distal 0.6 with annuli, basal annuli much more widely spaced then medial and distal annuli, medial annuli very narrowly spaced, subparallel, straight, vertical, ventral edge in distal 0.2 bearing small serrulae. Valvula 2 in distal 0.3 with widely spaced annuli, annuli not extending to ventral edge of valvula, distal 0.3 of dorsal edge of valvula 1 with partly prominent, rounded denticles.

\section{Male \\ Unknown.}

\section{Remarks}

The ovipositor is curved dorsally in Megaxyela inversa sp. nov. (Fig. 12D), which is an unusual condition in sawflies and unique in Macroxyelinae (Fig. 12A-B, E-H; Smith \& Schiff 1998: figs 16-21). The predominant number of sawflies and woodwasps have the ovipositor curved ventrally or the ovipositor is straight (see, e.g., figures in Weltz \& Vilhelmsen 2014). Among Xyelidae, the sheath is curved dorsally to a various degree in species of Pleroneura Konow, 1897 (e.g., Smith et al. 1977; Shinohara 1995, 2016) and in Xyela concava Burdick, 1961 (Burdick 1961).

Among Nearctic Megaxyela this species is most similar to M. bicoloripes and M. tricolor by the slender metatarsus and the red brown metafemur bearing an extensively infuscate apex. It is readily distinguished from all other Megaxyela species by the outline of the basal and medial portion of valvula 3, which in lateral view is straight dorsally and evenly curved ventrally. The remaining Megaxyela species have either both the dorsal and the ventral outlines of valvula 3 curved, or the dorsal outline is curved and the ventral straight (Fig. 11A-C, 11E-H; Smith \& Schiff 1998: figs 7-11).

The paratype is presumably from North America because of its discovery in a US collection and the holotype is from West Virginia. Morphometry and figures are from the paratype since the specimen used as holotype was discovered too late to include in this paper. 
Megaxyela langstoni Ross, 1936 sp. rev.

Figs $7 \mathrm{~A}-\mathrm{F}, 11 \mathrm{E}$

Megaxyela langstoni Ross, 1936: 131-132 ( ̂, type locality: USA, Mississippi, Starkville, Mississippi State University).

Megaxyela langstoni - Smith 1978: 25 (listed in synonymy with M. major). - Smith 1979: 10 (synonymized with M. major).

Megaxyela major - Smith \& Schiff 1998: 644-648 (misidentification, partim). — Ree 2012: [1] (damage to pecan). - Ree 2014: [2] (damage to pecan). — Ree 2016: [2] (damage to pecan).

\section{Type material}

\section{Holotype}

USA: ㅇ: "State College Miss. 4/7/32"; "J. M. Langston Collector"; "Pecan 283813"; [red:] "Holotype Megaxyela langstoni Ross ○"; "INHS Type \#1071"; "DEI-GISHym 30821" (INHS), left posterior leg missing. The locality data correspond with the present-day Mississippi State University of Agriculture and Applied Science in Starkville.

\section{Additional material examined}

USA: 1 +, Mississippi, Starkville [“Ag. Coll. Miss.”], 10 Apr. 1915, C.C. Greer leg., DEI-GISHym 30822 (USNM); 1 \%, Oklahoma, Pawnee County, Pawnee, 352736 East Hwy 64, 36.292 ${ }^{\circ}$ N, $96.716^{\circ} \mathrm{W}$, Malaise trap, 9-23 Apr. 2016, C. Apgar leg., DEI-GISHym 30796 (specimen used for barcoding) (USNM); 1 , 1 ${ }^{\Uparrow}$, Texas (USNM).

\section{Supplementary description}

\section{Female}

Synantennomere $33.8 \mathrm{~mm}$, filament $0.8 \mathrm{~mm}$, with (6-)8-9 articles. Pulvilli present on metatarsomeres $1-4$, on article 1 pulvillus $100 \mu \mathrm{m}$ long, on article $4170 \mu \mathrm{m}$ (Fig. 7D-E). See key for additional characters.

\section{Host plant}

Pecan (Carya illinoinensis; cited as "Carya pecan A. \& G." by Ross 1936) and possibly additional species of Carya (Dyar 1898b as M. major; Yuasa 1923 as Megaxyela sp. 1). Supposedly also the photo by Ree (2014) of gregarious larvae of $M$. 'major' feeding on pecan refers here.

\section{Remarks}

Smith $(1978,1979)$ treated Megaxyela langstoni as a synonym of M. major. With some reservation, Smith \& Schiff (1998) discussed differences in behavior, color and morphology as possible intraspecific variation. Here we reinstate $M$. langstoni $\mathrm{sp}$. rev. as a valid species. The analysis of the barcoding region of three females, all originating from a collection site in Oklahoma, resulted in two clades (DEI-GISHym 30796 and $30767+30797$, respectively) separated by a minimum pairwise distance of $13.5 \%$, while the two specimens included in the clade $30767+30797$ are separated by a mimimum pairwise distance of only $0.3 \%$ (Fig. 2). This observation is paralleled by different coloration of the adults corresponding with the type material and the descriptions of M. langstoni and M. major: Specimen 30796 agrees with M. langstoni in the predominantly red brown terga and the basally black pterostigma (Fig. 7A), while the specimens $30767+30797$ agree with $M$. major in the dorsally predominantly black terga and the unicolorous yellow pterostigma (Fig. 7G).

Several specimens included in the type series of M. langstoni were reared from the pecan Carya illinoinensis (Ross 1936). Ross (1936) also referred to the descriptions of larvae of M. major by Dyar 
(1898b) and Yuasa (1923). Dyar described the larvae as "gregarious on the young leaves of hickory" [= Carya spec.]. Yuasa (1923) noted "on hickory and pecan". If the association of larvae described by Yuasa as "Megaxyela sp. 1" with M. major by J.M. Langston and H.H. Ross is correct, M. major is a "solitary feeder on pecan and some other hickories" (Ross 1936). Citing M. major, M. langstoni has been listed as a pest of pecan in Texas, but "in most cases sawfly damage is just 'visual discomfort'
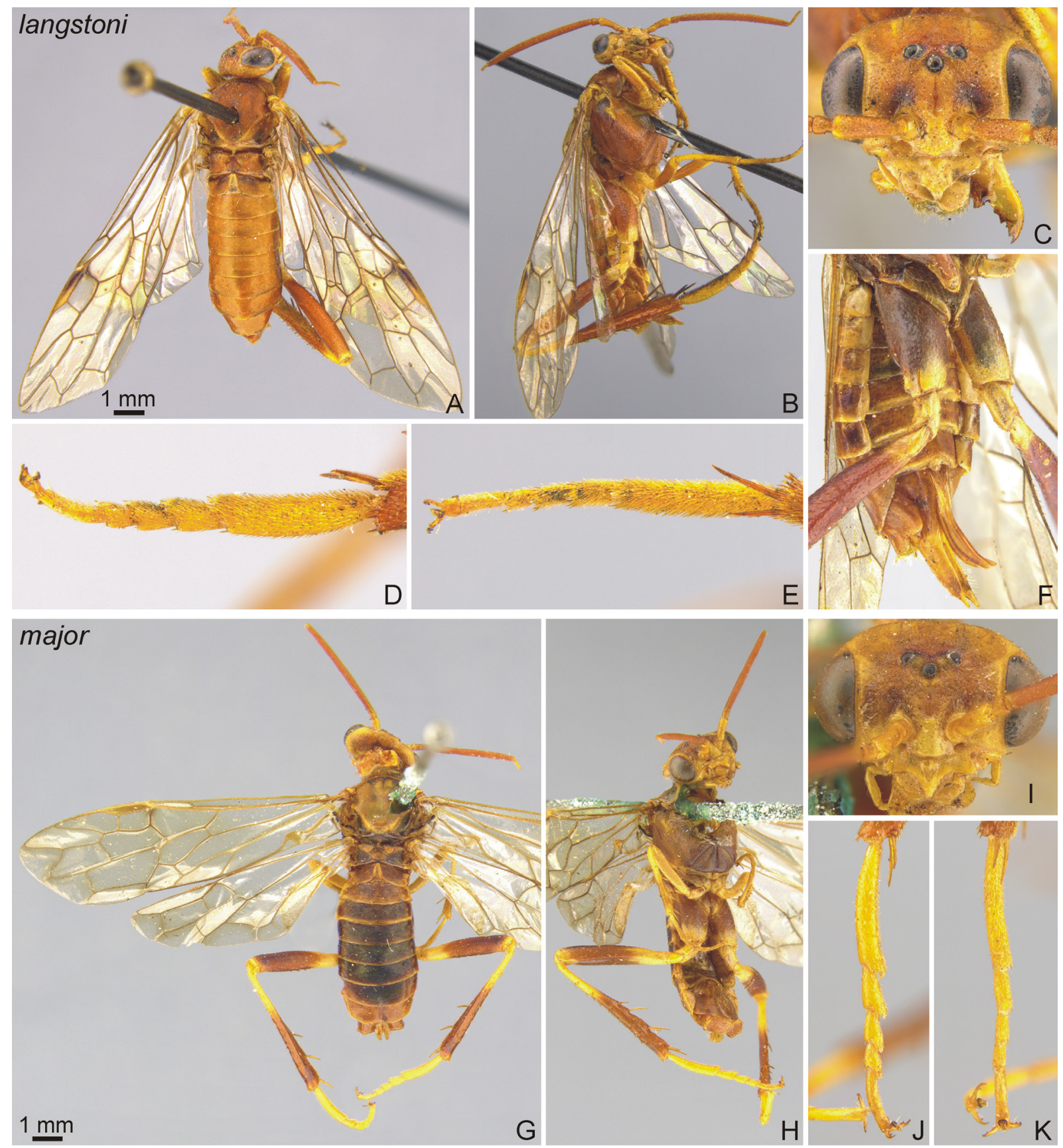

Fig. 7. A-F. Megaxyela langstoni Ross, 1936, $q($ A-C = holotype, DEI-GISHym 30821, INHS; D-F = 30822, USNM). G-K. M. major (Cresson, 1880), ठิ, paratype (30823, ANSP). A-B. + , holotype, habitus dorsal/lateroventral. C. + , holotype, head frontal. D-E. $q$, metatarsus, lateral/ventral. F. + , abdomen lateroventral. G-H. Habitus dorsal/lateroventral. I. Head frontal. J-K. Metatarsus lateral/ ventral. 
where the larvae have damaged some of the new foliage" (Ree 2012, 2014). Significant defoliations, which might justify a treatment, obviously are rare (Ree 2016).

Smith \& Schiff (1998) recorded Megaxyela major from 14 states of the eastern US. Collection data from Mississippi completely refer to M. langstoni (type material and additional specimens). We identified additional material from Oklahoma and Texas. For the distribution of M. major, we confirm Kansas (holotype of Odontophyes ferruginea), Texas (lectotype of Xyela major) and, upon additional specimens studied, also Oklahoma and Pennsylvania. Adults from Florida, Iowa, Missouri, New York and South Carolina need to be re-identified. The state records for Alabama, Arkansas, Georgia, Tennessee and Virginia are based on larvae solely. Since the larvae of four of seven Nearctic Megaxyela are unknown, and Megaxyela larvae generally display only vague specific differences according to our experience with East Asian taxa, these records require scrutiny. Ross (1936) discriminated the larvae of M. langstoni and M. major by the presence of a single large dark area vs pairs of black spots on the pronotum and the penultimate abdominal segment. But these character states might also apply to those Nearctic species of Megaxyela for which the larvae are still unknown.

Megaxyela major (Cresson, 1880)

Fig. $7 \mathrm{G}-\mathrm{K}$

Xyela major Cresson, 1880: 34 (ㅇ, type locality: USA, Texas).

Odontophyes ferruginea Bridwell, 1906: 94 (+, type locality: USA, Kansas, Baldwin).

Megaxyela major - Ashmead in Dyar 1898a: 214 (combination). — Smith \& Schiff 1998: 638-639 (key), 644-648 (description, distribution, hosts, references; including data of M. langstoni), figs 4, 7, 18-19, 33.

Odontophyes ferruginea - Ross 1932: 162 (synonymy with M. major).

\section{Type material}

USA: +, lectotype of Xyela major (designated by Cresson 1916): "Texas, (Belfrage)" (Cresson 1880) (ANSP, Type No. 330), studied by Smith \& Schiff (1998: 646). Cresson (1880) described the abdomen as "blackish-brown above". He did not refer to the pterostigma but noted "nervures ferruginous". Paralectotype ${ }^{\lambda}$ (here studied): "Tex.”; “12."; [blue:] "Para-Type 530.2"; "Megaxyela major (Cresson) Det. D. Burdick "54"; "DEI-GISHYM 30823"; ANSP. Fragments of fore legs glued to label, head glued to specimen, left antennal filament missing (Fig. 7G-H).

USA: + , holotype of Odontophyes ferruginea: [red:] "Type + Odontophyes ferruginea J. C. Bridwell”; [red:] "Odontophyes ferruginea Brid., o TYPE"; "Baldwin Kansas"; "Bridwell Apr."; [handwritten:] "on Salix shrub willow"; "USNM Ent 00778020" (USNM). Good shape; left antenna missing beyond scape; right hind tarsus missing. The synonymy with M. major by Ross (1932) is here confirmed.

\section{Additional material examined}

USA: 1 क , Oklahoma, Pawnee County, Pawnee, 352736 East Hwy 64, 36.292 ${ }^{\circ}$ N, $96.716^{\circ}$ W, Malaise trap, 23 Apr.-3 May 2011, C. Apgar leg., DEI-GISHym 30767 (specimen used for barcoding) (USNM); 1 q, same locality, Malaise trap, 9-23 Apr. 2016, C. Apgar leg., DEI-GISHym 30797 (specimen used for barcoding) (USNM); 1 + , Pennsylvania, Huntington, 3 Jun. 1934 (USNM).

\section{Supplementary description}

\section{Male}

Synantennomere $33.7 \mathrm{~mm}$, filament $0.7 \mathrm{~mm}$, with 7 articles. Pulvilli present on metatarsomeres $1-4$, on article 1 pulvillus $80 \mu \mathrm{m}$ long, on article $4120 \mu \mathrm{m}$ (Fig. 7J-K). See key for additional characters. 


\section{Host plant}

Supposedly pecan (Carya illinoinensis) and possibly additional Carya species (Ross 1936).

\section{Remarks}

See Megaxyela langstoni.

Megaxyela parki Shinohara, 1992

Figs 1D, 8A-H, 11F, 12F, 13D

Megaxyela parki Shinohara, 1992: 792-794, figs 4C, 4E, 6A-B (中, type locality: South Korea, Kangwondo, Mt. Samagsan near Chuncheon).

\section{Material examined or reported in literature}

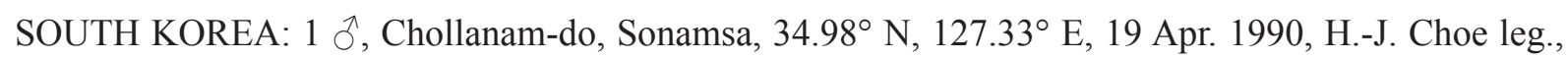
DEI-GISHym 710 (CALS); 1 ( (holotype, CIS), 4 q $ᄋ$ (paratypes, NSMT), Kangwon-do, Chuncheon,
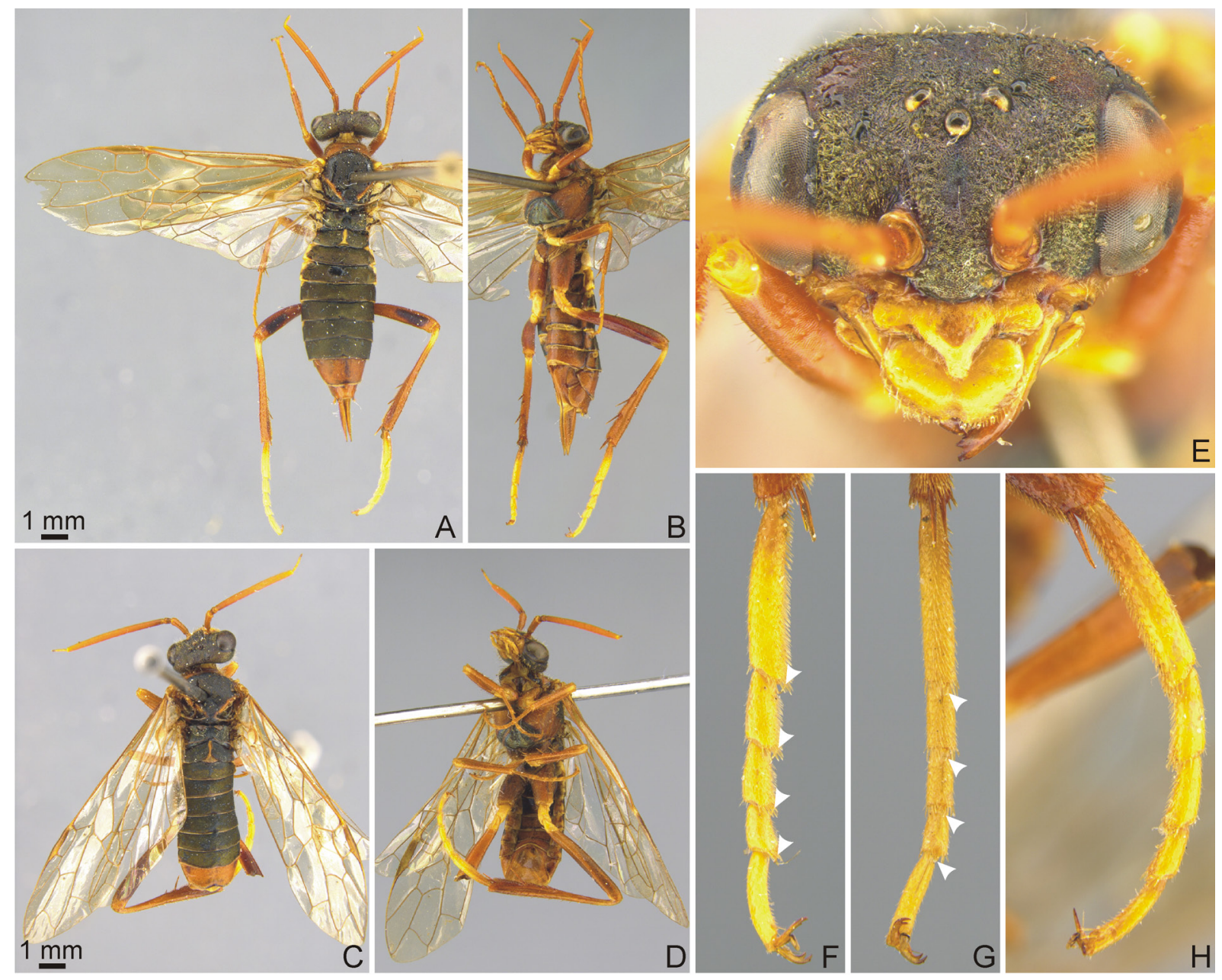

Fig. 8. Megaxyela parki Shinohara, 1992. A-B. Habitus dorsal/lateroventral ( NSMT). C-D. Habitus dorsal/lateroventral (ð, 710, NSMT). E. Head frontal (ð, 710, NSMT). F-G. Metatarsus lateral/ventral, arrowheads indicate pulvilli (ㅇ, 18509, NSMT). H. Metatarsus lateral ( $\hat{0}, 710$, NSMT). 


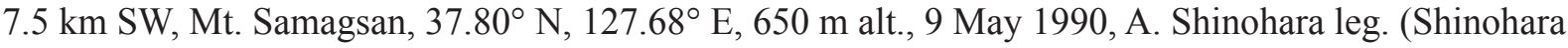
1992); 1 ㅇ, Kangwon-do, Mirugam (Pugdaesa), Mt. Odaesan, $37.80^{\circ} \mathrm{N}, 128.57^{\circ} \mathrm{E}, 1300 \mathrm{~m}$ alt., 24 May 1989, A. Shinohara leg. (paratype, USNM) (Shinohara 1992); 1 , same locality, 27 May 1989, A. Shinohara leg., (paratype, NSMT) (Shinohara 1992); 3 우, same locality, 29 May 1993, A. Shinohara leg., DEI-GISHym 18510 (NSMT); 1 , same locality, 30 May 1993, A. Shinohara leg. (NSMT); 1 \&, same locality, 31 May 1993, A. Shinohara leg., DEI-GISHym 18509 (NSMT); 1 +, same locality, 1 Jun. 1993, A. Shinohara leg. (NSMT).

\section{Description}

See Shinohara (1992) and Figs 8A-B, 11F.

\section{Female}

Ovipositor about $2.6 \mathrm{~mm}$ long, weakly curved ventrally, valvula 1 and valvula 2 without bulbous zone, without ctenidia (Fig. 12F). Pulvilli present on metatarsomeres 1-4, on article 1 pulvillus $130-150 \mu \mathrm{m}$ long, on article 4 150-180 $\mu \mathrm{m}$ (Fig. 8G-H).

\section{Male}

Color. Similar to female (Figs 1D, 8D-E, H). Tergum 8, sterna 4-6, subgenital plate and genitalia red brown, sterna 1-3 black with red brown mark medially.

Morphology. Body $9.8 \mathrm{~mm}$, fore wing $11.5 \mathrm{~mm}$ long. POL : OOL : OCL $=1.0: 1.8: 1.8$. Interantennal distance $1.2 \times$ as wide as distance between torulus and eye margin, malar space $0.4 \times$ as wide as interantennal distance. Eye $1.4 \times$ as long as wide, frons $1.5 \times$ as wide as maximum diameter of eye. Synantennomere $34.0 \mathrm{~mm}$, antennal filament $0.8 \mathrm{~mm}$, with 7 articles. Article 3 of maxillary palp $0.5 \mathrm{~mm}$. On hind leg, femur $3.8 \mathrm{~mm}$, tibia $5.1 \mathrm{~mm}$, tarsus $4.3 \mathrm{~mm}$, tarsomere $14.5 \times$ as long as wide, longer distal spur of tibia $0.5 \times$ as long as tarsomere 1. Claws and microsculpture similar to female. Subgenital plate bluntly pointed at apex. Valviceps of penis valve distally evenly rounded, basal third of upper side expanded to a round lobe coiled laterally, medial $0.4-0.7$ of upper edge with irregular teeth. Distal 0.4 of valviceps with long setae, lower portion of medial 0.4-0.7 with short setae (Fig. 13D).

\section{Remarks}

Megaxyela parki belongs to the group of East Asian species with extensively white terga 2-4. Among these species, it is unique in the completely red brown tergum 7 (black and laterally/ventrally white in other species). It is also easily identified by its comparatively short antennae with the antennal filament comprising 6-7 articles, long valvula 3 of the ovipositor sheath, almost completely black head, red brown antennae, and yellow white metatarsus.

The previously unknown male is similar to the female in color. Both male and female bear a much less dense hair cover on the posterior tarsi than other East Asian taxa. The larval host is still unknown.

Megaxyela pulchra Blank, Shinohara \& Sundukov sp. nov. urn:1sid:zoobank.org:act:1079C626-6C18-4EC2-86DB-863D9F49E768

Figs 9A-I, 11G, 12G, 13E, I

Megaxyela gigantea - Zhelochovtsev \& Zinovjev 1995: 396 (misidentification, partim). — Lelej \& Taeger 2007: 933 (misidentification, partim). — Lelej 2012: 62 (misidentification, partim).

Megaxyela aff. gigantea - Sundukov 2009: 213 (record from Russia, Primorskiy Kray).

Megaxyela sp. 1 - Shinohara et al. 2017: fig. 15 (phylogenetic analysis). — Blank et al. 2017: 115 


\section{Diagnosis}

Megaxyela pulchra sp. nov. is characterized by the following unique combination of characters: frons above the antennal toruli rugulose, head with black spot extending from postocellar area and vertex to the antennal toruli, pterostigma yellow brown and infuscate basally and anteriorly, pectus red brown, hypopygium of male red brown.

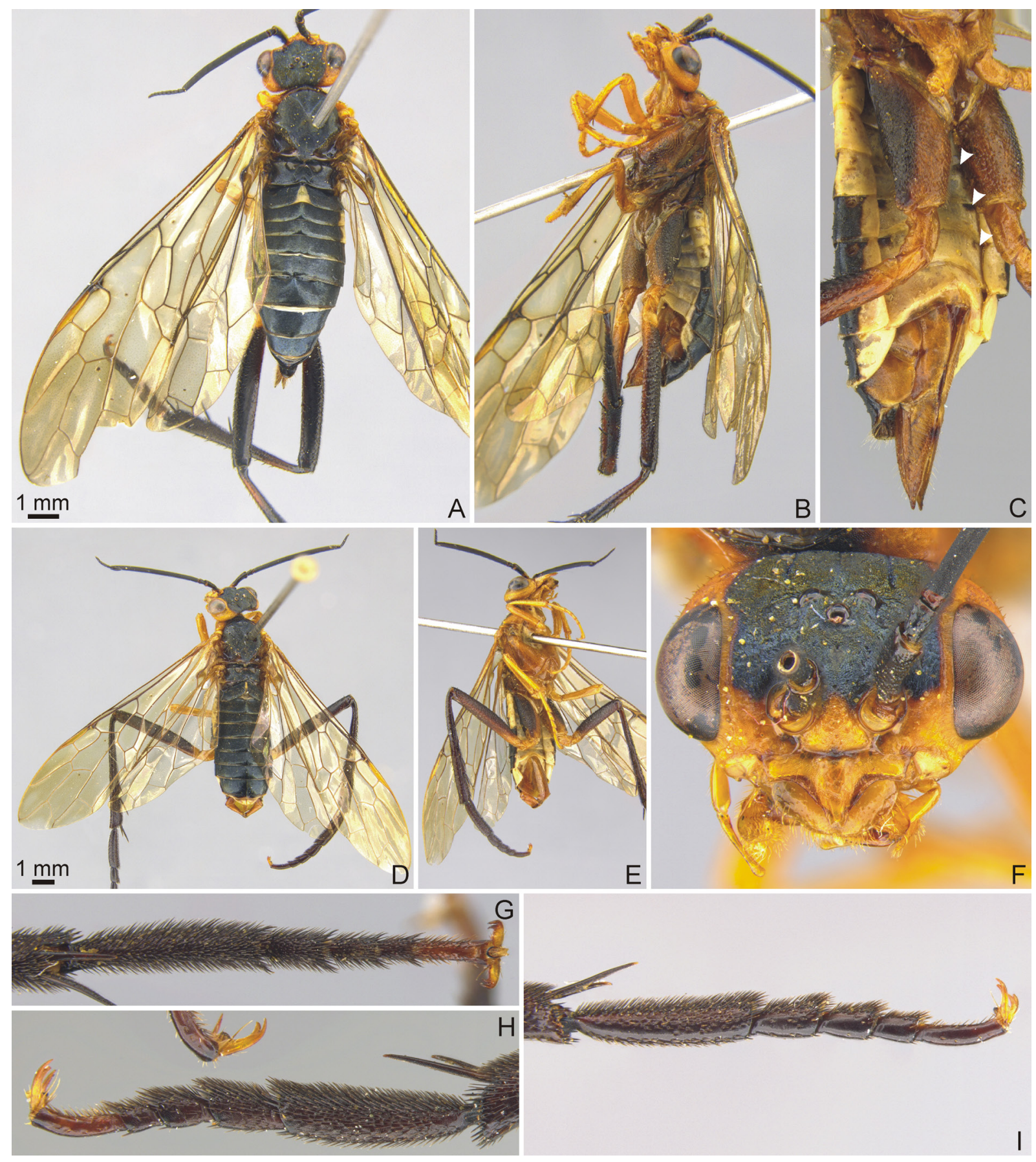

Fig. 9. Megaxyela pulchra Blank, Shinohara \& Sundukov sp. nov. A-B. Habitus dorsal/lateroventral (\%, holotype, DEI-GISHym 86249, ZIN). C. Abdomen lateroventral, arrowheads indicating black anterolateral spots on sterna ( $\left(+, 18504\right.$, NSMT). D-E. Habitus dorsal/lateroventral ( ${ }^{\lambda}, 22349$, NSMT). F. Head frontal ( $q$, holotype, 86249, ZIN). G-I. Metatarsus ventral ( + , 22346, NSMT), lateral ( $q$, 22346, NSMT), lateral ( ${ }^{\lambda}, 22349$, NSMT). 


\section{Etymology}

The Latin adjective pulcher (fem. pulchra) indicates the beauty of this species.

\section{Type material}

\section{Holotype}

RUSSIA: $q:$ "[vertically:] RU012 [horizontally:] RU [= Russia]: Primorskij Kraj: Ussuri Nature Reserve $43.644^{\circ} \mathrm{N} 132.346^{\circ} \mathrm{E} 150 \mathrm{~m}$ [alt.] 23. May 2016 leg. Kramp, Prous \& Taeger”; [red:] "Holotype Megaxyela pulchra sp.n. det. SM Blank 2016"; "DEI-GISHym 86249 (see ethanol coll.)", specimen used for barcoding (pinned specimen in ZIN, right midleg in ethanol collection of SDEI).

Paratypes $(11$ + $\odot, 4$ えぇ)

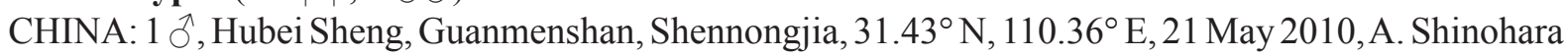
leg. (NSMT) (specimen DEI-GISHym 18504 used for barcoding); 1 ô, Jilin Sheng, $43.00^{\circ} \mathrm{N}, 126.00^{\circ} \mathrm{E}$, Jul. 1987 (CSCS); 1 q, Liaoning Sheng, $41.00^{\circ}$ N, $123.00^{\circ}$ E, 8 May 1958 (CSCS); 1 , , Shaanxi Sheng, Foping County, Daguping, $33.58^{\circ} \mathrm{N}, 107.77^{\circ} \mathrm{E}, 1320 \mathrm{~m}$ alt., 28. Apr. 2006, Mojun He leg. DEI-GISHym 22563 (CSCS); 1 q, Tibet Autonomous Region, Metok [“Motuo", Mêdok], $29.32^{\circ}$ N, $95.32^{\circ}$ E, $1050 \mathrm{~m}$ alt., 9 Apr. 1980, Yingtao Jin leg. (CSCS).

RUSSIA: 1 q, Primorskiy Kray, Anisimovka, $43.17^{\circ} \mathrm{N}, 132.80^{\circ} \mathrm{E}, 26$ May 1974, Berezantsev leg. (IBSS); 1 , , Primorskiy Kray, Lazovskiy Rayon, Lazo, $43.20^{\circ}$ E, $134.15^{\circ}$ N, 21-24 May 2008, V. Shokhrin leg.

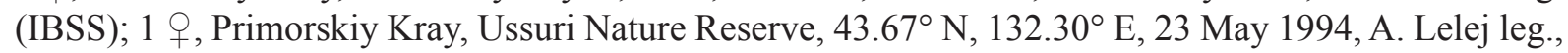
DEI-GISHym 18501 (NSMT); 1 ㅇ, Primorskiy Kray, Voroshilovskiy Rayon, Suputinka River, 43.63 N, 132.10 E, 11 Jun. 1935, T. Samoylov leg. (ZIN).

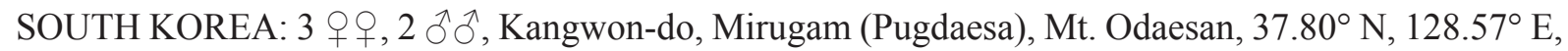
$1300 \mathrm{~m}$ alt., collected from Juglans ?mandshurica, 1 Jun. 2002, A. Shinohara leg. (NSMT) (including 1 ㄱ, 2 ఏぇ DEI-GISHym 18503, 22347, 22349 used for barcoding, also including DEI-GISHym 22346, 22348 illustrated in figures); 1 , same locality, 31 May 1998, A. Shinohara leg. (NSMT).

\section{Description}

\section{Female}

CoLor. Body red brown with black and white pattern, black parts with bronze to blue tinge (Fig. 9A-C). Head brown, black spot of frons and vertex ventrally extending to toruli and leaving narrow stripe along inner orbits brown (Fig. 9F). Antenna black, narrow base of scape brown. Thorax with following parts black: Large medial spot on pronotum, complete dorsal side of mesothorax and metathorax, variable marks on dorsal corner of mesepisternum, metepimeron and metepisternum; mesopostnotum posteriorly and lateral mesonotal lobes with shared small brown spot laterally extending to mesoscutellum. Abdomen in dorsal view with continuous white bands laterally on terga 2-3 (each about $0.1 \times$ as wide as tergal width), tergum 4 and 8 with narrower band or inconspicuously white, ventral portions of terga 2-4 and 8 completely white, of terga 5-7 black in dorsal half and white in ventral half, of tergum 9+10 brown (Fig. 9B-C). Sterna white, in two specimens on anterior margin of sterna 1-5 with pairs of black marks each about as wide as ocellar diameter (Fig. 9C), valvifer 2 and valvula 3 brown (tip of valvula 3 black only in holotype, Fig. 11G), membrane between valvifer 2 and valvula 3 pale. Legs brown with following black pattern: stripe on posterolateral margin of mesocoxa, dorsal, lateral and lateral third of ventral side of metacoxa, metafemur except for narrow base and fading stripe from base to middle along ventral side, metatibia and metatarsus. Wing hyaline and weakly brown stained, venation brown, pterostigma yellow brown with narrow base and anterior margin infuscate (Fig. 9A-B).

Morphology. Body 10.8-13.4 mm, fore wing 14.9-16.0 mm long. POL : OOL : OCL $=1.0: 1.9-2.1$ : 1.9-2.0. Interantennal distance $1.0-1.1 \times$ as wide as distance between torulus and eye, malar space 
0.6-0.7 $\times$ as wide as interantennal distance. Eye $1.3-1.4 \times$ as long as wide, frons at dorsal edge of antennal toruli 1.7-1.8 $\times$ as wide as maximum diameter of eye. Synantennomere 3 3.8-4.9 mm, filament $1.2-1.3 \mathrm{~mm}$, with (8-)9-10 articles. Article 3 of maxillary palp $0.4-0.5 \mathrm{~mm}$ long. Ovipositor sheath 3.1-3.4 mm, valvula $31.5-1.6 \times$ as long as valvifer 2, valvula $32.0-2.2 \times$ as long as wide (Fig. 11G). On hind leg, femur 4.6-5.4, tibia 5.3-6.2 mm, tarsus 3.7-4.4 mm, tarsomere 1 4.0-4.3 $\times$ as long as wide, longer distal spur of tibia 0.6-0.7 times as long as tarsomere 1, subapical tooth of claw stout and slightly shorter than apical tooth (Fig. 9G-H). Head dull, medial part of frons and vertex minutely areolate, frons above toruli rugulose, gena coriarious. Inner and outer orbits with continuous carina, on inner orbit separating red brown stripe along eye from black spot of frons (Fig. 9F). Mesoscutum and mesoscutellum homogeneously, minutely areolate. Mesepisternum coriarious, shining, with shallow pits. Metatarsomere 1 sparsely setose dorsally and dorsolaterally, densely setose lateroventrally and ventrally, setae up to $200 \mu \mathrm{m}$ long ventrally. Pulvilli absent on article 1 of metatarsus, present on articles $2-4$, on article 4 pulvillus $70 \mu \mathrm{m}$ long (Fig. 9G-H). Basal and medial sections of valvula 3 of ovipositor sheath convex dorsally, almost straight ventrally, preapical section concave on dorsal and ventral edge, medial to preapical section of dorsal margin and ventral margin with up to $150 \mu \mathrm{m}$ long setae (Fig. $11 \mathrm{G}$ ). Ovipositor about $2.8 \mathrm{~mm}$ long, weakly curved ventrally, valvula 1 and valvula 2 with bulbous areas close to middle, without ctenidia (Fig. 12G). Valvula 1 in distal 0.6 with very narrowly spaced, subparallel, straight, vertical annuli, ventral edge in distal 0.3 bearing very small serrulae. Valvula 2 in distal 0.6 with narrowly spaced annuli, distal 0.4 of dorsal edge of valvula 1 with small denticles.

\section{Male}

Color. Similar to female (Fig. 9D-E). Subgenital plate and genitalia red brown (Fig. 13I).

Morphology. Body 10.2-10.9 mm, fore wing 12.7-13.4 mm long. POL : OOL : OCL $=1.0: 1.9-2.2$ : 1.8-2.0. Interantennal distance $1.0-1.1 \times$ as wide as distance between torulus and eye margin, malar space $0.5-0.6 \times$ as wide as interantennal distance. Eye 1.3-1.4 $\times$ as long as wide, frons at dorsal edge of antennal toruli 1.7-1.8 $\times$ as wide as maximum diameter of eye. Synantennomere 3 4.4-4.8 mm, filament (1.0-)1.2-1.4 mm, with 9-11 articles (one male with left filament $1.2 \mathrm{~mm}$ long, 9 articles, right filament $1.0 \mathrm{~mm}$ long, 7 articles). Article 3 of maxillary palp $0.4-0.5 \mathrm{~mm}$. On hind leg, femur 4.3-4.6 mm, tibia 5.2-5.5 mm, tarsus 4.4-4.6 mm, tarsomere 1 4.2-4.8 $\times$ as long as wide, longer distal spur of tibia $0.5 \times$ as long as tarsomere 1. Claws, pulvilli and microsculpture similar to female (Fig. 9I). Subgenital plate bluntly pointed at apex. Valviceps of penis valve distally evenly rounded, basal 0.4 of upper side expanded to a round lobe coiled laterally (Fig. 13E), medial $0.4-0.8$ of upper margin almost straight, with numerous small teeth. Distal 0.8 of valviceps with long setae, most dense on lower portion in medial 0.2-0.5 (Fig. 13E).

\section{Host plant}

In South Korea, A. Shinohara captured two females and three males from Juglans ?mandshurica. Host records of $J$. ailanthifolia (cited as $J$. sieboldiana), J. mandshurica, J. regia (including the synonym J. sinensis), Pterocarya rhoifolia and P. stenoptera stated for Megaxyela gigantea by Saito (1941), Ko (1969) and Xiao (2006) might also contain the new species M. pulchra sp. nov.

\section{Remarks}

Among East Asian Megaxyela, this species is morphologically close to M. togashii. Both species have the frons above the antennal toruli rugulose (frons microareolate throughout in $M$. fulvago sp. nov. and $M$. gigantea) and extensively black (completely or largely red brown in M. fulvago sp. nov. and M. gigantea), valvula 32.0-2.2 $\times$ as long as wide (2.8-3.0 in M. parki), pterostigma infuscate basally and anteriorly (unicolorous yellow brown in M. fulvago sp. nov., M. gigantea and M. parki, completely black in M. euchroma sp. nov.), basal lobe of valviceps small and distally truncate, upper edge medially almost straight and lacking large teeth, long setae present on the lower portion in the medial $0.2-0.5$ 
(basal lobe more prominent in M. euchroma sp. nov., M. fulvago sp. nov., M. gigantea and M. parki sp. nov., upper edge raised medially in $M$. gigantea, large teeth on the upper edge present particularly in M. euchroma sp. nov., long setae absent in medial portion of valviceps in M. euchroma sp. nov. and M. parki sp. nov.).

Megaxyela pulchra sp. nov. differs from the Nearctic species of Megaxyela, except for M. langstoni and M. major, and from the East Asian M. euchroma sp. nov. in the presence of a broad, continuous white band dorsolaterally and ventrally on terga $2-3$. Such extensive white pattern on the basal terga is absent in most North American species, which at most bear a narrow white stripe along the ventral margin of the terga as observed in M. alisonae, M. bicoloripes and M. tricolor (Smith \& Schiff 1998; Blank, unpublished data). Megaxyela pulchra sp. nov. differs from M. langstoni and M. major, for example, in the black metatarsus (yellow white in M. major) and in the stout valvula 3 of the ovipositor sheath (Fig. 11G; slender in M. major, see Smith \& Schiff 1998: fig. 7).

Morphological differences between $M$. pulchra sp. nov. and M. togashii are faint: the mesoscutellum is homogeneously areolate and flat in $M$. pulchra sp. nov., but areolate in the middle, with a wide stripe along lateral and anterior margin rugose with areolate microsculpture in $M$. togashii; the distance between the toruli is $0.95-1.05 \times$ as wide as the distance between torulus and eye margin in M. pulchra sp. nov. $O$ but $1.20 \times$ in $M$. togashii $q$; the malar space is $0.6-0.7 \times$ as wide as the distance between toruli in $M$. pulchra sp. nov. but 0.4 in M. togashii. The two species exhibit different tendencies of coloration: the face, ventral part of mesepisternum and mesosternum, and dorsal portion of tergum 4 are paler in M. pulchra sp. nov., while the posteriolateral ridge of the mesoscutal lateral lobe is paler in M. togashii. The subgenital plate of the male M. pulchra sp. nov. is red brown as in M. gigantea, whereas it is white in the male M. togashii.

The anterior margins of the sterna always bear a pair of large black marks in M. togashii. Such marks are absent in other Megaxyela (see Smith \& Schiff 1998 for Nearctic species) except for M. pulchra sp. nov., whose female rarely bears small marks on the sterna. These spots are a putative apomorphy of the vicariant species M. pulchra sp. nov. from the East Asian mainland and M. togashii from Japan. Among Xyelidae, similar pairs of sibling species (or at least morphologically very similar species) with East-Asian mainland / Japanese vicariance have been observed among Xyela species associated with Japanese red pine, Pinus densiflora Siebold \& Zuccarini (Blank et al. 2005).

The specimens studied genetically are supported by a bootstrap of $100 \%$. The maximum intraspecific variation is $3.1 \%$. The nearest neighbor, $M$. togashii, is placed at a minimum pairwise distance of $8.0 \%$.

Zhelochovtsev \& Zinovjev (1995), Lelej \& Taeger (2007) and Lelej (2012) listed M. gigantea for the Russian Far East, but at least the female from Voroshilovskiy Rayon identified by A. Zinovjev refers to M. pulchra sp. nov. Sundukov (2009) noted a specimen from Lazo differing from M. gigantea, which is included as a paratype of M. pulchra sp. nov. here. The specimens published by Shinohara (1992) for South Korea all belong to M. gigantea .

Megaxyela togashii Shinohara, 1992

Figs $10 \mathrm{~A}-\mathrm{J}, 11 \mathrm{H}, 12 \mathrm{H}, 13 \mathrm{~F}$

Megaxyela togashii Shinohara, 1992: 789-792, 794, figs 1C-D, 2C-D, 2F-G, 4B, 4D, 5A-C (ㅇ đ, type locality: Japan, Honshu, Ishikawa Prefecture, Yoshinodani-mura, Senami).

Megaxyela togashii - Tanaka 1999: 57 (record from Japan, Honshu, Yamaguchi Prefecture). - Yamada 2000: 53 (record from Japan, Honshu, Aomori Prefecture). - Naito et al. 2004: 6 (record from 
Japan, Honshu, Hyogo Prefecture). - Shinohara 2006: 157 (record from Japan, Shikoku, Ehime Prefecture). - Shinohara et al. 2017: 222-230 (record from Japan, Hokkaido, larva, life history). Megaxyela gigantea - Watanabe 1992: 8 (record from Japan, Honshu, Okayama Prefecture). [See Ko (1969), Smith (1978) and Shinohara (1992) for numerous additional references].

\section{Material examined or reported in literature}

JAPAN: 6 larvae, Hokkaido, Ashoro town, Asahi, $43.233^{\circ} \mathrm{N}, 143.500^{\circ} \mathrm{E}, 100 \mathrm{~m}$ alt., $30 \mathrm{Jun} .2010$, A. Shinohara and H. Hara leg., on Juglans ailanthifolia, including DEI-GISHym 30805-30807 (NSMT) (Shinohara et al. 2017); 2 larvae, Hokkaido, Ashoro town, Nishikitoushi, $43.383^{\circ} \mathrm{N}, 143.367^{\circ} \mathrm{E}, 345 \mathrm{~m}$ alt., 1 Jul. 2010, A. Shinohara and H. Hara leg., on Juglans ailanthifolia ,including DEI-GISHym 30804 (NSMT) (Shinohara et al. 2017); 1 larva, Hokkaido, Shintoku town, $43.083^{\circ} \mathrm{N}, 142.817^{\circ} \mathrm{E}, 200 \mathrm{~m}$ alt., 26 Jun. 2011, H. Hara leg. (Shinohara et al. 2017); 1 larva, Hokkaido, Sapporo city, Misumai, $42.950^{\circ} \mathrm{N}, 141.250^{\circ} \mathrm{E}, 160 \mathrm{~m}$ alt., 19 Jun. 2013, H. Hara leg. (Shinohara et al. 2017); 1 larva, Hokkaido, Sapporo city, Koganeyu, $42.967^{\circ}$ N, $141.200^{\circ}$ E, 250 m alt., 19 Jun. 2013, H. Hara leg. (not preserved) (Shinohara et al. 2017); 1 ․ Honshu, Aomori Prefecture, Minami-Hakkoda, $40.60^{\circ} \mathrm{N}, 140.84^{\circ} \mathrm{E}$,

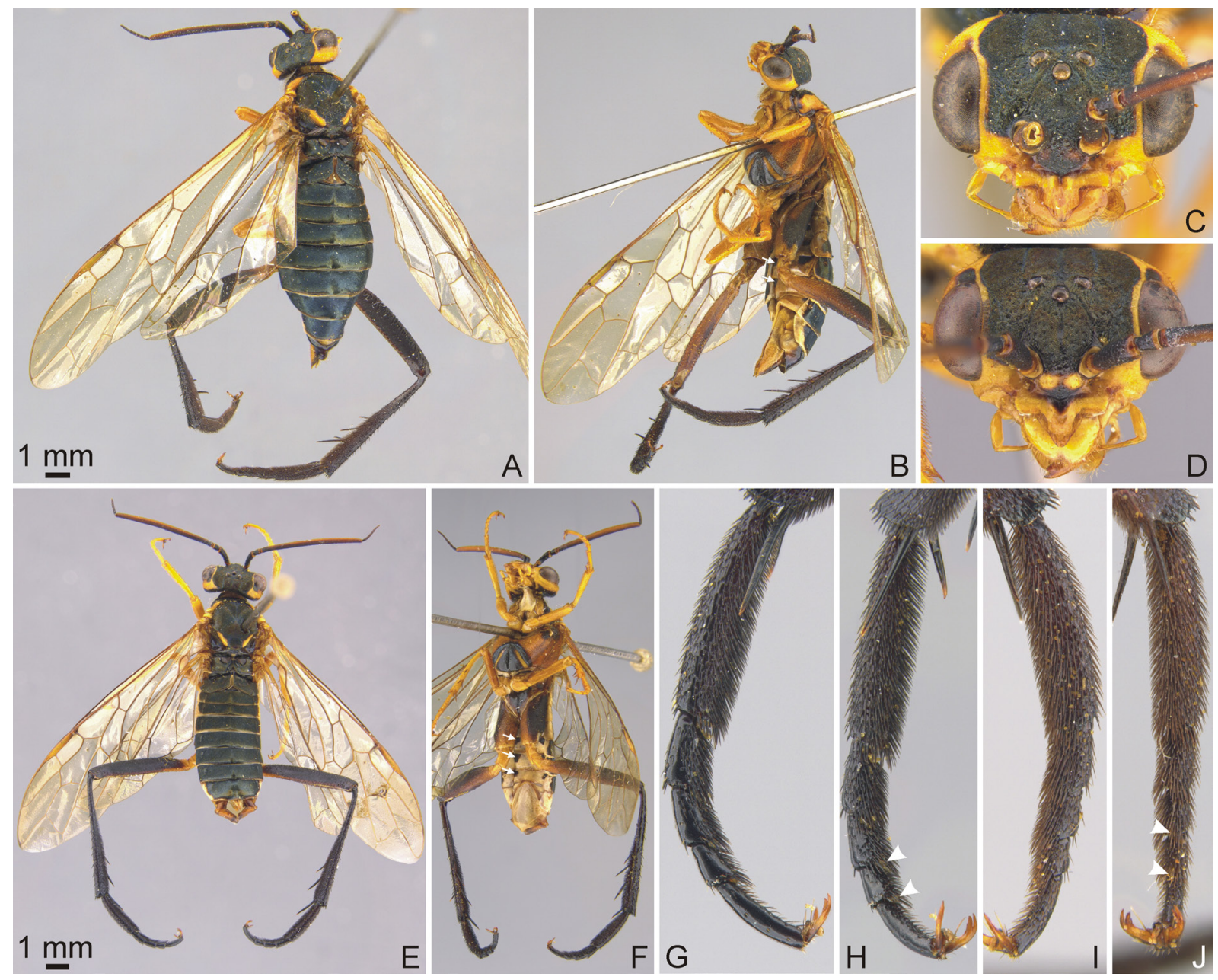

Fig. 10. Megaxyela togashii Shinohara, 1992, \&, holotype, DEI-GISHym 22352 (NSMT); đ, 22354, (NSMT). A-B. Habitus dorsal/lateroventral ()). C. Head frontal (). D-E. Habitus dorsal/lateroventral (ð). F. Head frontal (ð). G-H. Metatarsus lateral/ventral (†). I-J. Metatarsus lateral $/$ ventral (ð). Arrows in Fig. 10B and 10F indicate dark spots of abdominal sterna, arrowheads in $\mathrm{H}$ and $\mathrm{J}$ indicate minute pulvilli. 
30 May 1999, M. Yamada leg., M. Yamada coll. (Yamada 2000; reliable record, not re-examined); $1{ }^{\lambda}$, paratype, Honshu, Hiroshima Prefecture, Kamiyama, Kure, $34.28^{\circ}$ N, $132.57^{\circ}$ E, 7 May 1933, coll. Nakanishi (UOP) (Shinohara 1992); 1 +, Honshu, Hyogo Prefecture, Sayo-gun, Mikazuki-cho, Mihara, $34.95^{\circ} \mathrm{N}, 134.42^{\circ}$ E, 18 May 1995, T. Sasai leg., DEI-GISHym 22353 (KUEL) (Naito 2004); 1 , , Honshu, Hyogo Prefecture, Shiso-gun, Haga-cho, Akasai-keikoku, $35.23^{\circ} \mathrm{N}, 134.48^{\circ} \mathrm{E}, 680 \mathrm{~m}$ alt., 8 Jun. 1986, T. Morita leg., T. Morita coll. (Naito et al. 2004; reliable record, not re-examined); 1 , holotype, Honshu, Ishikawa Prefecture, Yoshinodani-mura, Senami, $36.32^{\circ}$ N, $136.65^{\circ}$ E, 29 Jun. 1964 , I. Togashi leg., DEI-GISHym 22352 (NSMT) (distal articles of right antenna glued to collecting label; Shinohara 1992); 5 larvae, 1 egg, Honshu, Hyogo prefecture, Tatsuno city, Shingu town, $34.867^{\circ} \mathrm{N}$, $134.567^{\circ}$ E, 35 m alt., 30 Apr. 2016, on Juglans ailanthifolia, A. Shinohara leg., including Shinohara's sample numbers 761-764 (NSMT) (Shinohara et al. 2017); 1 + , Honshu, Okayama Prefecture, Kawakami-gun, Bichu-cho, Nishiyuno, $34.80^{\circ} \mathrm{N}, 133.47^{\circ}$ E, 5 May 1986, A. Watanabe leg., A. Watanabe coll. (Watanabe 1992, misidentified as M. gigantea); 1 ऊ, Honshu, Okayama Prefecture, Tamagashi, Okayama-shi, $34.72^{\circ} \mathrm{N}, 133.97^{\circ} \mathrm{E}, 10 \mathrm{~m}$ alt., 3 May 2005, A. Shinohara leg., DEI-GISHym 22354, used for barcoding (NSMT) (Shinohara 2006); 1 , as preceding, except 2 May 2006, DEI-GISHym 22521 used for barcoding (NSMT) (Shinohara 2006); 1 specimen, Honshu, Yamaguchi Prefecture, Kuga-gun, Nishiki-machi, Mt. Jakuchi-san, Sancho [= summit], $34.47^{\circ}$ N, $132.05^{\circ}$ E, 1337 m alt., 6 Jun. 1993, K. Tanaka leg., K. Tanaka coll. (Tanaka 1999, reliable record, not re-examined); 2 larvae, Shikoku, Ehime prefecture, Kihoku town, Narukawa-keikoku, 33.200 N, $132.617^{\circ} \mathrm{E}, 650 \mathrm{~m}$ alt., 5 May 2016, on Juglans ailanthifolia, A. Shinohara leg., Shinohara's sample numbers 765-766 (NSMT) (Shinohara et al. 2017); 1 क, Shikoku, Ehime Prefecture, Narukawa-keikoku, Kihoku-cho, $33.20^{\circ} \mathrm{N}, 132.62^{\circ} \mathrm{E}$, $550 \mathrm{~m}$ alt., 8 May 2006, A. Shinohara leg. (NSMT) (Shinohara 2006).

\section{Description}

See Shinohara (1992) and Figs 10A-C, G-H, 11H (ovipositor sheath).

\section{Female}

Ovipositor about $2.4 \mathrm{~mm}$ long, weakly curved ventrally, valvula 1 and 2 with bulbous areas close to middle, without ctenidia (Fig. 12H). Body $12.6 \mathrm{~mm}$, fore wing $15.4 \mathrm{~mm}$ long. Black spot on face extending lateroventrally to mid-level of toruli, medially continuous with predominantly black subantennal area (holotype with two small brown spots) or subantennal area yellow (specimen from Mihara). Pulvilli absent on article 1 of metatarsus, present on articles 3-4, presence ambiguous for article 2, on article 4 pulvillus $70 \mu \mathrm{m}$ long.

Male (specimen from Tamagashi, DEI-GISHym 22354, Fig. 10D-F, I-J)

Body $12.0 \mathrm{~mm}$, fore wing $13.4 \mathrm{~mm}$. Antennal filament $1.3 \mathrm{~mm}$ long, with $8-9$ articles. Valviceps distally parabolically rounded, basal quarter of upper side expanded to a round lobe weakly coiled laterally, section of upper edge distal of lobe straight or with shallow elevations, close to the lobe with irregular teeth, in medial $0.3-0.8$ with numerous small teeth. Distal 0.7 of valviceps with long setae, dense in medial and lower portion of middle (Fig. 13F).

\section{Host plant}

Ten larvae identified by their COI sequences as M. togashii were found feeding on Juglans ailanthifolia (Shinohara et al. 2017). In addition, three adults were collected from trees of this walnut species (Shinohara 2006, citing the synonym J. mandshurica Maxim. ssp. sieboldiana [Maxim.] Kitamura). Japanese Wingnut, Pterocarya rhoifolia Sieb. \& Zucc., possibly represents an additional larval host (Shinohara et al. 2017). Takeuchi's (1949) record of Juglans for M. 'gigantea' (= M. togashii) in a checklist of the host plants of Japanese sawflies most likely concerns Saito's (1941) rearing record for M. gigantea from Korea (see also Takeuchi 1938). 


\section{Remarks}

Megaxyela togashii is the correct name for the Japanese species, which has been called M. gigantea by Takeuchi (1937), Togashi (1965) and subsequent authors up to Shinohara (1992). This species is most similar to M. pulchra sp. nov. in structure and color. See Remarks there for differentiation of these two species.

The clade including two genetically studied adults from Honshu, which were collected on the same site, is supported by a bootstrap of $100 \%$. The maximum intraspecific variation is $1.4 \%$. Under a wider geographical scope, Shinohara et al. (2017) observed a variation of $4.3 \%$ after inclusion of ten larvae from Hokkaido, Honshu and Shikoku. Even then the intraspecific variation is smaller than the minimum pairwise distance of $8.0 \%$ to the nearest neighbor, M. pulchra sp. nov.

Megaxyela tricolor (Norton, 1862)

Xyela tricolor Norton, 1862: 144 (ð’, type locality: USA, Kansas).

Megaxyela tricolor - Ross 1932: 162-163 (combination, description, key, distribution). - Smith \& Schiff 1998: 638-639 (key), 648 (description, distribution, references), figs 11, 22-25, 35.

\section{Material examined}

USA: 1 , West Virginia, Upshur County, Ruraldale, 12 Apr. 2014, photographed by S. Cresswell (Cresswell 2014).

\section{Supplementary description}

See Smith \& Schiff (1998). Female. Antenna black. Metafemur orange with extreme apex on outer surface black (1 $q$ studied by Smith \& Schiff 1998) or distal 0.4 black (Cresswell 2014).

\section{Remarks}

This is the first state record for West Virginia. The species has been found in Connecticut, Illinois, Kansas, Missouri and in Ontario (Smith \& Schiff 1998).

\section{Identification key to the species of Megaxyela}

1 a Valvula 3 of ovipositor sheath dorsally straight, ventrally evenly convex in basal and medial portion Fig. 11D).

b Ovipositor curved dorsally (Fig. 12D).

Male unknown. USA (West Virginia) .

M. inversa Blank \& D.R. Smith sp. nov.

- aa Valvula 3 of ovipositor sheath dorsally convex, ventrally various in shape (Fig. 11A-C, E-H; Smith \& Schiff 1998: figs 7-11).

bb Ovipositor curved ventrally (Fig. 12A-B, E-H, Smith \& Schiff 1998: figs 16-23, 26-27) .....2

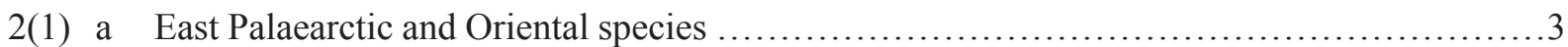

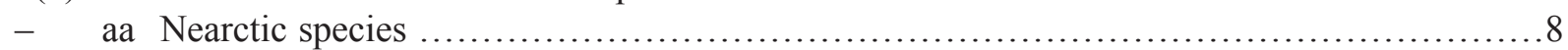

3(2) a Tergum 8 red brown (Fig. 8A, D).

b Eye surrounded by black except for red brown malar space (Fig. 8F).

c Antenna red brown (Figs 1D, 8A-D).

d Claw of hind leg with large subapical tooth (Fig. 8F-G).

South Korea (Fig. 14)

M. parki Shinohara, 1992 
- $\quad$ aa Tergum 8 black (e.g., Fig. 3A, D), sometimes laterally and ventrally white (e.g., Figs 4A, $5 \mathrm{~A}-\mathrm{D}, 9 \mathrm{C})$.

bb Eye at least narrowly lined with yellow or red brown on inner and outer orbits (Figs 3F, 9F, $10 \mathrm{C}-\mathrm{D}$ ) or face predominantly pale (Figs 4G, 5E).

cc Dorsal side of antenna black.

dd Claws bifid (e.g., Figs 3H-I, 4D, 5G) …....................................

4(3) a Metatarsus white, base of metatarsomere 1 black (Fig. 3A-B, D-E, H-I, K).

b Terga 2-6 with narrow, evenly wide line along ventral margin (Fig. 3C), terga $2-4$ laterally black in dorsal view (Fig. 3A, D).

c Head black, inner and outer orbits with narrow yellow lines, vertex with linear yellow spot (Fig. 3F-G).

d Pulvillus present on metatarsomere 1 (Fig. 3I-K).

e Mesepisternum with indistinct pits between minutely areolate microstructure, dull.

f Antennal filament composed of 7-8 (rarely 9) articles.

g $\circ$ : Ovipositor sheath black except for brown basal half of valvifer 2 (Fig. 11A).

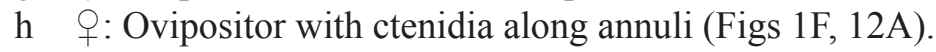

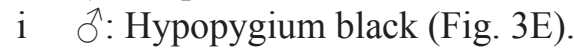

China (Zhejiang) (Fig. 14) ...................... euchroma Blank, Shinohara \& Wei sp. nov.

- aa Metatarsus black (e.g., Figs 4A-F, 5C-H).

bb Terga 2-3 or 2-4 with broad white band on dorsolateral and complete ventral portion, terga $3-5$ or $4-5$ less extensively white than preceding terga (Figs 4A, E-F, 5A-D, 9A-E, 10A-B, E-F).

cc Head more extensively red brown or yellow, at least gena and face below antennal toruli pale (Figs 4G, 5E, 9F, 10C-D).

dd Pulvillus absent on metatarsomere 1.

ee Mesepisternum with distinct pits, smooth or with coriarious microstructure, more or less shining.

ff Antennal filament composed of 9-10 articles (rarely fewer articles present on one antenna, check both antennae).

gg : : Ovipositor sheath red brown, valvifer 2 sometimes white, valvula 3 sometimes infuscated along dorsal margin (Fig. 11C, G-H).

hh 9 : Ovipositor without ctenidia along annuli (Fig. 12B-C, G-H).

ii $\delta^{\text {: }}$ :Hypopygium red brown (Figs 4F, 5D, 9E) or white (Fig. 10F) ......................

5(4) a Head, prothorax and mesothorax red brown, without black (Fig. 4A, E-G).

China (Hunan, Jiangsu, Zhejiang) (Fig. 14) ...M. fulvago Blank, Shinohara \& Wei sp. nov.

- $\quad$ aa At least mesoscutum and usually vertex partly black (e.g., Figs 5A, C, 10A, E) .....6

6(5) a At least ventral half of frons red brown (Fig. 5E).

b Pterostigma unicolorous yellow brown (Fig. 5A, C).

c Upper part of gena weakly imbricate, almost smooth, shining (Fig. 5B).

d Microsculpture of frons above antennal toruli minutely areolate, similar to microsculpture of vertex, with few shallow pits (Fig. 5E).

e Dorsal side of terga 2-4 with evenly wide, white lateral margins (Fig. 5A, C).

North and South Korea, Russia (Primorskiy Kray) (Fig. 14) ......M. gigantea Mocsáry, 1909

aa Black spot of frons ventrally extending to antennal toruli (Figs 9F, 10C-D).

bb Pterostigma yellow brown, narrow at base and anterior margin infuscate (e.g., Figs 9A, 10A).

cc Upper part of gena strongly imbricate, dull. 
dd Microsculpture of frons above antennal toruli rugulose, different from areolate microsculpture of vertex (Figs 9F, 10C-D).

ee White lateral margin on dorsal side of tergum 4 narrower than on terga 2-3 or absent (e.g.,

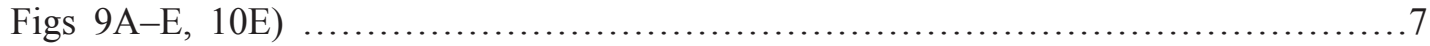

7(6) a Mesonotum black or with a small brown spot lateral to mesoscutellum (Fig. 9A, D).

b Preapical sterna white (Fig. 9B, E), sometimes with pair of small black marks on anterior margin (Fig. 9C).

c $\quad$ : Thorax ventrally red brown (Fig. 9B, E).

d : Ovipositor sheath red brown, sometimes tip of valvula 3 black (Fig. 11G).

e $\quad \widehat{T}$ : Hypopygium red brown (Fig. 9E).

China (Jilin, Liaoning, Shaanxi, Tibet), South Korea, Russia (Primorskiy Kray) (Fig. 14) ..M. pulchra Blank, Shinohara \& Sundukov sp. nov.

aa Mesonotum black with yellow stripes along posterolateral ridge on mesoscutal lateral lobe (Fig. 10A, E).

bb Sterna red brown to white, preapical sterna with pair of large black marks on anterior margin (Fig. 10B, F).

cc $\bigcirc$ : Mesepisternum red brown, black spot in dorsal corner, black stripe along pectus, pectus largely black medially (Fig. 10B).

dd : : Ovipositor sheath red brown with valvifer 2 ventrally yellow white, and valvula 3 with black stripe along dorsal margin (Fig. 11H).

ee $\delta^{2}$ : Hypopygium white (Fig. 10F).

Japan (Hokkaido, Honshu, Shikoku) (Fig. 14)

M. togashii Shinohara, 1992

8(2) a Metafemur, tegula and abdomen black, sterna with indistinctly pale posterior margins.

b Tarsomeres (2-)3-5 of hind legs white.

Canada (Ontario), USA (Indiana, Kansas, Massachusetts, Mississippi, Missouri, New York, Oklahoma, Pennsylvania) ........................................ aviingrata (Dyar, 1898)

- $\quad$ aa Metafemur red brown, sometimes apex narrowly black (e.g., Smith \& Schiff 1998, fig. 3). Tegula white. Sterna red brown and/or posterior margins of terga and sterna white.

bb Metatarsus sometimes completely black (e.g., Smith \& Schiff 1998: figs 14 and 15) .....9

9(8) a Head yellow and red brown, pronotum red brown (Fig. 7A-C, G-I).

b Metatibia red brown or black, basal 0.2-0.4 white (Fig. 7A-B, F-H)

- aa Head (except for clypeus, labrum, mouthparts, mandible) and pronotum black (e.g., Smith \& Schiff 1998: fig. 3).

bb Metatibia entirely black (e.g., Smith \& Schiff 1998: fig. 3) .11

10(9) a Basal 0.3-0.5 of pterostigma black, distal portion red brown (Fig. 7A-B).

b Dorsal side of terga red brown, terga $1(-2)$ medially more or less infuscate (Fig. 7A).

c Basal 0.05-0.10 of metafemur yellow white (Fig. 7B, F).

d Distal preapical metatibial spur reaches apex of metatibia (Fig. 7B), inner apical metatibial spur $0.5 \times$ as long as metatarsomere 1 or longer (Fig. 7D-E).

USA (Mississippi, Oklahoma, Texas) ...................... langstoni Ross, 1936 sp. rev.

aa Pterostigma uniformly red brown (Fig 7G).

bb Dorsal side of terga 1-7 predominantly black (Fig. 7G).

cc Basal $0.30-0.35$ of metafemur yellow white (Fig. $7 \mathrm{H}$ ).

dd Distal preapical metatibial spur not reaching apex of metatibia (Fig. $7 \mathrm{H}$ ), inner apical metatibial spur about $0.4 \times$ as long as metatarsomere 1 (Fig. 7J-K).

USA (Kansas, Oklahoma, Pennsylvania, Texas) ..................... major (Cresson, 1880) 
11(9) a Terga 1-7(-8) red brown, distal margins narrowly infuscate (Smith \& Schiff 1998: fig. 3).

b Metatarsomere 1 stout, $4 \times$ as long as wide, pilosity dorsally and ventrally dense (Smith \& Schiff 1998: fig. 15).

USA (New York, Ohio) ....

M. alisonae D.R. Smith \& Schiff, 1998

aa Terga black, distal margins narrowly white.

bb Metatarsomere 1 slender, 6-7 $\times$ as long as wide, pilosity dorsally sparse and ventrally dense (e.g., Smith \& Schiff 1998: fig. 14) ................................................. 12

12(11) a Metatarsomeres (2-)3-5 white.

b Ventral side of thorax and sterna red brown.

c Alvula 2 less than $3.0 \times$ as long as wide, $0.6 \times$ as long as metatarsus (Smith \& Schiff 1998: fig. 10).

USA(Michigan, Mississippi, Missouri, Pennsylvania, Virginia, West Virginia)

M. bicoloripes (Rohwer, 1924)

aa Metatarsus black.

bb Ventral side of thorax and sterna black, sterna with white distal margins.

cc Valvula $24.5 \times$ as long as wide, about as long as metatarsus (Smith \& Schiff 1998: fig. 11).

Canada (Ontario), USA (Connecticut, Illinois, Kansas, Missouri, West Virginia)

M. tricolor (Norton, 1862)

\section{Discussion}

Megaxyela is a morphologically well-defined genus of Macroxyelinae that also includes two Nearctic species of Macroxyela in the extant fauna. The carina along the inner orbit (e.g., Figs 3F-G, 4G, 6C, $8 \mathrm{E}$ ) is a unique character of Megaxyela among Xyelidae. In addition, the comparatively distal position of vein Sc2 of the fore wing (Figs 1A-B, 6F) and the extended hind legs (e.g., Fig. 3A-B, D-E) support this taxon morphologically. In the female the long hind legs may have provided the evolutionary predisposition for a derived oviposition behavior as observed by Saito (1941) in Megaxyela gigantea (Shinohara 1992). The monophyly of Megaxyela is also corroborated by the analysis of COI sequences: the nearest neighbors Megaxyela langstoni and Macroxyela ferruginea are separated by a pairwise distance of $13.7 \%$, which is only slightly larger than some interspecific gaps within Megaxyela (Fig. 2).

The branching of the cladogram in Fig. 2, which is based on genetic data from a restricted number of Megaxyela species, can partly be interpreted with help of morphological characters. Megaxyela fulvago sp. nov., M. gigantea, M. pulchra sp. nov. and M. togashii are included in a common clade, which is supported by the presence of bulbous areas on valvula 1 and valvula 2 of the ovipositor (Fig. 12B-C, E, G-H). Such an area is absent in the Nearctic taxa (Figs 7F, 12D; Smith \& Schiff 1998: figs 16-29), in the East Asian M. euchroma sp. nov. and M. parki (Fig. 12A, F) and in Macroxyela (Smith \& Schiff 1998: figs 30-32). Megaxyela pulchra sp. nov. and M. togashii share black spots on the anteriolateral side of the sterna (Figs 9C, 10B, F), that may be absent in M. pulchra sp. nov. Megaxyela fulvago sp. nov. and M. gigantea have in common the dull, minutely areolate and shallowly pitted face (Figs 4G, 5E). Megaxyela langstoni is very close to M. major in structure and color (Fig. 7). Although Smith \& Schiff (1998) already casted some doubt, these two taxa were treated as synonyms until now. Even more surprising in the course of this study was the discovery of a very large genetic distance $(13.5 \%)$ between these species, which led to the recognition of M. langstoni as a separate species. Equally large interspecific genetic gaps have been reported for Pleroneura and Xyela by Blank et al. (2013) and Schmidt et al. (2017).

Since Megaxyela has been collected rarely, only seven of thirteen known species could be analyzed genetically. Among these, the barcoding sequence of $M$. gigantea is very short and supposedly causes the (mis)placement of this species inside the clade of M. fulvago sp. nov. An exhaustive scoring of 

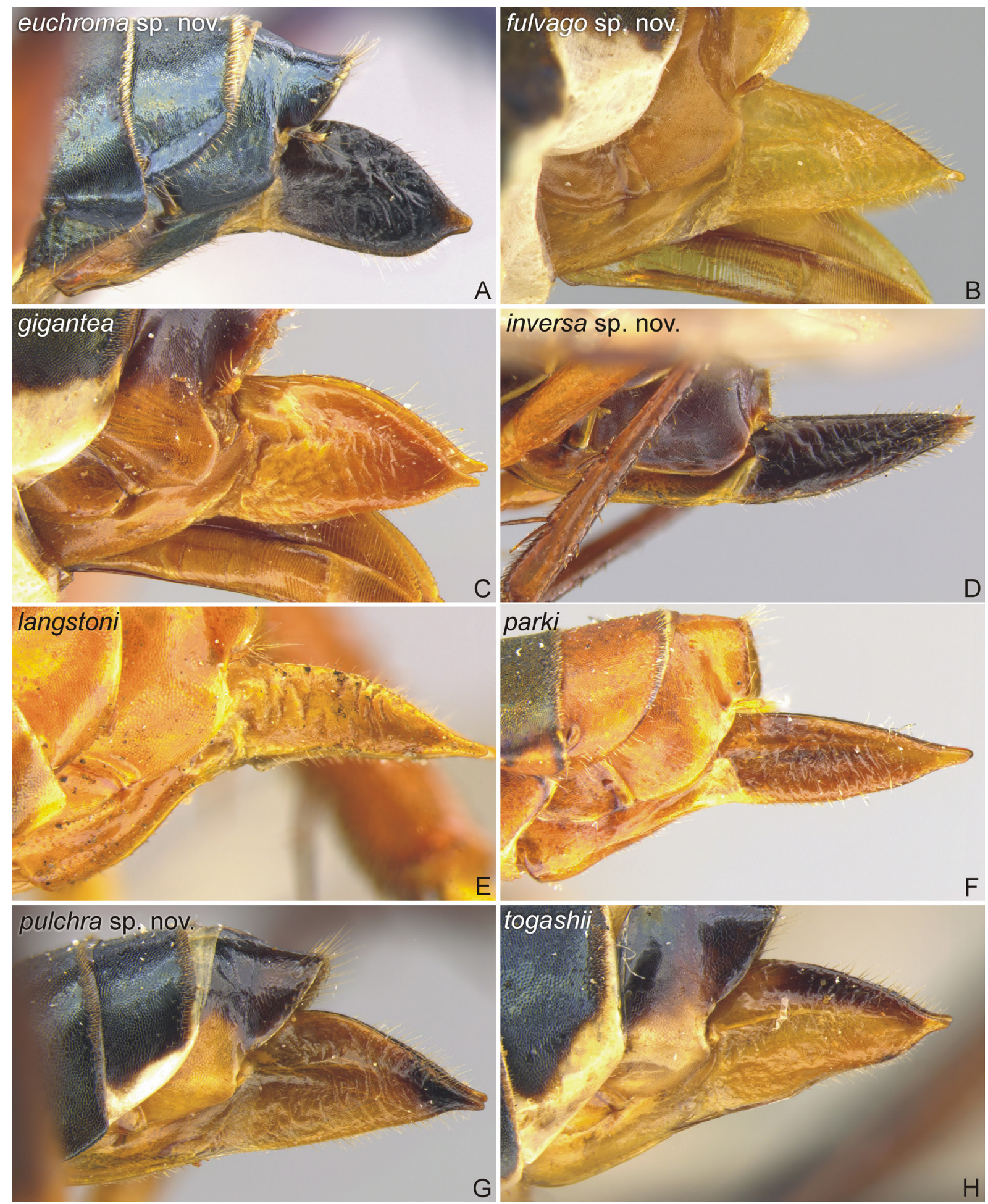

Fig. 11. Species of Megaxyela Ashmead, 1898, ovipositor sheaths. A. M. euchroma Blank, Shinohara \& Wei sp. nov. (holotype, DEI-GISHym 22554, CSCS). B. M. fulvago Blank, Shinohara \& Wei sp. nov. (5752, NSMT). C. M. gigantea Mocsáry, 1909, holotype of M. mikado Sato, 1930 (22350, NSMT). D. M. inversa Blank \& D.R. Smith sp. nov., paratype (22356, USNM). E. M. langstoni Ross, 1936, holotype (30821, INHS). F. M. parki Shinohara, 1992 (18510, NSMT). G. M. pulchra Blank, Shinohara \& Sundukov sp. nov., holotype (18501, NSMT). H. M. togashii Shinohara, 1992, holotype (22352, NSMT). Images not to the same scale. 

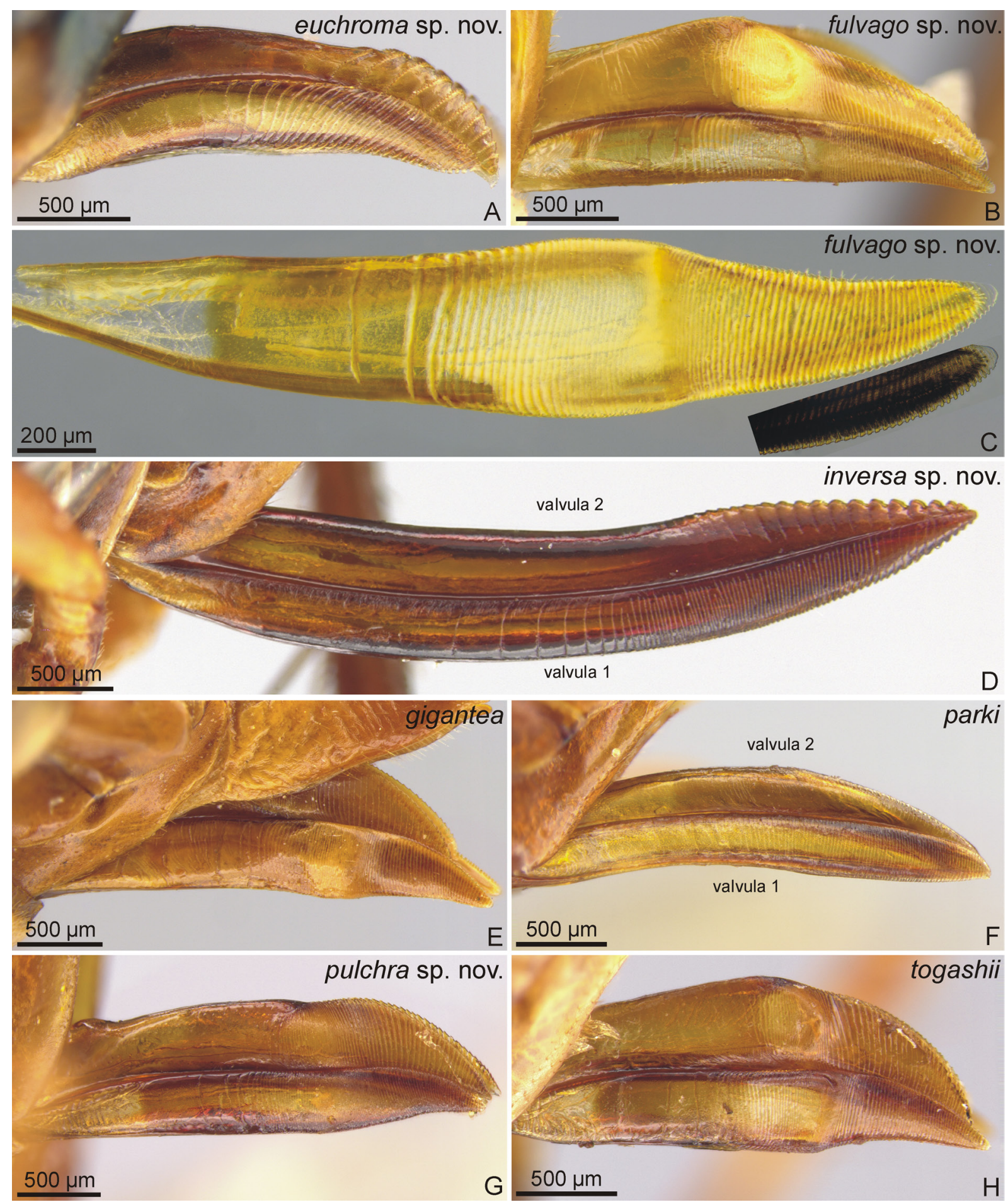

Fig. 12. Species of Megaxyela Ashmead, 1898, ovipositors. A. M. euchroma Blank, Shinohara \& Wei sp. nov., paratype, DEI-GISHym 22510 (NSMT). B-C. M. fulvago Blank, Shinohara \& Wei sp. nov., paratype (5752, NSMT). C. Complete valvula 2 (incident light) and tip of valvula 2 (insert, transmitted light). D. M. inversa Blank \& D.R. Smith sp. nov., paratype (22356, USNM). E. M. gigantea Mocsáry, 1909, holotype of M. mikado Sato, 1930 (22350, NSMT). F. M. parki Shinohara, 1992, paratype (18510, NSMT). G. M. pulchra Blank, Shinohara \& Sundukov sp. nov., paratype (22348, NSMT). H. M. togashii Shinohara, 1992 (22353, NSMT). The images in B and H have been flipped horizontally. 

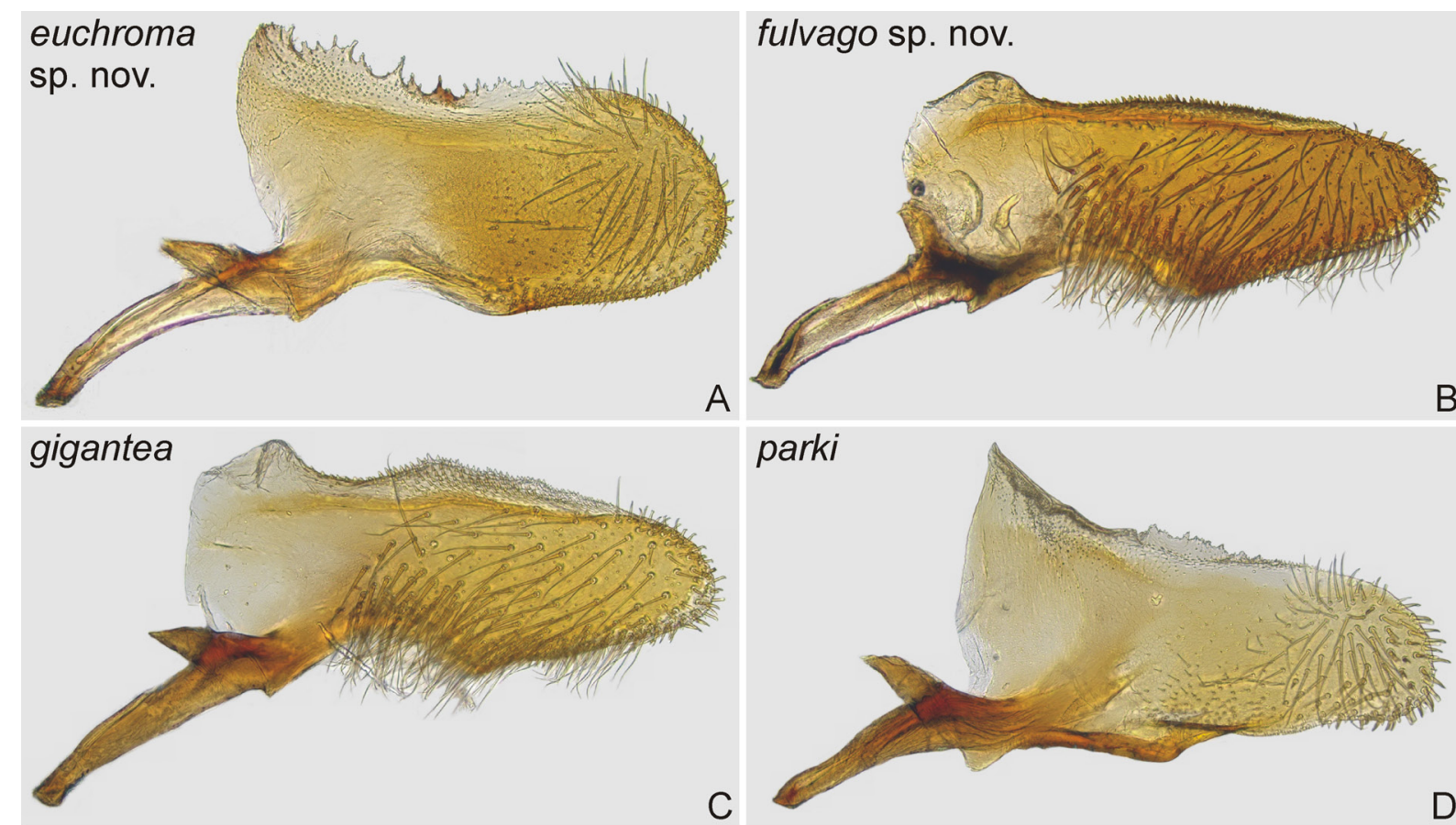

pulchra sp. nov.

C
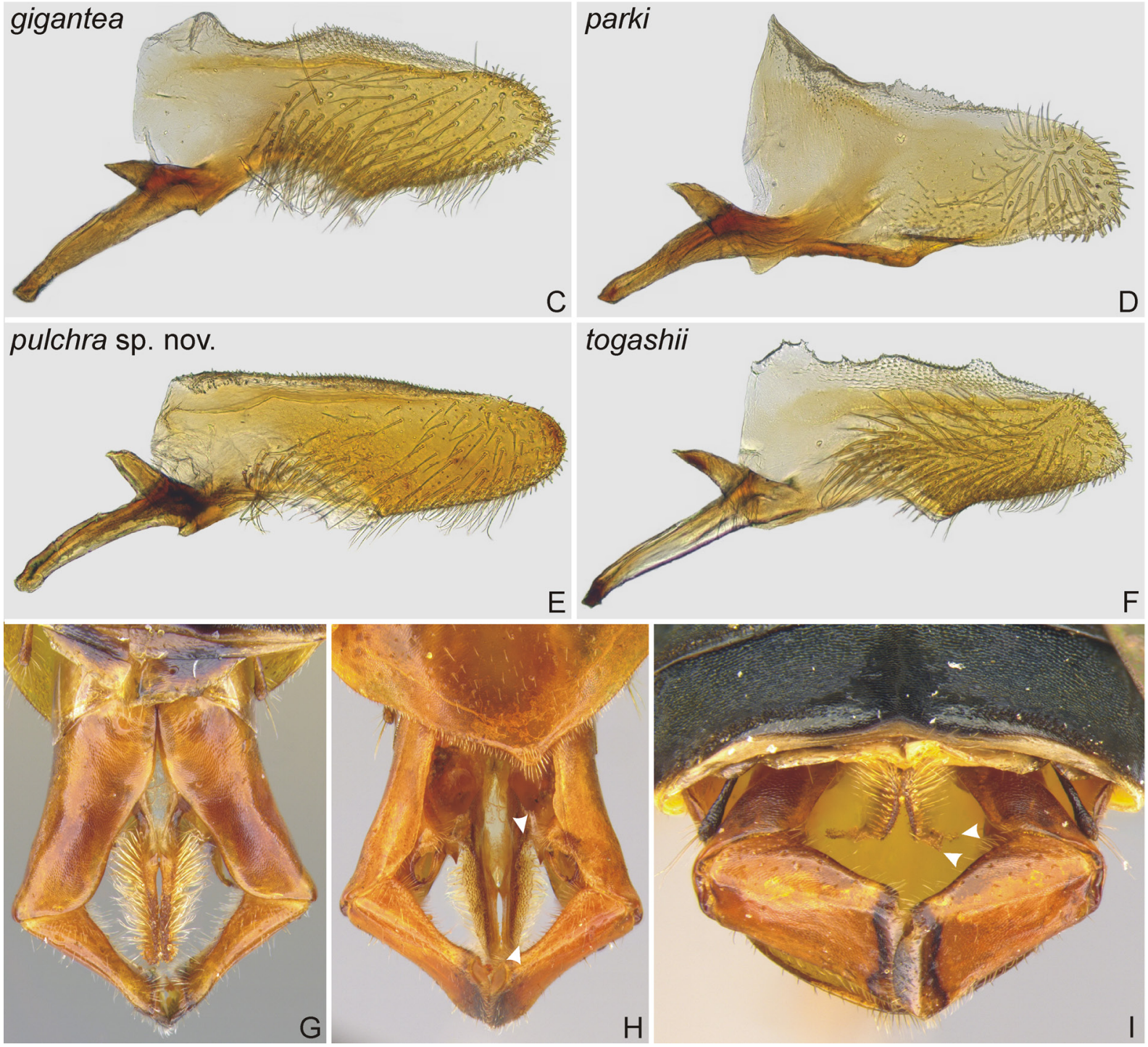

Fig. 13. Species of Megaxyela Ashmead, 1898, penis valves (A-F) and genitalia capsules (G-I). A. M. euchroma Blank, Shinohara \& Wei sp. nov. (DEI-GISHym 22513, NSMT). B. M. fulvago Blank, Shinohara \& Wei sp. nov. (5239, NSMT). C. M. gigantea Mocsáry, 1909 (708, NSMT). D. M. parki Shinohara, 1992 (710, NSMT). E. M. pulchra Blank, Shinohara \& Sundukov sp. nov. (18503, NSMT). F. M. togashii Shinohara, 1992 (22521, NSMT). G-H. M. gigantea, genitalia capsule in dorsal/ventral view (18507, NSMT). I. M. pulchra sp. nov., genitalia capsule in dorso-posterior view (22349, NSMT). Arrow heads in Fig. 13H-I indicate lobe of upper side of valviceps coiled laterally. Images not to same scale. 
morphological characters and the phylogenetic analysis of these data is required to gain a cladogram covering all Megaxyela species. This hypothesis might help to explain the evolution of characters like the number of tarsal pulvilli, the shape of the claw, the pilosity of the metatarsus and the color pattern of the abdomen, which show striking differences among the species. Additional barcoding sequences may be particularly significant for the identification of the larvae of Megaxyela, which remain poorly known. Proper knowledge of the larvae may provide supplementary data about distribution and host associations of the species.

Successful collecting of Megaxyela very much depends on luck, and several species appear to be very rare. The only two known specimens of $M$. inversa sp. nov. were collected at a time interval of 121 years. For most cases, single specimens were collected from undergrowth or lower branches of various plants, resembling the collection circumstances in many other sawflies. A number of unidentified larvae have been found on lower branches at a hight of 1-5 meters. Once, more than 50 adults of $M$. gigantea were collected at Mt. Nogodan, Korea, in 1996 within about 30 minutes. Those adults were flying around a single, unidentified tree near a road, but no specimens were observed on other trees nearby. A subsequent visit at this site in 1997, during exactly the same season, was unsuccessful (Shinohara, personal observations).

The record of M. fulvago sp. nov. from Hunan represents the most southern of a Megaxyela species in East Asia, extending the known distribution of Megaxyela in East Asia $600 \mathrm{~km}$ farther south (Fig. 14). The records of M. pulchra sp. nov. from Daguping (Shaanxi) and Metok (Tibet) and the record of an

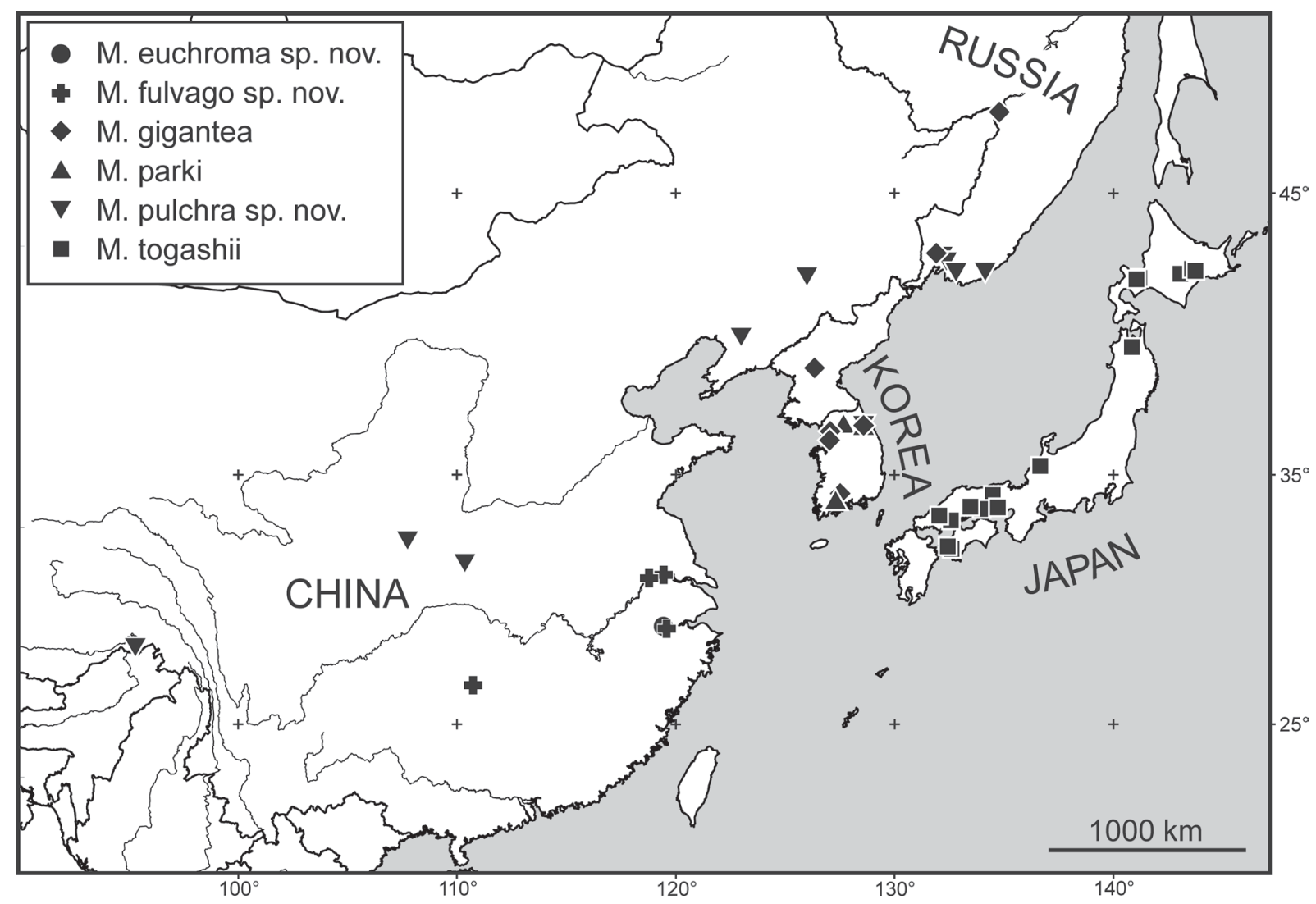

Fig. 14. Distribution of species of Megaxyela Ashmead, 1898 in East Asia. Records of M. togashii Shinohara, 1992 include reliable records published by Shinohara (1992, 2006), Tanaka (1999), Yamada (2000), Naito et al. (2004) and Shinohara et al. (2017). Other distribution data are based on examination of material in course of this work. 
unidentified Megaxyela larva from Gongshan (Yunnan; specimen illustrated by Taeger et al. 2010: pl. 21 fig. 3) extend the known distribution area of East Asian Megaxyela more than $2500 \mathrm{~km}$ westwards with regard to previously published data. Juglandaceae also occur in northern Burma and India (Lu et al. 1999) as well as in more western regions of Eurasia, but Megaxyela has never been recorded from there. In the Nearctic realm, extant Megaxyela and chiefly also their hosts occur in the East, leaving a striking gap in the West of the Nearctic or in the West of the Palaearctic in view of the global distribution. The record of ${ }^{\dagger}$ M. petrefacta and ${ }^{\dagger}$ Carya florissantensis Manchester from Oligocene deposits of Florissant (Colorado) and additional records of fossil Juglandaceae from the western USA (Brues 1908; Manchester 1987) indicate that in the extant fauna both these sawflies together with their hosts exhibit a relict distribution. A thorough phylogenetic analysis might shed light on the zoogeographic relationships of the Megaxyela species of the Old and the New World.

\section{Acknowledgements}

We are grateful to the following colleagues who supported this study through the loan of collection material, through providing freshly collected specimens, and through valuable additional information: C. Apgar (Pawnee, OK, USA), D. Azuma (Philadelphia MA, USA), C. Barr and W. Middlekauff (Berkeley CA, USA), S.A. Belokobylskij and A.G. Zinovjev (St. Petersburg, Russia), Z. Vas, S. Csősz and L. Zombori (Budapest, Hungary), C. Favret and K.R. Zeiders (Champaign IL, USA), S. Fitzgerald and D. Judd (Corvallis OR, USA), H. Goulet (Ottawa, Canada), E.R. Hoebeke and J.K. Liebherr (Ithaca NY, USA), J.-W. Kim (Raleigh NC, USA), H.-S. Lee (Suwon, South Korea), A. Lelej (Vladivostok, Russia), T.L. McCabe (Albany NY, USA), N. Hirai (Sakai, Japan), K. Maeto (Kobe, Japan), K.-T. Park (Chuncheon, South Korea), G.L. Parson and F.W. Stehr (East Lansing MI, USA), A. Sharkov (Columbus OH, USA), H. Vårdal and L.-Å. Janzon (Stockholm, Sweden), D. Wahl (Gainesville FL, USA), K.-S. Woo (Suwon, South Korea), and G.-Y. Yang (Beijing, China). We are grateful to D. Kulanek and C. Kutzscher (SDEI) for their successful effort in the genetic lab. H. Goulet and an anonymous referee contributed supportive suggestions which helped to improve the manuscript.

SMB's contribution was partly funded by the German Research Foundation (DFG) within the graduate colleague "Evolutionary Transformation and Mass Extinctions" (GRK 503). The Smithsonian Institution supported a visit of SMB at the USNM in 2002 by a Short Travel Grant. AS's work was partly supported by a Grant-in-aid for Scientific Research No. 15570093 from the Ministry of Education, Culture, Sports, Science and Technology, Japan and by JSPS KAKENHI Grant No. 25440223. MW's work was partly supported by the National Natural Science Foundation of China (No. 31672344) and an Innovation Platform Project of the Key Laboratories of Hunan Universities (No. 15K150).

\section{References}

Barbier Y. \& Rasmont P. 1996. Carto Fauna-Flora (CFF) version 1.2. Université de Mons-Hainaut, Mons.

Benson R.B. 1945. Classification of the Xyelidae (Hymenoptera, Symphyta). Proceedings of the Royal Entomological Society of London, Series B: Taxonomy 14: 34-37. https://doi. org/10.1111/j.1365-3113.1945.tb00013.x

Blank S.M. 2002. The western Palaearctic Xyelidae (Hymenoptera). In: Viitasaari M. (ed.) Sawflies (Hymenoptera, Symphyta) I. A Review of the Suborder, the Western Palaearctic Taxa of Xyeloidea and Pamphilioidea: 197-233. Tremex, Helsinki.

Blank S.M. \& Schönitzer K. 1994. Sensillenverteilung auf den äußeren Genitalien einiger BlattwespenWeibchen (Hymenoptera: Symphyta). Mitteilungen der deutschen Gesellschaft für allgemeine und angewandte Entomologie 9: 251-255. 
Blank S.M., Kramp K. \& Shinohara A. 2017. Xyela fusca spec. nov. from Japan elucidates East AsianNorth American relationships of Xyela (Hymenoptera, Xyelidae). Zootaxa 4303 (1): 103-121. https:// doi.org/10.11646/zootaxa.4303.1.6

Blank S.M., Shinohara A. \& Altenhofer E. 2013. The Eurasian species of Xyela (Hymenoptera, Xyelidae): taxonomy, host plants and distribution. Zootaxa 3629 (1): 1-106. https://doi.org/10.11646/ zootaxa.3629.1.1

Blank S.M., Shinohara A. \& Byun B.-K. 2005. The East Asian Xyela species (Hymenoptera: Xyelidae) associated with Japanese Red Pine (Pinus densiflora; Pinaceae) and their distribution history. Insect Systematics \& Evolution 36: 259-278. https://doi.org/10.1163/187631205788838393

Bridwell J.C. 1906. A second species of the hymenopterous genus Odontophyes Konow (Xyelidae). Entomological News and Proceedings of the Entomological Section of the Academy of Natural Sciences of Philadelphia 17 (3): 94.

Brues C.T. 1908. New phytophagous Hymenoptera from the Tertiary of Florissant, Colorado. Bulletin of the Museum of Comparative Zoology 51: 259-276.

Burdick D.J. 1961. A taxonomic and biological study of the genus Xyela Dalman in North America. University of California Publications in Entomology 17: 285-355.

Cresson E.T. 1880. Descriptions of new North American Hymenoptera in the collection of the American Entomological Society. Transactions of the American Entomological Society 8: 1-52.

Cresson E.T. 1916. The Cresson types of Hymenoptera. Memoirs of the American Entomological Society 1: $1-141$.

Cresswell S. 2014. April Unknown - Megaxyela tricolor. Available from BugGuide, http://bugguide. net/node/view/908657 [accessed $20 \mathrm{Jul} .2016]$.

Darriba D., Taboada G.L., Doallo R. \& Posada D. 2012. jModelTest 2: more models, new heuristics and parallel computing. Nature Methods 9 (8): 772. https://doi.org/10.1038/nmeth.2109

Dyar H.G. 1898a. Description of an unusual sawfly-larva belonging to the Xyelinae. Psyche 8: 212-214 [May 1898].

Dyar H.G. 1898b. Notes on some sawfly larvae, especially the Xyelidae. Canadian Entomologist 30: 173-176 [July 1898]. https://doi.org/10.4039/Ent30173-7

Hadley A. 2010. CombineZP, Image Stacking Software.

Hall T.A. 1999. BioEdit: a user-friendly biological sequence alignment editor and analysis program for Windows 95/98/NT. Nucleic Acids Symposium Series 41: 95-98.

Harris R.A. 1979. A glossary of surface sculpturing. Occasional Papers in Entomology 28: 1-31.

Huber J.T. \& Sharkey M.J. 1993. Structure. In: Goulet H. \& Huber J.T. (eds) Hymenoptera of the World: An Identification Guide to Families: 13-59. Agriculture Canada, Publication 1894/E, Ottawa. Available from http://www.esc-sec.ca/aafcmonographs/hymenoptera_of the_world.pdf [accessed 10 Aug. 2017].

Jukes T.H. \& Cantor C.R. 1969. Evolution of protein molecules. In: Munro H.N. (ed.) Mammalian Protein Metabolism: 21-132. Academic Press, New York. https://doi.org/10.1016/B978-1-4832-32119.50009-7

Kearse M., Moir R., Wilson A., Stones-Havas S., Cheung M., Sturrock S., Buxton S., Cooper A., Markowitz S., Duran C., Thierer T., Ashton B., Meintjes P. \& Drummond A.J. 2012. Geneious Basic: an integrated and extendable desktop software platform for the organization and analysis of sequence data. Bioinformatics 28: 1647-1649. https://doi.org/10.1093/bioinformatics/bts199 
Kim C.-J, Lelej A.S., Park B. \& Lee J.-W. 2016. Review of the family Proctorenyxidae (Hymenoptera: Proctotrupoidea), with description of new species from South Korea. Zootaxa 4103 (1): 94-100. https:// doi.org/10.11646/zootaxa.4103.1.12

Ko J.-H. 1969. A List of Forest Insect Pests in Korea. Forest Research Institute, Seoul.

Konow F.W. 1899. Ueber einige neue Chalastogastra. Wiener entomologische Zeitung 18: 41-46.

Kopylov D.S. 2014. New sawflies of the subfamily Madygellinae (Hymenoptera, Xyelidae) from the Middle-Upper Triassic of Kyrgyzstan. Paleontological Journal 48: 610-620. https://doi.org/10.1134/ $\underline{\mathrm{S} 0031030114060070}$

Krasilov V.A. \& Rasnitsyn A.P. 1982. Unikal'naja nahodka: pyl'ca v kishechnike rannemelovyh pilil'shhikov. [A unique find: Pollen in the intestine of early Cretaceous sawflies.] Paleontologicheskij Zhurnal [1982] (4): 83-96. [In Russian.]

Kumar S., Stecher G. \& Tamura K. 2016. MEGA7: Molecular Evolutionary Genetics Analysis version 7.0 for bigger datasets. Molecular Biology and Evolution 33 (7): 1870-1874. https://doi.org/10.1093/ molbev/msw054

Lara M.B., Rasnitsyn A.P. \& Zavattieri A.M. 2014. Potrerilloxyela menendezi gen. et sp. nov. from the Late Triassic of Argentina: the oldest representative of Xyelidae (Hymenoptera: Symphyta) for Americas. Paleontological Journal 48: 182-190. https://doi.org/10.1134/S0031030114020075

Lelej A.S. (ed.) 2012. Annotirovannyj katalog nasekomyh Dal'nego Vostoka Rossii. Tom I. Pereponchatokrylye. [Annotated Catalogue of the Insects of the Russian Far East. Volume I. Hymenoptera.] Dal'nauka, Vladivostok. [In Russian, abstract in English.]

Lelej A.S. \& Taeger A. 2007. Nadsem. Xyeloidea. 1. Sem. Xyelidae - Ksielidy. [Superfam. Xyeloidea. 1. Fam. Xyelidae.] In: Lelej A.S. (ed.) Opredelitel' nasekomykh Dal'nego Vostoka Rossii. [Key to the Insects of the Russian Far East.] Tom. IV. Setchatokryloobraznye, skorpionnicy, pereponchatokrylye. [Neuropteroidea, Mecoptera, Hymenoptera.] Ch. 5: 922. Dal'nauka, Vladivostok. [In Russian.]

Lu A., Stone D.E. \& Grauke L.J. 1999. Juglandaceae. Flora of China 4: 277-285. Science Press, Beijing and Missouri Botanical Garden Press, St. Louis. Available from http://flora.huh.harvard.edu/china/ mss/volume04/JUGLANDACEAE.published.pdf, online version http://www.efloras.org/florataxon. aspx?flora $\mathrm{id}=2 \&$ taxon $\mathrm{id}=10460$ [accessed 1 Oct. 2016].

Maa T. 1949. A synopsis of Chinese sawflies of the superfamily Megalodontoidea (Hymenoptera). Chinese Journal of Zoology 3: 30-42.

MacGillivray A.D. 1912. New genera and species of Xyelidae and Lydidae. Canadian Entomologist 44: 294-299. https://doi.org/10.4039/Ent44294-10

Manchester S.R. 1987. The fossil history of the Juglandaceae. Monographs in Systematic Botany from the Missouri Botanical Garden 21: [1-6], 1-137.

Microsoft Research 2015. Microsoft Image Composite Editor (ICE), version 2.0.3. Available from http://research.microsoft.com/en-us/um/redmond/projects/ice/ [accessed 13 Jul. 2017].

Mocsáry A. 1909. Chalastogastra nova in collectione musei nationalis Hungarici. Annales historiconaturales Musei Nationalis Hungarici 7: 1-39.

Naito T., Yoshida H., Nakamine H., Morita T., Ikeda T., Suzuki H. \& Nakanishi A. 2004. [Species Diversity of Sawflies in Hyogo Prefecture, Central Japan.] Museum of Nature and Human Activities, Hyogo, Monograph of Natural History and Environmental Science (1): 1-2 + pls 1-10 + 1-85. [In Japanese.]

Norton E. 1862. Notice of several new species of Tenthredinidae. Proceedings of the Entomological Society of Philadelphia 1[1861-1863] (5): 143-144. 
Prous M., Vikberg V., Liston A.D. \& Kramp K. 2016. North-Western Palaearctic species of the Pristiphora ruficornis group (Hymenoptera, Tenthredinidae). Journal of Hymenoptera Research 51: 1-54. https://doi.org/10.3897/jhr.51.9162

Rasnitsyn A.P. 1966. Novye Xyelidae (Hymenoptera) iz mezozoja Asii. [New Xyelidae (Hymenoptera) from the Mesozoic of Asia.] Paleontologicheskij Zhurnal [1966] (4): 69-85. [In Russian.]

Rasnitsyn A.P. 2008. Hymenopterous insects (Insecta: Vespida) in the Upper Jurassic deposits of Shar Teg, SW Mongolia. Russian Entomological Journal 17: 299-310.

Ree B. 2012. Insects. Texas Pecan Pest Management Newsletter 12 (1): [1-3].

Ree B. 2014. Sawfly. Texas Pecan Pest Management Newsletter 14 (2): [1-3].

Ree B. 2016: Insects. Texas Pecan Pest Management Newsletter 16 (2): [1-3]. Available from http:// presidio.agrilife.org/files/2011/08/Texas-Pecan-Pest-Management-Newsletter-March-31-2016.pdf [accessed 13 Jul. 2017].

Rohwer S.A. 1924. A new sawfly of the family Xyelidae(Hymenoptera). Proceedings of the entomological Society of Washington 26: 215.

Ross H.H. 1932. The hymenopterous family Xyelidæ in North America. Annals of the Entomological Society of America 25: 153-169. https://doi.org/10.1093/aesa/25.1.153

Ross H.H. 1936. A new pecan sawfly, Megaxyela langstoni n. sp. (Hymenoptera: Xyelidae). Entomological News 47: 131-132.

Ross H.H. 1937. A generic classification of the Nearctic sawflies (Hymenoptera, Symphyta). Illinois Biological Monographs 15: 1-173. https://doi.org/10.5962/bhl.title.50339

Saito K. 1941. [A dendro-entomological contribution.] Bulletin of the Agricultural and Forestry College Suigen (Suwon) (6): 1-235. [In Japanese.]

Sato K. 1930. Anew species of the genus Megaxyela Ashmead from Korea(Hymenoptera; Tenthredinidae). Journal of Chosen Natural History Society 3: 4-5.

Schmidt S., Taeger A., Morinière J., Liston A., Blank S.M., Kramp K., Kraus M., Schmidt O., Heibo E., Prous M., Nyman T., Malm T. \& Stahlhut J. 2017. Identification of sawflies and horntails (Hymenoptera, 'Symphyta') through DNA barcodes: successes and caveats. Molecular Ecology Resource 17: 670-685. https://doi.org/10.1111/1755-0998.12614

Schulz W.A. 1906. Strandgut. Spolia Hymenopterologica [1906]: 76-269.

Shinohara A. 1992. The sawfly genus Megaxyela (Hymenoptera, Xyelidae) in East Asia. Japanese Journal of Entomology 60: 783-796.

Shinohara A. 1995. The sawfly genus Pleroneura (Hymenoptera, Xyelidae) in East Asia. Japanese Journal of Entomology 63: 825-840.

Shinohara A. 2006. New collection records of Megaxyela togashii (Hymenoptera, Xyelidae), a rare sawfly from Honshu and Shikoku, Japan. Japanese Journal of Systematic Entomology 12: 157-158.

Shinohara A. 2016. The sawfly genus Pleroneura (Hymenoptera, Xyelidae) of Japan: P. itoi n. sp. and a key to species. Zootaxa 4121: 495-500. https://doi.org/10.11646/zootaxa.4121.4.9

Shinohara A. \& Smith D.R. 1979. The Sato types of sawflies (Hymenoptera: Symphyta). Bulletin of the National Science Museum, Series A, Zoology 5: 281-288.

Shinohara A., Hara H., Kramp K., Blank S.M. \& Kameda Y. 2017. Bird droppings on chestnut leaves or sawfly larvae? DNA barcodes verify the occurrence of the archaic Megaxyela togashii (Hymenoptera, Xyelidae) in Hokkaido, Japan. Zootaxa 4221: 220-232. https://doi.org/10.11646/zootaxa.4221.2.6 
Smith D.R. 1967. A review of the larvae of Xyelidae, with notes on the family classification (Hymenoptera). Annals of the Entomological Society of America 60: 376-384. https://doi.org/10.1093/ aesa/60.2.376

Smith D.R. 1978. Suborder Symphyta. (Xyelidae, Pararchexyelidae, Parapamphiliidae, Xyelydidae, Karatavitidae, Gigasiricidae, Sepulcidae, Pseudosiricidae, Anaxyelidae, Siricidae, Xiphydriidae, Paroryssidae, Xyelotomidae, Blasticotomidae, Pergidae). In: Van der Vecht J. \& Shenefelt R.D. (eds) Hymenopterorum Catalogus (nova editio)14. W. Junk Publishers, The Hague.

Smith D.R. 1979. Suborder Symphyta. In: Krombein K.V., Hurd Jr. P.D., Smith D.R. \& Burks B.D. (eds) Catalog of Hymenoptera in America North of Mexico. Volume 1, Symphyta and Apocrita (Parasitica): 3-137. Smithsonian Institution Press, Washington D.C.

Smith D.R. \& Schiff N.M. 1998. The genera Macroxyela Kirby and Megaxyela Ashmead (Hymenoptera: Xyelidae) in North America. Proceedings of the Entomological Society of Washington 100: 636-657.

Smith D.R., Ohmart C.P. \& Dahlsten D.L. 1977. The fir shoot-boring sawflies of the genus Pleroneura in North America (Hymenoptera: Xyelidae). Annals of the Entomological Society of America 70: 761767. https://doi.org/10.1093/aesa/70.5.761

Smith E.L. 1968. Biosystematics and morphology of Symphyta. I. Stem-galling Euura of the California region, and a new female genitalic nomenclature. Annals of the Entomological Society of America 61: 1389-1407. https://doi.org/10.1093/aesa/61.6.1389

Sundukov Yu.N. 2009. Podotrjad Symphyta - Sidjachebrjuhie. [Suborder Symphyta - Sawflies.]. In: Storozhenko S.Yu., Sundukov Yu.N., Lelej A.S., Sidorenko V.S., Proshchalykin M.Yu. \& Kupianskaya A.N. (eds) Nasekomye Lazovskogo zapovednika. [Insects of Lazovsky Nature Reserve.]: 212-220. Dal'nauka, Vladivostok. [In Russian.]

Taeger A., Blank S.M. \& Liston A.D. 2010. World catalog of Symphyta (Hymenoptera). Zootaxa 2580: $1-1064$.

Takeuchi K. 1937. [Megaxyela gigantea Mocsary found in Honshu, Japan.] (In Japanese.) Akitu 1: 25.

Takeuchi K. 1938. A systematic study on the suborder Symphyta (Hymenoptera) of the Japanese Empire (I). Tenthredo 2: 173-229.

Takeuchi K. 1940. Chinese sawflies and woodwasps in the collection of the Musée Heude in Shanghai. Notes d'Entomologie Chinoise 7: 463-486.

Takeuchi K. 1949. Alist of the food-plants of Japanese sawflies. Transactions of the Kansai Entomological Society 14: 47-50.

Tanaka K. 1999. [Several species of sawflies from Yamaguchi Prefecture.] Kita-Kyushu no Konchu 46: 57-58. [In Japanese.]

The Plant List 2013. Version 1.1. (online). Available from http://www.theplantlist.org/ [accessed 14. Jul. 2016].

Togashi I. 1965. [On the female of Megaxyela gigantea Mocsáry.] Kontyû 33: 235-236. [In Japanese.]

Viitasaari M. 2002. The suborder Symphyta of the Hymenoptera. In: Viitasaari M. (ed.) Sawflies (Hymenoptera, Symphyta) I. A Review of the Suborder, the Western Palaearctic Taxa of Xyeloidea and Pamphilioidea: 11-174. Tremex, Helsinki.

Watanabe A. 1992. [Megaxyela gigantea collected in Okayama Prefecture.] Suzumushi (127): 8. [In Japanese.] 
Weltz C.-E. \& Vilhelmsen L. 2014. The saws of sawflies: exploring the morphology of the ovipositor in Tenthredinoidea (Insecta: Hymenoptera), with emphasis on Nematinae. Journal of Natural History 48: 133-183. https://doi.org/10.1080/00222933.2013.791941

Xiao G.-R. 2006. Suborder Chalastogastra (Symphyta). In: Hua L.-Z. (ed.) List of Chinese Insects. Vol. IV: 187-200 + 331-335. Sun Yat-sen University Press, Guangzhou.

Yamada M. 2000. [Ten species of Symphyta newly recorded from Aomori Prefecture.] Journal of the Natural History of Aomori (5): 53-54. [In Japanese.]

Yuasa H. 1922. A classification of the larvae of the Tenthredinoidea. Illinois Biological Monographs 7 (4): $1-172$.

Zhang J. 1989. [Fossil insects from Shanwang, Shandong, China.] Shandong Science and Technology Publishing House, Jinan. [In Chinese, abstract in English.]

Zhang H. \& Zhang J. 2000. Xyelid sawflies (Insecta, Hymenoptera) from the Upper Jurassic Yixian formation of Western Liaoning, China. Acta Palaeontologica Sinica 39: 476-492.

Zhelochovtsev A.N. \& Rasnitsyn A.P. 1972. On some Tertiary sawflies (Hymenoptera: Symphyta) from Colorado. Psyche 79: 315-327. https://doi.org/10.1155/1972/63630

Zhelochovtsev A.N. \& Zinovjev A.G. 1995. Spisok pilil'shhikov i rogohvostov (Hymenoptera, Symphyta) fauny Rossii i sopredel'nyh territorij. I. [A list of the sawflies and horntails (Hymenoptera, Symphyta) of the Fauna of Russia and Adjacent Territories. I.] Entomologitcheskoe obozrenie 74: 395415. [In Russian, abstract in English.]

Manuscript received: 28 October 2016

Manuscript accepted: 21 December 2016

Published on: 5 September 2017

Topic editor: Gavin Broad

Desk editor: Kristiaan Hoedemakers

Printed versions of all papers are also deposited in the libraries of the institutes that are members of the EJT consortium: Muséum national d'Histoire naturelle, Paris, France; Botanic Garden Meise, Belgium; Royal Museum for Central Africa, Tervuren, Belgium; Natural History Museum, London, United Kingdom; Royal Belgian Institute of Natural Sciences, Brussels, Belgium; Natural History Museum of Denmark, Copenhagen, Denmark; Naturalis Biodiversity Center, Leiden, the Netherlands; Museo Nacional de Ciencias Naturales-CSIC, Madrid, Spain; Real Jardín Botánico de Madrid CSIC, Spain. 